


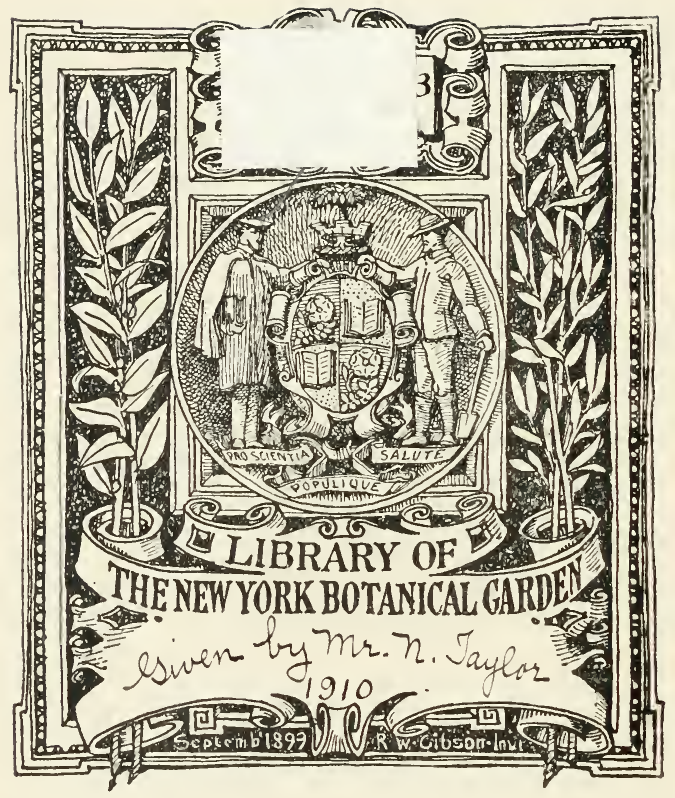








\section{R. M. MOSCOSO,}

MAETRU NORMARTTA DE LA ANTIGLA FE'LEIA NORMAI.

1)E XAXTU DOMIXIO.

\section{LAS}

\section{FAMILIAS VEJETALES}

REPRESFITADAS EN I. 1

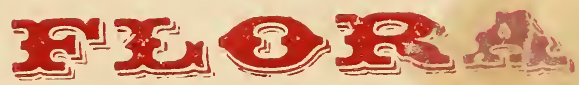

DE

SANTO DOMINGO

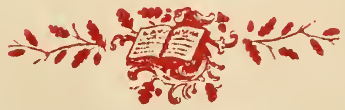

SANTO DOMING().

LIBRERIA I PAPELERIA DE LUIS A. WEEER.

79-ConsistortaL 7!!

$18 ! 7$. 



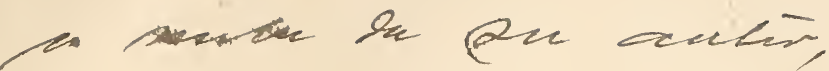

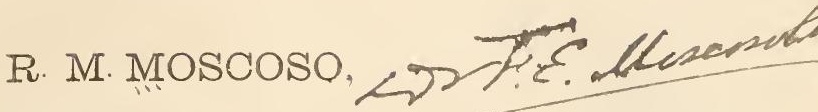

MAENTRO NORMALISTA DE LA ANTIGLA ESCLIIATRRAL

I)E SANTO DOMINGO.

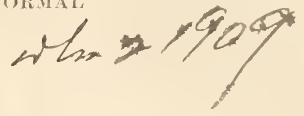

() $40 m 6$

\title{
FAMILIAS VEJETALES
}

\author{
REPRFEETADAK WX IA.
}

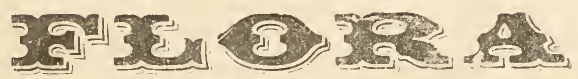

DE

\section{SANTO DOMINGO}

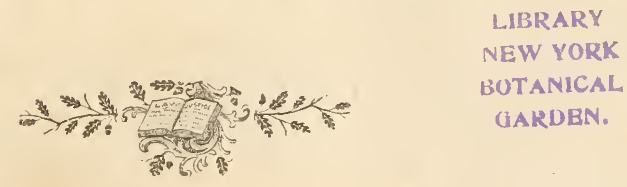

SANTO DOMINGO.

LIBRERIA I PAPELERIA DE LUIS A. WEBER.

7!)-CONSISTORIAL- 7 ?

1897. 
ES PROPIEDAI.

Tipografia Conercial. 


\section{ADVERTENCIA.}

Las dilicoltadesé inconvenientes con que hemos trope-

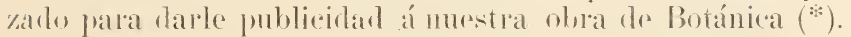
i la benérola soliciturl de mumerosas persolas interesadas en que diese á conorer al priblicon algo que serelacione con la botánica re nuestro país. hamme impulsado á dar á luz el presente charlermo.

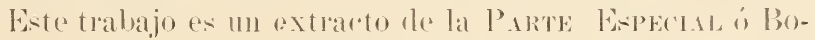

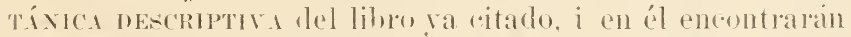
las personas que se dediuan á esta rase de esturlios. todas las familias rejetales. con sts géneros i esperies mats sonesalientes representadas en nnestra Flora.

()jalá que este pohre esfueron arrespondal á los deseros del públian. i que al mismo tiempo le inspire en los conorimientos de las ('iencias Natmales. para yue se emprendiren en mostro país trabajos le ntilidarl general.

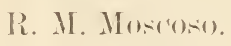

Sinto Dominger. Abril d 18997.

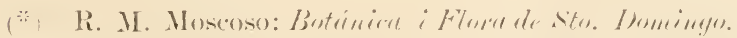




\section{ABREVIACIONES I SIGNOS USADOS EN ESTE CUADERNO.}

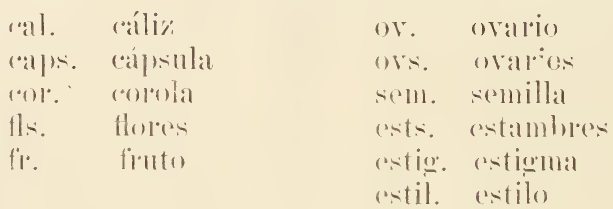

En las formulas florales, el número comprendido en el signo radical, indica el número de piezas de cadla uno de los vorticilos fiorales; P. significa perianto, 1. androceo, (x. ginecen.

Este signo is , significa indefinido is numernoso, este (o) mulo i este otro $\quad \therefore$ ! certezal por ohservarión persomal.

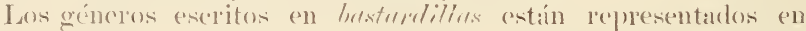
mestra Flora: los escritos en caracteres ordinarios lo están tamhiém, pero cultivados reult. I. Lás especies escritals en busturlilleis soll espontaneas of naturalizadas, las ceritas en caracteresordinat rios se coltivan jor ornamento of ntiliclad. 


\section{TIPO I.}

\section{T IL()FITIS}

Vejetales puramente celulares, formando un curpo homogirneo, sin diferenciación de trillos ni hojes (talo).

\section{('LASE I. ILAAS.}

Talofitas provistas de clorofila, a reces coloreadas de amarillo, pardo ó rojo por prigmentos especiales; genrralmente aruáticas

ORDEN I. Cianoficens. Algas ritódicas. Pigmento azul demominada fiecocianina.

1. Fan. Nostocáceas. C'ítolus rerlondearlos ó tilamentosos, articularlos ó nó, (oon ó sin morimiento vihratosl'io. Se multiplican por división de los elementos histológiros en 1,2 ó 3 direceiones distintas.

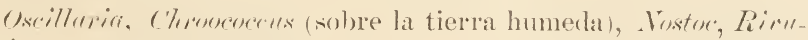
laticle.

2. Fam. Bacteriáceas. ('ítilosile formas variables. (o) movimientos tambien variahles. So multiplican pol secomentación del protoplasma. en dos mitades. Los

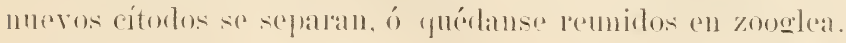

Por sus formas, las bacteriáceas se dividen en micrococous 
(citorks ésfericos); Bactericu (citodos en formas de varillas cor-

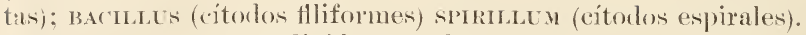

Los micrococens se dividen en dos seciones, conforme di las . formas de evolución que presentan sus epecies:

1. (Yommigrmes. (oblorem los alimentos oróánicos, sólidos i) liquidos, presentándose en masas gelatinosas: J/conconcens condidus. Cohn (aparece en el queso), . V. cyanus Cohn, (ap)arece en la leche), etc.

2. I'répgums. Se desarrollan en los cuerpos de los animales y producen enfermedades contagiosas: $1 /$. irroine, Colm (bacte-

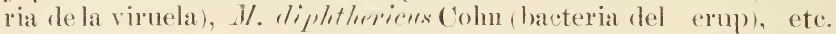

Los bacterium se dividen tambien en dos secriones:

1. C'mmogrmos. ('olorean las materias alimenticias: Bacto-

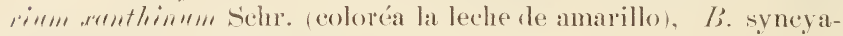
num Schr. (colorcia la leche de azul), etc.

¿. Zimmignas. Prodncen el fermento de la putrefaceión: Is. trom, Ehrlog. (aparece en las aguas estancadas i do fuentes, etc), etc.

Al género burillus pertenecen estas especies notahles: I'. smb-

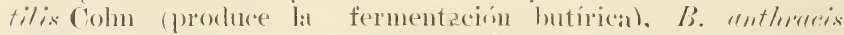

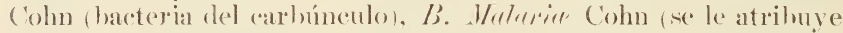
la causa del paludismo), li. Kovelii (bacteria de la tuberculosise),

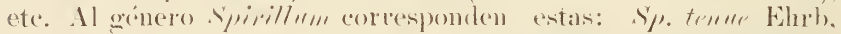

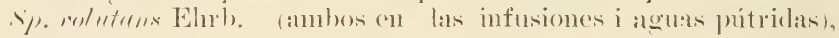
efere

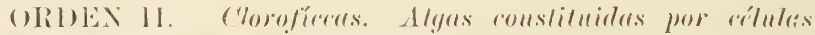

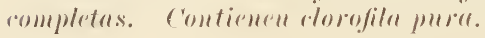

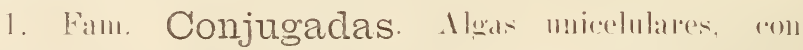

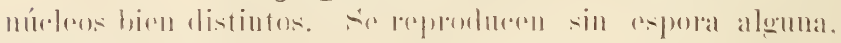

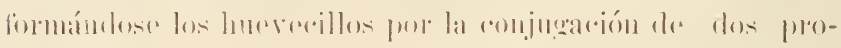

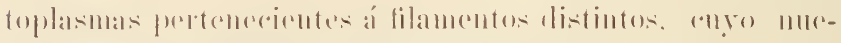

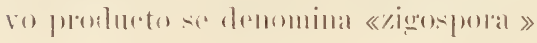

Viven en las aguas entancadas formando grandes masats voroles.

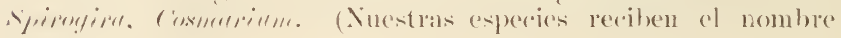
villatir de laturl).

2. Fan. Cenobiadas. Ilyan mirelulares, rom of 
sin morimiento. Los indiviolos forman rolonias ó «reno-

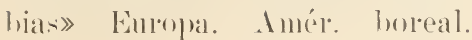

:) Fam. Conferváceas Algas fomatas por taliynes celulares. molinariamente filamentosoa-rtionlados. sim-

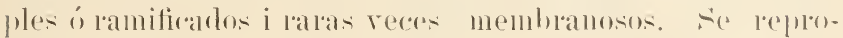
fureen por zonspolas. formándose los huevecillos pol fusión de isogametas móviles. por anteromoide i oosfera i pol ousfera i polinorlios.

Algas marinas a de agua dulcee a veces parásitas solore otras

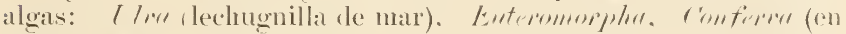
las costas del N.), ete.

t. Fan. Sifonáceas. Ilgas formadas de nua colula ranmilicarla, presentando en ocaroiomes la aparienr.ia rlo

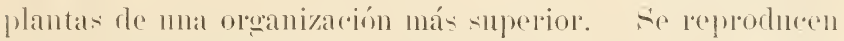
por zoospolas. formándose los huevecillos romo en las ronfervác('as.

Algas esencialmente marinas: ('oulerpu: C'. firstigintu Montog i ('. rricifolin Agh. (en las costas del N.), Proyojmix: B. rommlr-

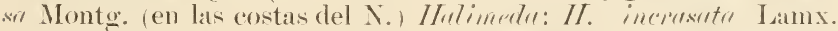

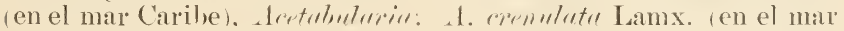
('aribe).

¿. Fanı. Caráceas. Ilgas formadas pol 111 talı témue. de rélulas latogas i rolotas alternativanente. danrlo

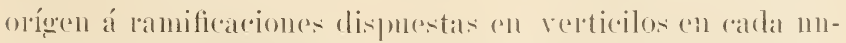
lo. La reprodureión es sexual: los hurerecillos se poodu(en por medio de mn anterozoirle i mua ooslela. Jai esperies monóicas i dióicas. Los anteridios i las onsferas se forman solne las l’amificalciones.

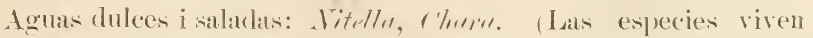
en los arroyuelos proximos á cecarse, principalmente en los del (ihas. 


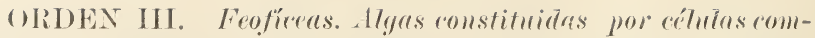
pletas. Comtienen clorofila asociada á un pigmento provio, denomincelo firoficiure.

1. Fam. Diatomáceas. Mlgas micelulares. libres c) reunidas en colonias filiformes. curas memhranas celulares están inpregnadas de silice que forma nna especeie de (aparazón 2-ralvo (frístulo), de figura regular, que se dilata ó se contrae según rue el protoplasma interno (endocromo) ammente de volúmen ó se contraiga. Se reprodncen por conjugación en unos asos i en otros por división, dísminuyeudo ol tamaño de los individuos gradualnente. volviéndose a restablecer las dimensiones primitivas, constituyendo entónces mna «auxospora» que se reculne de sul

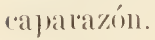

Algas de aguas dulces ó saludas: Virricule, Jefoxim, Frustu-

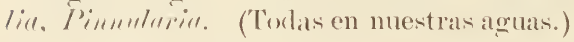

„. Fam. Fucáceas. Algas marinas de dimensiones romunmente gigantescals. ron «fondes» filanuentosas i ramificadas, ó desenrueltas en explansiones membluanosas i

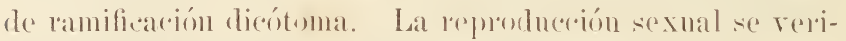
fiea por medio de oosferas i anterilios producidos en ravidades cubiertas de pelos interiolmente. llamadas «conceptí("ulos»:

Fineres conecptáculos colocados en la extremidad de las from.

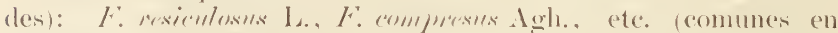
muestras costas), suryus:mm (conceptáculos distribuidos en distintos puntos de las frondes): ㄷ. rulgure Agh., cen las costas, i en los rios hasta una ó don millas de su desembocadura).

URDEA IV. Rodofímers. Algus constituides por cétules completas; contienem un pigmento supermumerario rojo, denominado ficoeritrina. 
1. Fam. Coralináceas. Algas formadas por haces de filamentos celulares incrustados de arbonato de cal. La calcificación se opera en todo el individuo. excepto en los órganos reproductores. La reproduceión es sexual i asexual; los ónganos reproductores se hallan encerrarlos en receptáanlos en forma de botella.

Junto con las marléporas dan lugar á las formaciones llanarlas

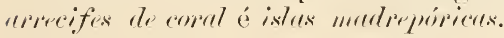

¿. Fant. Gigartináceas. Mlgas formadas pol filamentos paralelos i por células dispuestas en séries, vuyo talo maciso, (armoso i cartilaginoso, se geelitica.

diggertinu, ciellopllygllix.

3. Fam. Nemaliáceas. Algas formadis por filamentos ramificados. Se reproducen por medio de anteridios que producen anterozoides.

Algas de aguas dulces i salarlas: Lemermen, Bretrordensyermum (en las aguas de los rios):

\section{(H,AsE II. HON(BOS.}

Talofitas desproristas de clorofila i semralmente adaptadas á la vida parasitaria.

ORDEN I. Mixomicetos. Hongos de talo desmudo, de consistencia gelatinosa i gran morilidad. Reproducción por esporas inmóriles.

Fam. Gastromixáceas. Talo pluriceinlar con plasmodio produrido por fusión; los protoplasmas de las mixamibas se mezelan. A parato esporf́fero con ó sin pedícelo; esporos internos ó externos. 


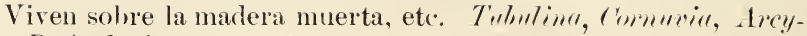
"', Reticulariu, etc.

ORDEN II. Oomicetos. Hongos de talo micelular, emruelto por una membrana de celulose. Reproducción por huetecillos.

I. Fan. Mucoráceas. Talo filamentoso, ramificado (pedícelo) sosteniendo superiormente una esferita (esporangio) con numerosas esporas.

Mucro: M. Inncedo. (Forma regetaciones microseópieas solore el pan, los frutos, el estiércol de caballo, ete, i se le denomina rulg. moho), l'hlizopm.s nigricun.x (Forma vegetaciones negruzeas de 1 í \& cent. sohre las mismas sustancias, pero especialmente sobre las frutas caruosas, i se le denomina de igual modo). ete.

2. Fim. Saprolegniáceas. Se reproducen por zoosporas de doble generación. formándose los huevecillos por heterogania.

Se desarrollan en el agua, sobre animales i plantas, causándo-

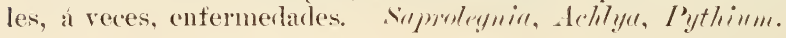

3. Eam. Peronosporáceas. Micelio filamentıso, interno; receptáculo fiructiforo rexterno; espolas exógenas. Los horevecillos se forman por heterogamia.

Viyen parásitas solore el parenguima de has faneróganus. I'p-

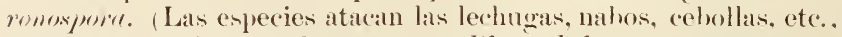
causándoles enfermedades graves), Phytoplitlorim. (Las especies atacan las papas, mustuel'zos, masambei, ete.).

ORIOEN III. Miportérmeos. IIomgos perásitos sobre ias plantas trerestes, especiulmente sobre los cerrales. Reproduceión por esporas.

1. Fan. Ustilagineas. Se reprouluen por espo-

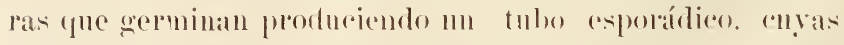
células desarrollan remas (esporílios) que envian talos que 
penetran la epidermis de las plantas atacarlas.

lstiluyo: I. mendis (ataca el ovario del maiz, i produce la bubor del maiz), $I$. dextmens (ataca el ovario del millo), ete.

¿. Fan. Uredíneas. Se reproducen por varias formas de esporas; éstas germinan, despues de ma vida latente, produciendo esporidios.

Se desarrollan sobre las fanerógamas, prorluciendo manchas, deformaciones, ete. Eindroply,gllım.

ORDENIV. Basidiomicetos. Receptáculo fructifero con asporas exógenas situadas en la extremidad de ciertas células especiales (basidios) formándo á reces un tejido membranoso (himenio).

1. Fam. Himenomiceas. Receptáculo fructifero formado de un pedícelo (estipe) sencillo ó ramificado. á veces ensanchado en su extremidad superior en ma especie de sombrerillo; hasidios recubriento toda la superficie lisa del receptáculo, ó ma parte de éste solamente. ó la parte inferior del sombrerillo.

Viven sobre el estiéreol, maderas en descomposición, ete. Lguricuk, Amanita. (Las poeas especies dominicanas de estos géneros, se denominan vulgarmente parregüitus), Polipurres. (laveria (Las especies se denominan orejots de pulo). ete.

¿. Fam. Gasteromiceas. Receptáculos finctifiros más a ménos globulosos formados de nua capa exterma (peridio) i de ma materia interna, al prineipio carnosa (gleba) dividida en compartimentos tapizados por el himenio; 2-4-9 esporas en carla hasidio.

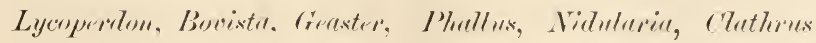


(flor de la tierra). La gleba exhala un olor mui fétido, C'yutlus: (abundante en las aceras), ete.

ORDEN I. Ascomicetos. Hongos multicelulares, de formas reriadisimas. Reproducción por esporas endógenas formadas en las ascas (céhulas matres de las esporas).

1. Fam. Discomicetáceas. Ascas situadas al exterior del «peritecio» mui abierto i en forma de disco.

Saccheremnyces: S. cerevisire (produce la fermentación de la cerveza), s. albicuns (produce las aftas ó sapillo en la mueosa bucal.

2. Fam. Perisporiáceas. Iscas situadas al interior del peritecio cerrado, i de forma esférica. I reces producen «conidios» (gérmenes reprorluctores que propagall al regetal).

Viven sobre materias orgánicas en descomposición, parásitos sobre hojas i tallos, of pelos, cuernos, animales, ete. Aspergitlus, Erysiple (sobre los uveros (Vitis) i rosales), Tuber (bajo la superficie de la tierra), Micresponon: $1 /$. Andonimii (produce la ti-

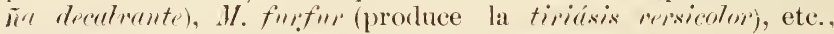

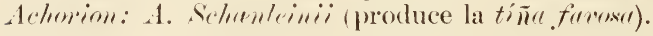

:3. Fam. Pirenomicetáceas Ascas sitnadas al interior del periteeio rue se alne por un poro terminal.

Viven solbre materias orcánicas en descomposición, ó parásitas sobre animales y plantas.

4. Fanr. Liquenes. Los líquenes son el resultado de la simbiosis de mo hongo i una alga, donde predomina la vila del primero. El talo puede presentar formas i ronsistencias diversas: los hai gelatinosos. (Pustáceos, foliáceos. firutienlosos; también pmede sel simple ó lamificado. Lat consistencia depende del predominio de uno de los dos ve- 
getales que lo constitiyen. Los apotecios son semejantes á los de de $1 \approx \mathrm{i}: 3 \approx$ familias anteriores. La reproducción se verifica por esporas $i$ soridios.

Se dividen como sigue:
A. - Lípuenes Ifeterómerrse (domina el hongo sobre el alga).

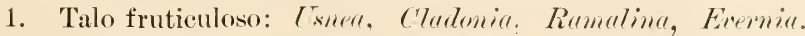
2. Talo foliáceo: I'ermelia, I'eltigere.
3. Talo crustácen: Temucaria, etc.

B. - Línuenes IInmómeros (domina el alga sobre el hongo, ó ambos están en proporciones iguales).

1. Talo frnticuloso: Eplede, ete.

2. Talo gelatinoso: Leptoginm, Lichine, collema, etc.

Viven solre los vegetales, sobre las piedras, tierra, etc.

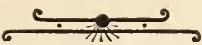





\section{TIPO II.}

\section{MLSCINEAS}

Vegetales provistos de un haz fibro-rascular rudimentario; taIo i hojas diferenciados; sin raices rerdaderas ni flores.

\section{Chane I. Hepíticas.}

Muscineas generalmente rastreras, provistas de talo, of de talo i hojas, éstas siempre sin renas; protonema pequeño i rudimentario; esporogonio sin columele.

ORDEN I. Marcancias. Aparato regetativo compuesto de "In talo (fronde); exporangio indehiscente ó con dehiscencia transtersal ó apical.

1. Fam. Ricciáceas. Organos sexuales iuclusos en al talo; receptáculos nulos, lo mismo que los eláteres.

Ricciele. (En los estanques).

2. Fam. Marcanciáceas. Organos sexuales en receptáculos pedicelados; existe 14 esporangio superior con esporas i cláteres. El aparato vegetativo está formado por un pedíecelo ensancharlo siiperiormerte á modo de somblerillo. 
Marchuntiu: M. dermpunda L. (común en las aceras de Sto. Dgo.) etc.

ORDEN II. Tungermannias. Aparato regetatiro foliciceo; esporangio dehiscente longitudinalmente.

1. Fam. Anticerotáceas. Talo acintarlo, no foliáceo; órganos sexuales colocarlos en cavidarles que se abren para dejar salir los anterozoides. ('aps. 2-valva filiforme ú oval.

Antlencerses.

2. Fam. Yungermaniáceas. Talo con hojas sesiles en 2 ó 4 séries, dos en la cara superior i otra en la inferior (anfigastrias). Caps. pedunculadas, colocadas en los extremos del talo; dehiscencia longitudinal 1-4-valva.

Lejenuia (capss. 1-valva). Frullania (cap. t-valva, membranácea) etc. (Las especies de esta familia viven sobre la corteza de los árboles ó sobre la tierra húmeda).

\section{CLASE ll. MISGOS.}

Muscineas ron un talo ergnido, provisto de lojas; protonema bastante grande; esporogonio con columela.

ORDEN I. Esfagnoides. Esporangio sesil.

1. Fam. Esfagnáceas. (aps. de dehiscencia opercular. Hojas de dos formas: unas grandes, con agujeros, incoloras, i otras más pequeñas i coloreadas.

śplucyumm. (Las especies son unas monéicas i otras dióicas).

2. Fam. Andreáceas. ('aps. de dehiscencia valval (4-6-valva).

Andrea. 
()RDEN II. Brimódes. Exporangio prdicelado.

1. Fam. Fascáceas. ('alps. indehiscente: perlicelo eorto.

Musgos mui pequeños con protonema peremue.

2. Fam. Briáceas. ('aps. de dehiscencia operenlar: perlícelos largos, terminales ó laterales.

Comiprende esta fimilia numerosisimas especies. Nuestros géneros viven en los bosques húmedos, solpre troncos, rocas, tierra, i tambien en los muros húmedos i lugares próximos á las fuentes.

Los principales géneros de la flora dominicana son:

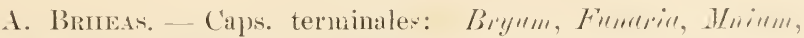

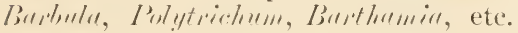

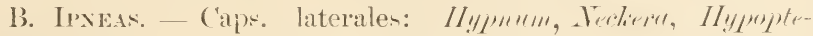
Iyginim, ete.

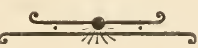




\section{TIPO III.}

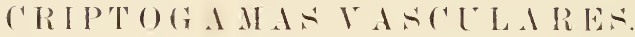

(CORMOFITAS).

Vrgeteles rou órganos regetatiros difrerenciados (tullo, hojes i

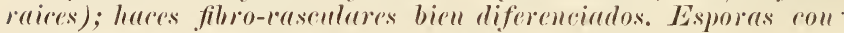
un protulo domde apureeren los anteridios i arquergonios.

\section{('LASE I. FHITNEAS}

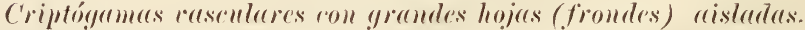

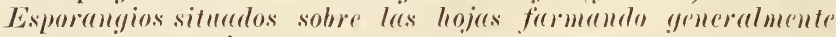
grupros prequeños ó soros.

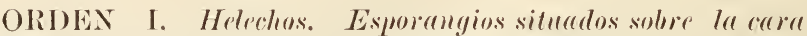

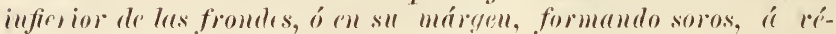
ress con indusio i anillo.

1. Fan. Hímenofiláceas Henangios senta-

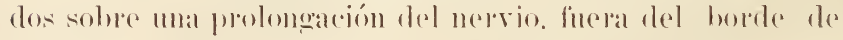
la fonte. soros malewinales con anillos transwersales.

Helechos á véces trepadores con ó sin raices. Tivichermunex.

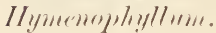


2. Fam. Ciatáceas. Esporangios perlicelados; anillo completo, longitudinal i oblicuo.

Helechos arborescentes, con aspecto de palmeras. ('inthor:

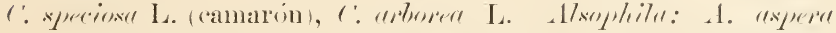
L. (Las especies viven en la Hilera (entral, sierra de Jarabacoa, ete., proximas á las corrientes).

3. Fam. Polipodiáceas. Esporangios pedicelados; anillo incompleto, longitudinal i vertical.

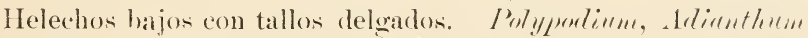
(culantrillo de pozo). Asylemium, I'terix, Acrostichume (calagualal),

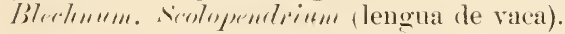

t. Fam. Gleiqueniáceas. Framangios sentados: anillo complete transversal: solos desmulos.

Helechos esm fron les de urecimient) indetinido. Hertemsir.

․ Fam. Osmundáceas. Eisporangios pedicelados i) subsesiles: anillo incompleto, transversal. Las frondes se morlifican desapareciendo el parenquima, i los esparangios forman panojas sobre ellas.

\section{()sinuendu leneren $\mathrm{L}$.}

(i. Fam. Esquiceáceas. Finorangins sentarlos, lispurstos en expigas simples ó compuestas; anillo appical.

Helechos de tallos erectos a volubles. Anemin, Schlizun, Lyyrulienin.

ORDEN II. Taratimas. Esporangios sobre ó a lo Rergo de las uerriaciones de los foliolos fértiles; anillo incomenleto ó mulo.

1. Fam. Maratiáceas. Fiporangios "xteriores, 
soldados entre si ó libres: anillo rulimentario; indusio nulo: protalo ácres.

Marattin.

2. Fam. Ofioglosáceas. Ksporangios interiores. soldados entre si ó libres: anillo bulo; protalo subterráneo.

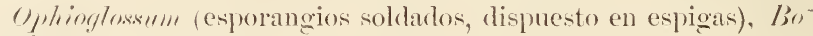
tipy dium (esporangios lihres, dispuestos en projas).

OPIOEN III. Hidropterideas. Esporangios mumerosos i encerados on espororapros; segmentos trensformados, que se desarrollan próximos á les raices. - Plantas acréticas ó de los lugaves hímedtos.

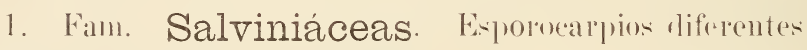
(diclines); prefoliarión pleglada.

Aarolln.

2. Fam. Marsiliáceas. Esporocapios commes (monoclines): prefoliación circinada.

Marsilier, Pilnlariu.

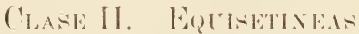

Coreacterses de la inicel

Fam. Equisetáceas. Tallo artirulado: ramifieariones verticiladas: lugjas perpuenas soldadas entre si. memhranosas, dentalas i formamdo ma especie de ocoea eu

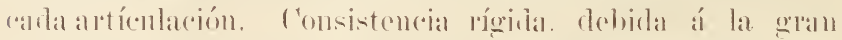
antidad de siliee que rontienen las rélulas epodérmicas. (Hoanos sexuales formando nu cono ó espiga en la extremi- 
dad del tallo Espolas eon dos rlases de protalo, verdes folmbarlos. mo masculino i otro femenino.

['n silo género, con varias especies, de las cuales, tan sólo mna en nnestra flora: Eynixetum giguntemm L. (cola de Caballo).

\section{('LASE III. LICOPODNEAS.}

Criptógamas reascularess ros ramos dicótomos i lagjas pequeñas. Esporangios solitarios, en la rave superior ó en la base de las. liojes.

1. Fann. Licopodiáceas. Euporas prolucimul, al germinar un potalo monóico, tubereuloso, sin remotilar. con los anteriblios i aryuegonios en su cara superior.

Licoprodium (tallo delgado i ramoso, cubierto de hojas pequeñitass, l'siletum (tallo anguloso ó deprinuido, dicótomo; hojas po(as, mui pequeñas).

2. Fan. Selagináceas. Eiporangios cul la l)i se de las hojas terminales, yue son mui complactas formando nua espigar monóica. con los macerosporangios en la base y los michesporangios an la parte superior: protabo femenino formasto en al interior de los esporangios; las micosporas forman anteridios. Tallo comprimido, ramificarlo. con hojas rlísticas. uninervias, en 4 series, dos mayores i dos menoles.

Viven en los hosques sombrios i húmedos. Selagimella. 


\section{FANEROGAMAS.}

CLATE DE LAS FAMILIAS (*)

\section{TIPO IV. GIMNOSPERMAS.}

Tallos aéreos, ramosos i leñosos; hojas simples.... conifera. Tallos ( en muestras especies) subter'meón; lojas compuestas

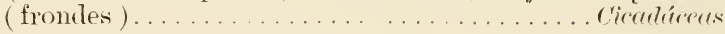

\section{TIPO V. ANGIOSPERMAS. \\ ('LASE I .MONOCOTHLDGNEAs.}

1. Perianto corolino i bien desarrollado; fruto casi siempre apsular............................

Perianto escamoso i pequeño; fruto nunea capsular. ... 13

2. Flores regulares....................... 3

Flores irregulares....................... 10

3. Flores hermafroditas..................... 4

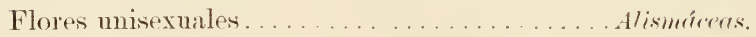

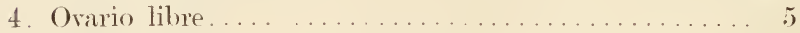

Ovario allherente ....................... ;

5. Perianto regular. Plantas torrestes . . . . . . . . Lilicireres.

Perianto subregular. Plantas aenáticas.... Pontedericicess.

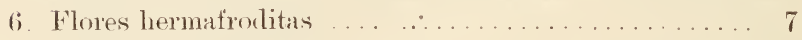

Flores unisexuales. . . . . . . . . . . . . . . . Dirscomericens.

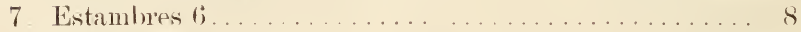

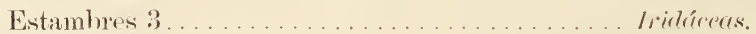

8. Perianto corolino................... Amarilistúress.

(*) De la obra Bsit. i fl. de stre. Inger. ya cit. 
Perianto con las :3 divisiones externas sejaloides. .... ?

9. Estigmas 3, distintos. . . . . . . . . . . . Promelinereets.

Estigmas 3, soldados ............... rommelimécees.

10. Estambres 6, algunos (1-5) trausformado en estaminodios 11 Estambres 1, raras veces 2 ó 3 haciendo cuerpo con los pis-

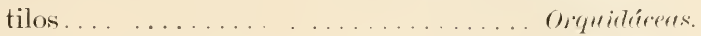

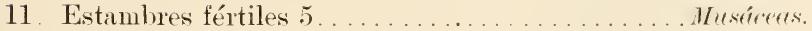

Estambres fértiles $1 \ldots \ldots \ldots \ldots \ldots \ldots$. $2 . \ldots \ldots$

12. Con una antera fértil............... Kingiberécens.

Con una semi antera fértil . . . . . . . . . . . Mermutréres

13. Inflorescencia en espádice.................. 14

Inflorescencia en espigas ó panojas. . . . . . . . . . . . 1s

14. Plantas leñosas. . . . . . . . . . . . . . . . . . Prelumes.

Plantas herbáceas . . . . . . . . . . . . . . 15

15. Terrestres... ........................ . . . . . .

Acuáticas............................ 17

16. Perianto i espádices patentes. . . . . . . . . . . . Arricens.

Perianto i espádices oscuros. . . . . . . . . . . . Tifuéceres.

17. Plantas flotantes i pequeñas, con tallos i hojas reducidos. . . . . . . . . . . . . . . . . . Lemméren.

Plantas sumerjidas i grandes, con tallos i hojas bien desa-

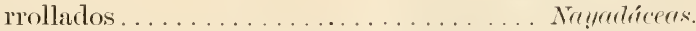

18. Flores con varias brácteas; lígula hendida... Germincéers. Flores con una sola bráctea; lígula entera..... C'ipercicens.

\section{('LASE II, I)ICO'THEUONEAS.}

1. Perianto doble....................... 2

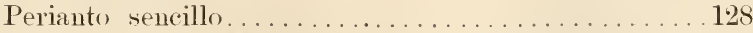

2. Corola con los pétalos más ó ménos libres entre sí . . . . 3 Corola con los pétalos soldados entre sí . . . . . . . . 92

3. Plantas herbáceas por lo común............... 4

Plantas leñosas por lo común. . . . . . . . . . . . . 5

4. Hojas alteruas ó radicales................. 45 
Hojas opuestas. . . . . . . . . . . . . . . 76

5. Flores regulares ó subregulares. . . . . . . . . . . . . . . 9

Flores irregulares........................ (;

6. Carpelos uno................... Leguminoses.s.

Carpelos varios. . . . . . . . . . . . . . . . . . 7

7. Flores hermafroditas................... 8

Flores monóicas. . . . . . . . . . . . . . . Regonicúcers.

8. Hojas compuestas.... . . . . . . . . . . Srepindéceas.

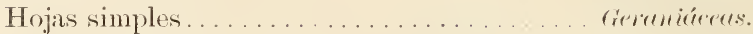

9. Androceo polistemone. . . . . . . . . . . . . . . 10

Androceo isostemone $o$ diplostemone... . . . . . . . . 25

10. Hojas opuestas . . . . . . . . . . . . . . . . 11

Hojas alternas. ...................... 14

11. Ovario libre... ..................... 12

Ovario adherente..................... 13

12. Estambres solore el receptáculo.............. chusicicces.

Estambres sobre el cáliz.... . .......... Litirrirúcers.

13. Fruto (arnoso...... . . . . . . . . . . . . Mirtrécers.

Fruto capsular. . . . . . . . . . . . . . . . Suxifiugriecrs.

14. Estambres insertos sobre al risco... . . . . . . . . . . 15

Estambres insertos sobre el cáliz...............2t

15. Corola imbricada ó valvar . . . . . . . . . . . . . . 16

Corola convoluta . . . . . . . . . . . . . . . . . . 2:3

16. Ovarios distintos ... . . . . . . . . . . . . . . 17

Orario compuesto. . . . . . . . . . . . . . . 18

17. Pétalos imbricalos. Arbustos volubles. . . Menisperméreers. Pétalos valvares. Arbustos erectos........... Amomciceus.

18. Hojas punteadlas. . . . . . . . . . . . . . . . . . 1!

Hojas sin puutos. . . . . . . . . . . . . . . . . . 20

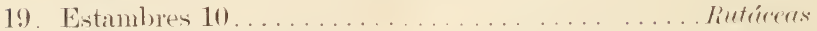

Estanbres numerosos. . . . . . . . . . . . . Bixcícens.

20. Cáliz valvar. . . . . . . . . . . . . . Tilirirees.

Cáliz imbricarlo...................... . 21

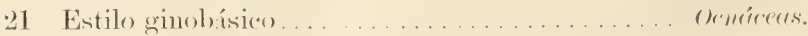

Estilo terminal . . . . . . . . . . . . . . . . 22 
-2) Anteras 2-Ficulares.

Trinstiemicicents.

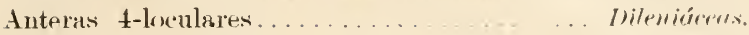

3:3. Anteras 1-celdadas.

Vulvariests:

Anteras 2-celdadas.

Esterenaliácers.s.

2t. Estilo 1, con varios estigmas. Plantas carmosas. c'actárors. Fstilos rarios (ó 1), con un sólo estigma (adla nno. Plantas

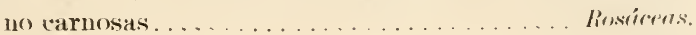

g.) Ovarios distintos, simples . . . . . . . . . . . . 26

Ovari" (ompuesto... . . . . . . . . . . . . . . . . 27

26. Hojas compuestas. . . . . . . . . . . . . . . simmonbrioras.

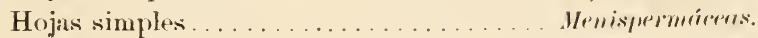

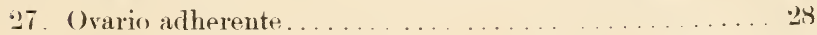

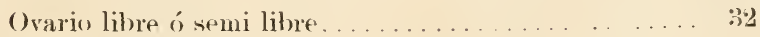

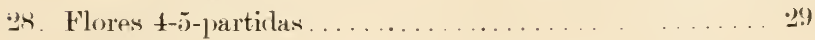

Flores 5 -partidas. . . . . . . . . . . . . . . . .

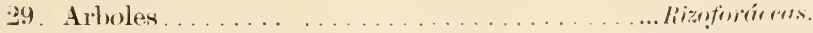

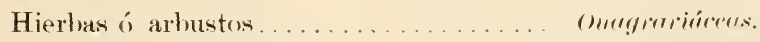

30) Carpelos en número de $5 \ldots \ldots \ldots \ldots \ldots \ldots$. . . . . . . . . . .

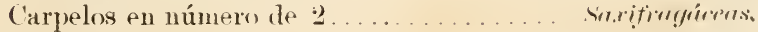

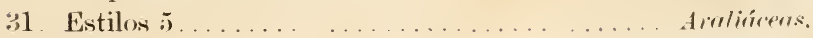

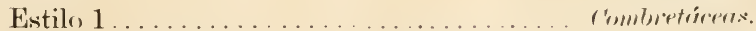

32. Estambres isostemones i opositipétalos... . . . . . . . 333

Estambres isostemones ó diplostemones i alternipétalos. .3t

33. Hojas opuestas. Tallos trepadores. . . . . . . . Vitricens.

Hojas alternas. Tallos erectos ó trepardores. . Remuricers.s.

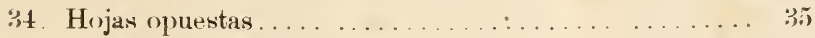

Hojas alternas......................... 38

35. Hojas simples. . . . . . . . . . . . . . . . . 36;

Hojas compuesto-pimmadas ................

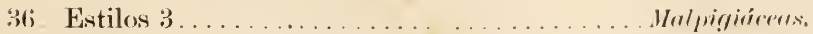

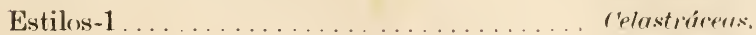

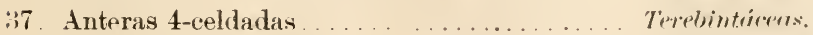

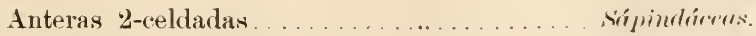

3s Hojas compuesto-pimmalas . . . . . . . . . . . . . . . 39!

Hojas simples. . . . . . . . . . . . . . . . . . t:i 
39. Androcess diplostemone, en tubo... 40

Androceo insostemone, libre........ _ . . . ..... 41

41. Arboles cou canales oleo-resinəsos. . . . ... . . Terebintúrers Arboles sin canales oleo-resinosos........... Meliciurus.

41. Hojas con glándulas transparentes. ... . . . . . . Rutúceres. Hojas sin glíndulas transparentes . . . . . . . . . . . 42

42. Otario de 3 carpelos i ma sola semilla ...... Terefluntréces. Ovario de 3 carpelos, cada uno con una semilla. Suppindécen.

43. Fruto drupáceoo........................ 44

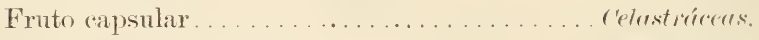

44. Drupa con una semilla ................. Terebintricers.

Drupa con 4-6 semillas..................Aquifolicicras.

45. Flores regulares ó subregulares . . . . . . . . . . 46;

Flores irregulares. . . . . . . . . . . . . . . 70 ()

46. Androcen polistemone.................. 47

Androceo isostemone 6 diphostemone ........... 5. 5)

47. Estambres hipogiuos.................... 48

Estambres periginos. . . . . . . . . . . . . . . . 51

48. Pistilos distintos.................. Remumenláceres. .

Pistilos soldutos . . . . . . . . . . . . . . . . . . . . 49 49

49. Sépalos $2 \ldots \ldots \ldots \ldots \ldots \ldots \ldots \ldots \ldots \ldots \ldots \ldots \ldots \ldots \ldots \ldots \ldots \ldots$

Sépralos $4-6 \ldots \ldots \ldots \ldots \ldots \ldots \ldots \ldots \ldots$. Niuferieners

5) . Estivación imbricada .................. Portulecrécers

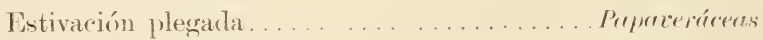

51. Filamentos monadelfos. . . . . . . . . . . . . Mudericeres

Filamentos libres........ . . . . . . . . . . 52

5.2. Pétalos valvares . . . . . . . . . . . . . . . Tilirícenss

Pétalos imforicados..... . . . . . . . . . . . . . . 5.

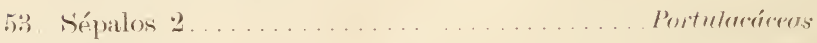

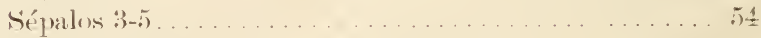

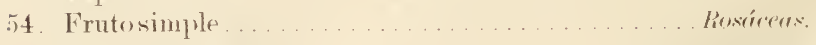

Fruto compueste. . . . . . . . . . . . . . . Lericrers.

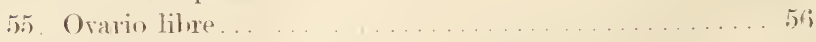

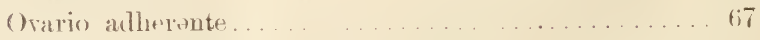

56 Pistil.) 1, ó indefinidos (1-15), distintes. Remumeulárers. 


\section{$-2.5-$}

Pistilos definidos (2)-5), distintos ó soldarlos. . . i7

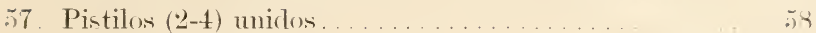

Pistilos (5) distintos ó uniclos................... (i)

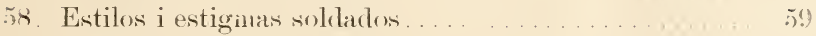

Estilos i estigmas $3, \pm 6(; \ldots \ldots \ldots \ldots$. . . . .

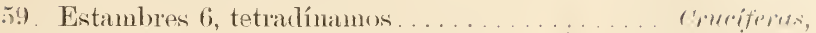

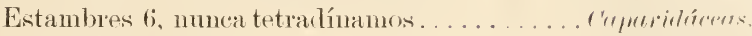

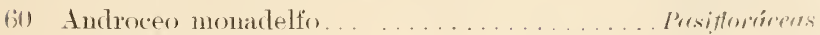

Androceos poliadelfo . . .................... til

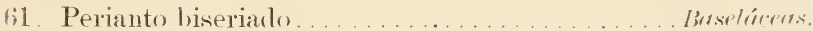

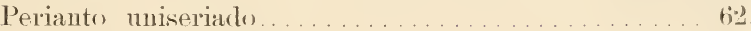

62. Flores hermafroditas. . . . . . . . . . . Trumeróners.

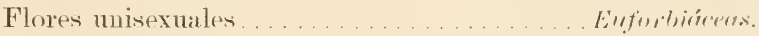

(3:3. Estilos distintos

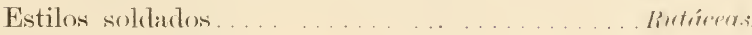

iit. Androcen isostemone. . . . . . . . . . . . . . (i).

Androceo diplostemore . . . . . . . . . . . . . . 6 6t

(i.). Filamentos alternipétalos............. Eivitongilómers.

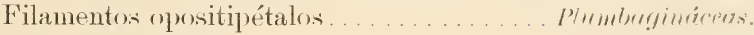

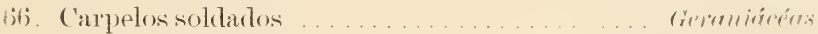

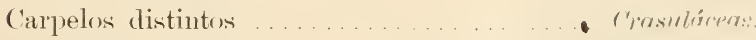

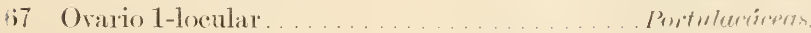

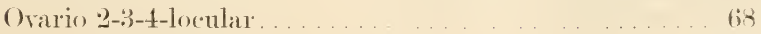

tix. Flores en umbelas. . . . . . . . . . . . . . . . . . . ti?

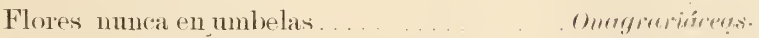

(i)! Ovario 2-celdado. Hierbas. . . . . . . . . . . . Embeliferes.

Ovario 3-5-celdado. Arboles. . . . . . . . . . . . . Alulicioses.

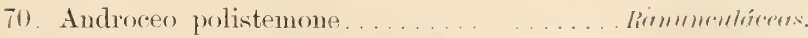

Androceo anisostemone ordinariamente. . . . . . . . . 71

71 Filamentos momalelfos.................... 7 . . .

Filamentos poliarlelfos . . . . . . . . . . . . . . . $7: 3$

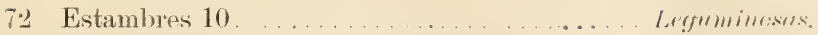

Estambres 8 ó ménos . . . . . . . . . . P Poligullireres.

7:). Cáliz con espolón. . . . . . . . . . . . . . . . . . . . 74

(áliz sin espolón. . . . . . . . . . . . . . . . . . 
74. Sépalos 3-4; arroetos i)

Bulsuminear:

Sépalos 5 ; carpeles 3

Tropeóleas.

75. Estambres 5

Violúceres.

Estambres 6

c'apuridéces:

76. Androce polistemone.................. 7 7

Androcet isnstemone ó diplostemone. . . . . . . . . . . 78

77. Estambres sobre el receptáculo, en una serie ... Clusicuccus.

Estambres sobre el cáliz, en varias séries....... Mirtúcen.

78 . Pistilos distintos . . . . . . . . . . . . . . . . . . . . . . . 79

Pistilos soldados. . . . . . . . . . . . . . . . . . . . . . 80

79. Pistilos 3 ó más. Plantas carnosas . . . . . . . . C rusulúceas.

Pistilos 2. Plantas lechosas. ... . . . . . . . . Asclepiudácen.s.

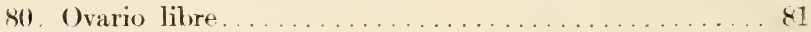

Ovario adherente . . . . . . . . . . . . . . . . . . 83

81. Androceo isostemone i opositipétalo ............ 82

Androceo anisentemone i alternipétalo........... 8t;

42. Estigma 3-1obado.... . . . . . . . . . Portuluerécers.

Estigma entero....................... Mirsinácres

83. Hojas opuestas, 3-5-7-nervias . . . . . . Velustomécees.

Hojas alteruas, 1-nervias. . . . . . . . . . . . . 84

44. Estilo $1 \ldots \ldots \ldots \ldots \ldots \ldots$. . . . . . . . . . . . . . . .

Estilos $2-3 \ldots \ldots \ldots \ldots \ldots \ldots \ldots \ldots$. . . . . . . . . . . . . . .

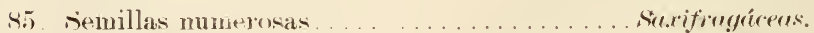

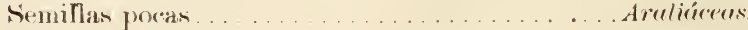

s6. Hojas simples . . . . . . . . . . . . . . . . . $8_{6}$

Hojas compuestas. ................... r'igotiluecros.

87. Hojas dentudas ó lobadas.................. 88

Hojas enteras. . . . . . . . . . . . . . . . 87

88. Pétalos 4; estambres 6. . . . . . . . . . . . C'ruciferus.

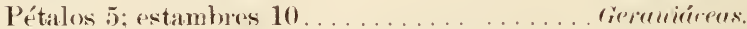

89. Pétalos insertos sobre la garganta del cáliz... L Litureriéceus. Pétalos hipoginos........................ 90

90. Flores irregulares. .................. Poligulácees.

Flores regulares. . . . . . . . . . . . . . . . . . 91

\$1 Pitales unguiculados, de limbo dentado a parti- 
(1)

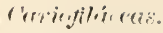

Pétalos sesiles, de limbo entero.

Hijericuere..

9.). Androcer polistemone . . . . . . . . . . . . . . . . 93

Androceo isostemone ij diplostemone... . . . . . . . . 95

9:3. Filamentos monadelfo, $10 \ldots \ldots \ldots \ldots \ldots$ Legumimosets.

Filamentos numerosos.................... 94

94. Unidos totalmente. . . . . . . . . . . . . . . llalcricers.

¿nidos en la base, entre sí ó con la corola.. Termstiemiri eus.

95. Ovario adherente .................... 96

Ovario libre. . . . . . . . . . . . . . . . . . 102

96. Anteras colerentes ................... 97

Anteras libres. . . . . . . . . . . . . . . . . . . 99

97. Flores en capítulos iuvolucrados. . . . . . . . . c'ompuestus.

Flores solitarias . . . . . . . . . . . . . . . . . . 98

98. Plantas erectas....................belińceas.

Plantas trepadoras. . . . . . . . . . . . . . rucribitćcens.

99. Hojas opmestas. . . . . . . . . . . . . . . . . 10

Fojas alternas . . . . . . . . . . . . . . . . . . . . 101

100. Hojas con estípulas. Nativas. . . . . . . . . . . . Pubriceors.

Hojas sin estípnlas. Cultivadas. . . . . . . . Cuprifolicireas.

101. Flores dióicas. . . . . . . . . . . . . . . Estirarúceres.

Flores monóicas . . . . . . . . . . . . . Cucurbitciceus.

10.2. Flores regulares. . . . . . . . . . . . . . . . . . 103

Flores irregrulares. . . . . . . . . . . . . . . . . . . . 121

10:3. Estambres 5 ó $10 \ldots \ldots \ldots \ldots \ldots \ldots$

Estambres 2 ó $4 \ldots \ldots \ldots \ldots \ldots$. . . . . . . . . . . . . . . . . .

104. Estannhres opnestos á los lóbulos de la corola . . . . . 105

Estambres alternos con los lóbulos de la corula..... . 107

105. Hierbas ci arbustos.... . . . . . . . . . Plumbugimécess.

Arboles ó arbustos . . . . . . . . . . . . . . . . . . 106

106. Ovario 2-5- 1 Flores unisexuales. . . . . . . . . Eluemúcus. celdado , Flores hermafroditas.......... supotúcres.

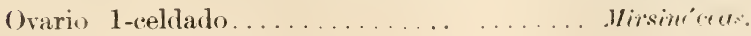

107. Fruto drupáceo; arbustos... . . . . . . . . . . . . . . 108

Frnto no drupáceo; hierbas. . . . . . . . . . . . 110 
108. Estilo 1

Estilo ()

109. Druja сон 1 semilla.

Aremifoliriresess.

Drupa (a) 4 semillas.

Olarcieceres.

Trebeméneses.

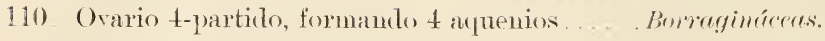
()vario nunce formaudo apuenios . . . . . . . . . . 111

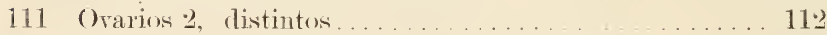

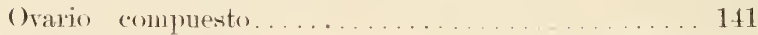

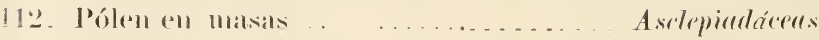

Pólen pulverulento. . . . . . . . . . . . . . . 11:3

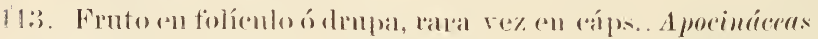

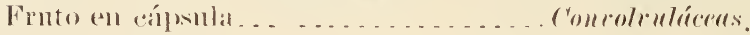

114. (Nando 1-reldarlo... . . . . . . . . . . . . . . . 11.

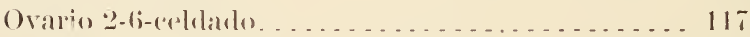

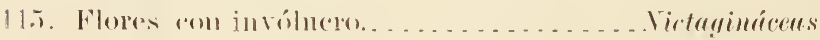

Flores sin imvilutero. . . . . . . . . . . . . . . . . . 116 ;

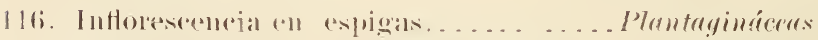

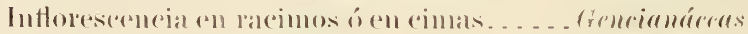

117. IIojas radicaldx. . . . . . . . . . . . . . Plantaginéceres Hojas altermals. . . . . . . . . . . . . . . . . . . 11 s

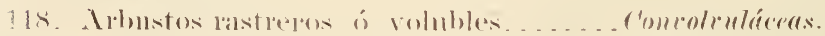
Irbintas exerotos. . . . . . . . . . . . . . . . . . 117

1!). Fruto con t semillas. . . . . . . . . . . Borroginueres.

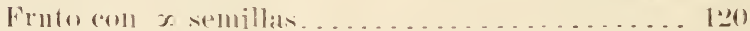

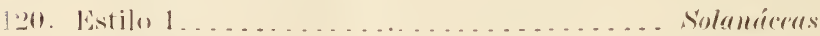

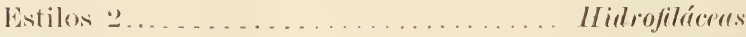

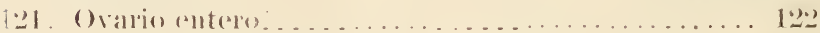

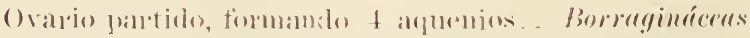

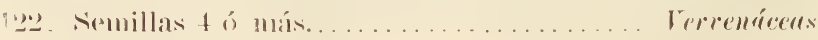

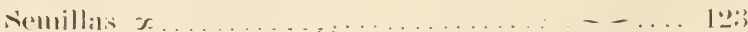

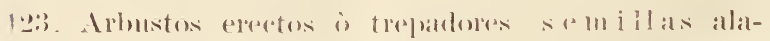

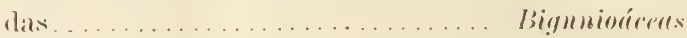

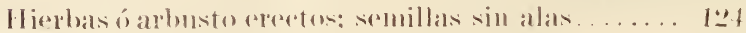


124. Finto t-is-cediado.

Pedulicicens

Fronta 1-"2-reldarlo. 125

12.). Fruto 1-celiato (iesurericieces

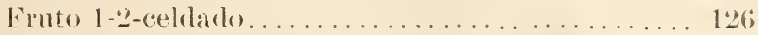

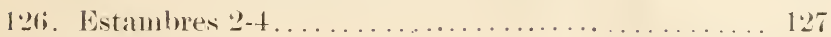
Estambres ì.

Siblanciceres

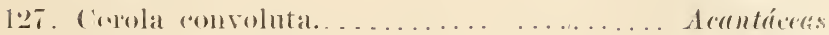

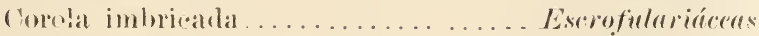

12s. Plautas herbáceas. . . . . . . . . . . . . . . . 1290

Plantas leñosas. . . . . . . . . . . . . . . . . 14:

129. Ovario libre del tubo del perianto............ 1:30

()vario adberente al tubo del perianto... . . . . 143

1:30. (Marios distintos ó numerosos . . . . . . . . . . . . 131

() vario (eompluesto ó simple i 1100 solannente. . . . 2333

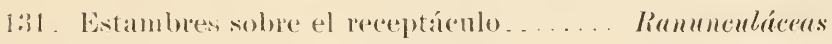

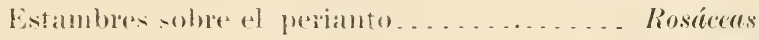

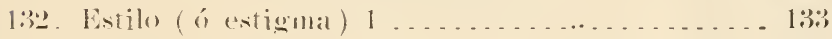

Estilos (o estigmas) 22-12 . . . . . . . . . . . . 185

1:3.). Ovario 1 locular con 1 semilla . . . . . . . . . . . . 134

Orario plurilocular con varias semillas... Litrariáceas.

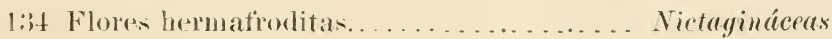

Flores diclines. . . . . . . . . . . . . . .... Trtícréces

1:3.). Ovario 1.3-reeldado (’on ignaal número de semillas.. 1:36; (Ivario t-se -celdido con igual número de semillas. 140)

1:36. Orario 1-celdado . . . . . . . . . . . . . . . . . 137 ()vario :3-celdado................... Euforbacens

137. Hojas opnestas...................... 138

Hojas alternas.. . . . . . . . . . . . . . . . . . 139

l:3s. Simillas $1 \ldots \ldots \ldots \ldots \ldots \ldots \ldots \ldots \ldots$. Amarantáceas

Nemillass .................... ('asioflláceus.

1:39. Hojas con estípulas. . . . . . . . . . . . . P’oligonácéas.

Hojas -in estipulas.... ............ Quenopodiáceus.

140. Hojas opnestas. . . . . . . . . . . . . . . . . 141 
Hojas alternas.......................... $1+2$

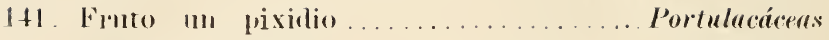

Fruto ma cápsula .................... Cariofiláceas.

It2. Fruto ma baya................... Fitolacáceets.

Fruto un utínlo. . . . . . . . . . . . . . Amarantáceas.

14:3. Flores irregulares. Tallos volubles. . . Aristoloquicúcens Flores regulares. Tallos erectos...... . . saxifrayácers.

14. Intlorescencia nunca amentácea........... 14i

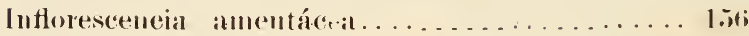

i t.i. Hojas opuestas. . . . . . . . . . . . . Lorantácente. Hojas altermas. . . . . . . . . . . . . . . . . . 14ti

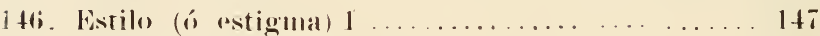
Estilos (ó estigmass $2-3 \ldots \ldots \ldots \ldots \ldots \ldots$

147. Hstambres: :-12, dispmestos en variassélies. Lanrácers. Estambres dispuestos ell ma sola série....... Itis

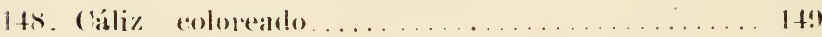

Cáliz vertosu . . . . . . . . . . . . . . . . . . 150

1 t:). Hojas con estípulas. . . . . . . . . . . . . . Stamidrícuns.

Hojas sin estípulas . . . . . . . . . . . . . Timeleácrus

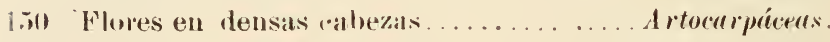
Flores ell espígans ó racimos.................. 151

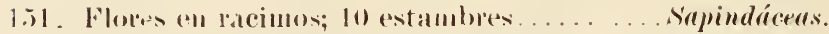
Flores all espígas; s-10 estambres...... Combretáceas.

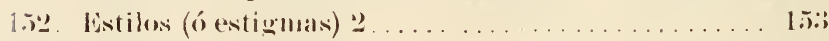
listilos (ó estigmas) 3 . . . . . . . . . . . . . . . 15

1.i.: Plantas expinescentes . . . . . . . . . . . . C'eltideres Plantas inermes........................ 1.it

1.it. Arboles latescentes. . . . . . . . . . . . . . Moráceres Hierbas 6 allonstos sin littex ............. Érticúrerex.

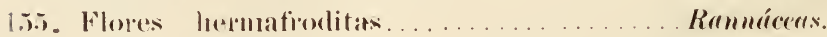
Flores unisexuales. . . . . . . . . . . . . ... Euforbicicen.

linf Flopes: las masculinas ent amentos. . . . . . . 1 . Flores: ambas an amentos . . . . . . . . . . . . . . . . 1.i 
157 Hojas simples; nuez con iuvólucro C'upulíferas. Hojas compuestas; nuez sin invólucro... Juglandaceas 1.5. Fruto seco; semillas con pelos sedosos... . . . . Salicíceas Fruto carnoso; semillas sin pelos. . . . . . . . . . 159

159. Hojas alternas.................. Miricúcens Hojas opuestas. . . . . . . . . . . . ... . . . . . . 160

160. Estambres $8 \ldots \ldots \ldots \ldots \ldots \ldots \ldots \ldots$ Batidacens

Estambres 26 más................ Piperáceas

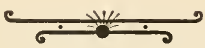




\section{TIPO IV.}

\section{G I II NOSPER II L X}

Planters con races, tallos, hojus, iflores imperfectess é incompletas; semillas desmudas, esto es, no encerradas en un pericarpio; pistilo escamoso sin estigma; embrión procisto generolmente de rerios cotiledones resticiludos.

1. Fan. Cicadáceas: Flores dióicas, en espigans amentiformes terminales. Las masculinas estan formarlas por escamas carnosas, en cuya cara inferior llevan los sacos polinicos. Las femeninas se componen de escamas más gruesas, espiralmente sentadas alrederlor de un eje grueso, i en cuya superficie iaferior se insertan dos óvulos ortótropos. Fr. drupácro. rojo. - Plantas con aspecto de paluclas, de tallo recto, simple: hojas grandes i pinnadas. 'Trópicos.

I'nico género en nuestrat flora: Zamia: Z. integrifolle L. : Z. undie daco., Z. dethili.s Ait., Z. furfurecen Ait, ete. localizadas en la l'rov. de sto. Dgo., con el nombre vulgar de guáyigax.

2. Fanı. Coniferas: Flores monóicas ó dióicas, c'l 
amentos; las mascalinas formadas por un sólo estambre, $́$ le muchos soldados entre sí ó con una escama, llevando dos ó más sacos polínicos en su cara inferior; las femeninas reducidas á simples escamas ú hojas carpelares abiertas; órulos desnudos en la base de la cara interna de cada escama. Fr. leñoso (cono) ó carnoso (baya). - Arboles ó arbustos resinosos, de hojas persistentes, simples i amenudo aciculares, reunidas eu hacecillos ó fascículos. Konas templadas.

A b i e t i u e a s: Flores masculinas con las escamas leñosas. empizaradas, en espiral, que se transforman en un cono ó estróbilo.

P'inu:: único género indigena en nuestra flora, con la especie I'. accidentulix Sw. (pino), en las Sierras de Jarahacoa, Baní, Samaná (?), etc.

Cup res in eas : Flores masculinas reunidas en gran número en la base de las escamas, i poeo numerosas, formando un cono seco i dehiscente (gálbulo) ó una especie de haya indehiscente.

Thuja: Th, orientalis (árbol de vida), cultivada.

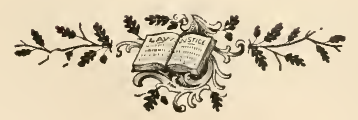




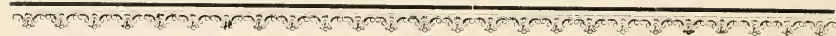

\section{TIPO V.}

\section{NQIOSTERMAS.}

Plantas con raices, tallos, hojas, $i$ flores generalmete pecfectas i rompletas; semillas producidas on ol interior de un pericarpio arrado; pistilo completo; rmbrión con uno ó dos cotiladones.

\section{('LASE I. MONOCOTHEDONEAS}

Angiospermas con un sólo contiludóm; hacecillos fibro-resculares sin zoma del cembium, i de regetación 11 o limitada, espareidos irregularmente en la masa parenquimatosa; hojas ale nerviaciones generalmente paralsla i ressi simpre sin estipulas. Flores perficetas i romummente regulares, de perianto doble cuyo numero radiral es 3 segum la fórmula general P.3+3; A. 3+ 3; G. 3 .

()RI)EN I. Lilifforas. Flores regulares i hermafroditas; pirianto bien desarrollato i rorolino; niverio con 3 ó 4 caridades, i embrión encuelto por al endospermo.

1. Fan. Liliáceas. Flores perfectas, regulares.

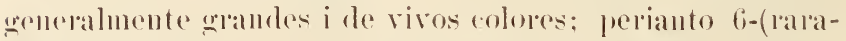
mente 4)-partido: (ests. (i (ralas reces 4); anteras introrsas. () vario libre, :"-lormlar; óvulos so ; estilos terminales, con :" 
estignas. Fr. en rípsula 3-locular, loculícida, ó una baya. Senus. provistas de 11 endospermo carnoso; embrión recto. -Hierbas, arbustos ó álboles, con raices bulbosas ó tuberosas; hojas sencillas, alternas, enteras, por lo comun estreclas i de hase envainadora; escapo sencillo ó ramiticado. \%onas templadas i calidas, trópions.

L i li eas-Fr. cáps. loculicida.

Allium: A. sativum (ajo) A. cepa (cebolla), A. fistulosum (cebollin) i A. porrum (puerro), cultivados.

Alor: A. mulgaris Lam., A. spiereta L. (sáhilas), Iucca: J. alowfolic L. (hayoneta, flor de Jericí en el Cibao), Polianthes: P. tuberosa (azucena) cult.

Asparageas. - Fr. ma baya.

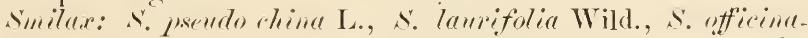
lis H. B. et Kth., i otras, conocidas todas con el nombre de brjuets rlino.

¿. Fam. Pontederiáceas. Flores hermafioditas, irregulares; perianto tulular, (i-partido; ests. 6 , ó 3 por aborto, desiguales i periginos. Ov. libre, 3-locular. con $\infty$ ivulos; estilo terminal con un estigma sencillo. Fr. capsular, con :3 (ó 1) celdas, loculícido, ó un aruenio. Sems. o ; murlospermo amiláceo; embrión recto. -- Plantas acuáti"as ó palnulicas, peremes ó con rizoma rastrero; hojas radicales. Flores bracteadas, amarillas ó azules. Trópicos.

Ireterenthera limesce Vahl., en los pantanos del Cibao. Pontederia cordata (lila de agua), cult.

:Fam. Dioscoreáceas. Flores dióicas, perpuenas; perianto verdoso, (i-partirlo, biseriado; 6-estambres. ()vario:3-locular, atllerente, con 3 3 ó 6 óvulos; estilos 3. ráps. :-locular baya ó sámara. Sems. alarlas en la rápsula. 
redondas en las bayas; endospermo carnoso. Hierbas ó arbustos volubles con rizoma feculento ó leñoso, hojas alternas. simples, palmatinervias. amemudo cordiformes. Inflorescencia en espigas ó racimos. Zonas cálidas i templadas.

Dioxcorea: D. alute L. (ñames), D. setina L. (mapuei,) D. tuberculífera (bondá ó bondai) produce retonos dilatados á modo de bulbillos, en las axilas de las hojas; D. pillesinscula Bert., silvestre. Rinjania: $R$. lirestatn L. (ñame-mapnei), $R$. angustifollia L., R. mutre L., ete., en los bosques.

4. Fam. Iridáceas. Flores hermafroditas; perianto regular ó irregular con 6 divisiones biseriadas; 3 estambres. Orario 3-locular, adherente, con o óvulos; estilo sencillo con :3 estigmas á menudo petalóisleos. Cap. 3-locular, loculícida. sems. œ redondas ó aladas; endospermo carmoso. Hierbas vivaces con rizoma tuberoso ó bulboșo, i hojas radicales. Flores bracteadas, en espigas, corimbosó panojas. Extratrópiros. Cabo de Buena Eisperanzd.

Sisypinchiem pulmifolinm L. (celolla de pahma).

5. Fam. Amarilidáceas. Flores hermafioditas: perianto ordinariamente regular con 6 divisiones biseriadas, ó tubuloso: (i estambres libres ó roherentes entre sí por ma membrana petalóidea (corona). Ovario 3-lorular: óvulos $\infty$. Fruto, nua cápsula :3-locular. loculícirla, haya. pixidio ó arquenio. śems. $1-\infty$. endospermo carnoso. Hierbas peremnes, buloosas, acaules, rara rez caulecentes; hojas por lo comm ladicales, simples i estrechas. Flores 
grandes sobre mu escapo carnoso, acompañadas de brácteas espatáceas. 'Trópicos.

A III a r il ideas.-Bulbo.

Amuryllix: A. Regime L. (lirio), A. ecnestre Ait., (duende) 1. Belladomine L. (lirio), ete. A. vittata, en los jardines. I'un'rectium: I'. caribanm L. (lirio), I'. oratum Mill (lirio), etc., en las costas. Crinum: (:. Americumem L. (lirio), en las sierras de Jánico.

$\perp g$ a veas. - Raices fibrosas ó rizomas.

Agure: A. Americuna I. (maguei), A. viripare L. (maguei común). Fourcroya: F. cubensis Haw. [cabuya]. Alstremeria: A. dulie Tuss. [lirio].

II ipoxideas.- Rizoma tuberenloso.

Myprorix: II. erectu L., ete.

i. Fan. Bromeliáceas. Flores hermafroditas; per'ianto regular de 6 divisiones biseriadas, las a steriores sepalóiles; 6 estambres. Ovario libre ó adherente, 3-locular: escilo :3-fido. Frnto en cápsula 3-locular, de ordinario septícida, ó una baya (solosis). Sems. $\infty$; endospermo amiláceo.-Plantas herbáceas ó frotesentes, commmente "pititas; hojas sentadus i envainadoras, espinoso-dentadas rn la márgen casi siempre. Flores en espigas, lacimos simples ó compuestos. Trópicos americanos.

Br. om elicas. - Ovario adherente; baya.

Alunemesse renlgeris Lindl. (piña) Beromelie: B. Pingrein L. [malla], R. chrysenthe Jace. [malla de burro[.

Tilan I sieas. - Ovario libre; cápsula. 
Tilandsia: T. nsuecrides L. [gnajaca, yedra]. T. lingulate L. T. preniculatr L., T. serretn L., ete., [piñas de agua].

7. Fam. Commelináceas. Flores hermafroditas; perianto doble, el externo sepalóide, el interno petalóide. 6 ests. hipoginos, á reces ménos por aborto. Or. 2-ó3locular; óvulos pocosó on; estilo sencillo; estigma indiviso. Caps. 2-3-locular, loculícida con pocas sems.; endospermo carnoso. - Hierbas carnosas, anuales ó vivaces; tallo amemudo rastrero: hojas envainadoras en la base. Flores bracteadas. solitarias ó diversamente agrupadas. \%onas intertropicales.

Commelymu: ('. commumin L. [suelda-consuelda]. Tradescantia: T. discolor Ait. [harquito, maguei]: ete., T. crassifolia [cucaracha] cult.

ORDEN II.-Melobialas. Flores regulares, ordinariamente unisexuales; perianto bien desarrollado; orario con ci caridades; embrión frecuentemente sin endospermo.

1. Fan. Alismáceas. Flores hermafrorlitas ó m $^{\mathrm{i}}$ sexmales; perianto regnlar ron 6 divisiones en 2 séries. la exterma sepalóide $i$ persistente. Ests. (i ci múltiplos de seis. :3, 6 o omás ovaros lihres ó coherentes parcialmente, eada mono con 1 óvnlo. Aquenios en número igual al de los ovarios.-Hierbas acenticas ó palustres.-Zonas templarlas i cálidas.

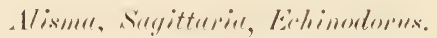

ORDEN III.- Escitumineas. Flores irregulares, hermafroditas, raras ceces misexuales por aborto; seis ests. de los ruales 1-5 abortan ó se transforman en estrminodios; embrión ordinariamente con emelospermo. 
1. Fam. Musáceas. Flores hermafioditas; perian to con 6 divisiones biseriadas i petalóides; 6 ests., el posterior estéril ó nulo. Ov. adherente, 3-locular, con pocos ó o óvulos. Estilo sencillo. Fr. :3-locular, umbilicado, en haya indehiscente 0 en (áp.s. dehiscente. Semillas ariladas: endospermo amiláceo ó carnoso. - Hierbas vivaces con rizoma: tallo áéreo mui pequeño; hojas mui grandes con largos peciolos envainadores, i convolutas en la estivación. Flores envuelt is en varias brácteas espatáceas, i con nectarios en los ovarios.-Trópicos.

Eran i as. - Baya ó caps.; sems. $\infty$ en las celdas.

Mrese: H. prepedisiace L. (plátanos), M. sapientum L. [guineo común], K. rejia Rumph. (plátano congo), etc. Ravenala Madagascariensis [árbol del viajero] cult.

He li coni e as.-- ('áps.; scons. solitarias en las celdas.

Helicomia: II. Bilıai sw. (plátamo cimarrón) en la Hilera Central.

2. Fam. Zingiberáceas. Flores hermafroditas; perianto doble. el externo pequeño, 3-fido, amenudo entero, persistente; el interno grande, tubuloso, (rn seis divisiones hiseriadas, las 3 exteriores petalóides, las de las série interna desiguales, 2 (laterales) más pequeñas, la posterior (labelo) más gr nde; 1 sólo estambre fértil; filamento petalóide; antera 2-locular. Or. adherente 3-locular con $\infty$ óvulos. Cáps. :-locular; sems. $\infty$ ó pocas; endospermo amiláceo.-- Hierhas vivaces con rizoma rastrero i hojas radicales ó caulinas: vernación convoluta. Flores terminales c) radicales. Regiones tropicales del Asia.

Zingiber officinale Rose. (jengibre). Amommm: A. syluestre Sin 
(jengibre cimarrón). C'urenum lonqu L. (jemgibrillo). Alpinia: A. nutans (boca de dragón) cult.

3. Fam. Marantáceas-Intera 1-locular (media) por abortu de una celda. terminal ó lateralmente pegada al filamento. Fruto en cáps. ó en baya.-Hierbus nunca aromáticas. Cetera Zingiheraca. Regiones intertropicales.

Maranta: M. indica Tuss. (sagú), produce el arrow root del Comercio, M. Alomyn Jacq. (lerén). Camma: C. edulix Ker. (capacho), C. indice Ait., ('. glanea L. C. occidental is Rose. (cigarrones).

ORDEN IV.-Ginándreas. Flores hermafroditas, orquidácus; perianto bien desarrollado; tres estambres, de los cuales uno ó dos suelen abortar; orario 3-locular i embrión sin endospermo.

1. Fam. Orquidáceas. Perianto irregular con t; divisiones biseriardas; la pieza superior (labelo) distinta de las otras, ell forma, coloración i porte, á reces con una prolongación en su base (espolón). Estambres 3, soldados con los estilos i los estigmas [qunostemo], pero por lo común umo solamente, quedando los demás convertirlos en astaminodios; pólen coherente en masas [poliniclios]. OV. adherente, 1-locular, con : placentas parietales; óvulos $x$. (áps. membranosa ó carnosa; sems. $\infty$ i mui peyueñs; en dospermo mulo.--Plantas viraces, terrestres ó epifitas; hojas simples, enteras, radianles ó caulinas. Flores en espigas ó racimos, basilares ó terminales. Zonas templadas i cáliclas.

En nuestra flora se encuentran los siguientes géneros, en su mayoría epititos: Epridrudrom, Blotic, Calanthe, Bromegletonier,

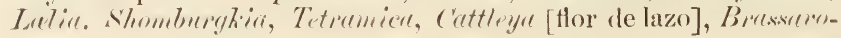


la, Letiopsix, Cutesetum, Lycaste, Maxillaria, Oncielium (mariposa; angelitos), Browien, Tomopsis, (yyrtoperdium (piñuela), TaniIla (bejucos de lombriz), Isochilns, spirmenthes, Stelis, Cymbidium, Plenrothallis, Malaxis, Diemia, Liparis, Ilabenaria, Corenichix, Limodorum, Pelexia, Ponthiera, Stemorrlnymchos.

ORDEN V.-Espadicifloras. Flores generalmente unisexnales; inflorescencia en espádice encerrado en una espata.

1. Fam. Palmas. Flores hermafroditas ó polígamax, monóicas ó dióicas; perianto coriáceo; 22 verticilos persistentes, el externo más pequeño, i ambos rudimentarios: 6 ests. libres ó soldados entre sí ó con el perianto. ()r. libre, trígono, 3-locular; celdas uniovuladas; ur sólo óvulo se desarolla. Bayá drupa, con el pericarpio tibroso ó córlleo, carnoso ó crustáceo. Sem. soldada con el endocarpio; endospermo voluminoso. oleaginoso, sólido ó lue“o, i en este último caso lleno de un líquido lechoso.-Plantas leñosas, arborescentes; estípite columnario, espiuoso ó inerme, coronado por una copa de grandes lojas inermes ó espinosas, pinnadas ó palmeadas cuando adultas. Zonas cálidas de América i Africa.

Oreedera: O. oleracen Mart. (palma de yagua), Euterpe (cacheo), Gemoma (manacla), Cocos: C. micifer L. (cocotero), Elreis guineensix L. (corozo), Acrocomia: A. sclerocarpa Mart (catei), Copernicin: (C. tectorum Mart. (cana), Thrinax:T. Argentere Mart. (guano), T. parviftor Sw. (guanillo), Phoenix: Ph. dactylifera (dátil) cult.

2. Fann. Aráceas. Flores unisexuales, mui raras réces hermafroditas; perianto nulo ó rudimentario en las unisexuales, patente i laciniado en las hermafroditas; ests. œ, libres ó soldados; pólen á véces aglutinado. Ors. 6-1 agregados, distintos ó soldados, 1-loculares. Baya inclehis- 
cente; sems. 1 ó 2 ; endospermo carnoso ó farináceo.--Hierbas acaules ó arborescentes ó treparloras por raices adrenticias, con rizomas ó tubérculos; hojas alternas, lobadas ó cordiformes, palmatinervias. Flores en espárlices envueltos en una espata; las masculinas en la parte superior del espádice; las femeninas en la hase, i ambas separadas por nectarios glandulosiss.

Aroideas.--Flores diclines; perianto nulo.

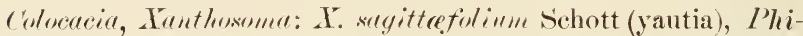
lodendron (tra-trá ó zapatico) P'istia, Arum: A. maculatum (corazón de Jesús), 1. italicum (corazón de María) cult., Caladiu n: C. violaceum i C. hicolor [canangas], eult.

Ca la ceas.--Flores hermafroditas, ó misesuales monócas; perianto patente.

Momstera: M. crenurefinlin Sichott | mata pueren], Pothers, ete.

3. Fam. Tifáceas. Ehores misexuales; perianto escamoso ó cerdoso. B-filo enl las masculinas; ests. co. ()vs. libres ó soldarlos, sesiles ó estipitados, 1-loculares i 1-ovulados. Drupa: endospermo carmoso ó farináceo.-- Hierbas acuáticas ó palúdicas, peremmes, con rizoma; tallos cilíndri"os con hojas alternas i lineales. Flores en espádices rennirlos en espigas ó cabezas, con mol cepata foliácea i eaduca; las flores masculinas ormpan la partesuperior, i las femeninas la inferiór. Konas tropicales a intertroppioales.

Tipha: T. angustifolin I. [eneal.

? 4. Fam. T_ennáceas. Inuas dulcess i estancarlas, comprendidas en las zonas templadas. 
5: Fun. Nayadáceas. Floreshermafroditas ó muisexuales: perianto rulo, is con uno tubuloso 2-t-partido; ests. definidos, 1-t; ants. 1-2-t-loculares. Ors. 르 libres, 1 -loculares; estilos uno, á véces dos ó tres, ó nulos. Fr. en aquenio, folículo ó baya; sem. sin endospermo.--Plantas acuáticas, marinas ó fluviales, por lo común sumergidas: tallos articulados; hojas altermas ú opuestas, enteras, envainadoras, i con frecuencia estipnladas. Flores solitarias ó en glomérulos axilares. ó en espádices simples ó compuestos con espata común. Zonas cálidas i templadas.

Nrijas (en las aguas dulces), Potemogeton (id.), Ruppin, Thalassic (en las costas del mar Caribe).

ORDEN VI. Glumaceas. Flores comumente hermafroditas; perianto mulo ó rudimentario; inflorescencin en espigas ó panojas sin espata.

1 Fam. Gramináceas. Perianto de dos ó tres escamas pequeñitas [glumélulas'] libres ó soldadas; ests. de 6 á 1 , pero comunmente 3 . Ov. simple, 1-locular, con 1 óvnlo ascendente; 2 ć3 estigmas. Fr. ma cariópside. rara reza'prenio; endospermo farinoso i alundante.--Plantas herbáreas, ó leñosas arborescentes, annales ó peremues; tallo lleno ó hueco, articulado i simpre cilíndrico; hojas alternas, dísticas, envainadoras. con una membrana estipular [lígula) en el purto de separación de la vaina con el limbo. Flores con dos brácteas desiguales (glumillas), 1 ó más rennidas ell espignetas, cada mia de éstas con dos brácteas opnestas ell su hase (glumas) que se remuen ell expigas ó panojas. Sin límites determinados.

Polypogon, Paspalum, Millium, Agrostis, Aulropogom [pachulí], Aristiclo, Eleusine, (pata de gallina), Digituriu, Manisuris, Cenchrus, 
Panicum (yerba de guinea; millo), Pennisetum, Setaria, Poa, Biomus, Arumce, (caña de Castilla), Guaduu, (carrizo), Phrogmites (carrizo), Bambusı (bambú; caña brava), Oiłyza (arroz), Zea (maiz) sacchumu (caña de azúcar), etc.

2. Fam. Ciperáceas. Perianto de mia sòla escamita: 3 ests. generalmente. Ov. simple, 1-locular. rodeado de cerdas hipoginas; órulo derecho; estilo 2-3-tido. Fr. un aquenio desnudo ó incluso en la escama; endospermo fariunso Hicrbas antules ó peremnes. con rizomas escamosos, ramiticados ó articulados; tallos comunmente triangulares: hojas radieales ó caulinas i estrechats, á véeces nulas. Flores en espignillas escanosals. Ignal liseminación que la anterior.

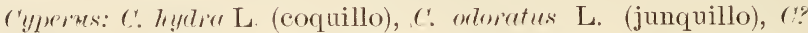
olfersinus (yabacoa ó cortadera). Lyllingia: K. odorata Vahl. (caramaná). Srirpus: S. pelustris L. (junco), Ramirea, Scleria, Gadium, Sthemus. Mariscus, Finbristylis, Rhymchospore, Macherimu, etc.

\section{('LASE II. DICOLILEDONEAS.}

Angiosprermas ron dos rotiledomes; harecillos floro-bosculares formumdo círenlos comcéntricos perperudiculares al eje del tallo,

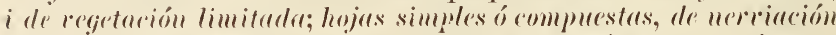
retienlade, pinuade ó palmerada, i bastantes vicess com estipulas. Flores commmmente regulares iperfectas, come al perianto doble;

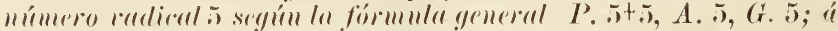
récess al redical es t, i ordinariamente en mumero múltiplo al de éstos.

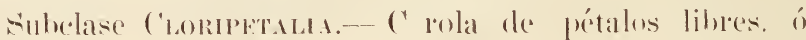
IIIIli.

(BRDES I. Amentécos. Flores unisexuales; las masculiues an cumento; periento mulo ó incompleto, pequeno i simple. Orenrio 1-locular. Plantas leñosas. 
1. Fam. Cupuliferas. Plantas de las rejiones templadas de ambos hemisferios. Produre el avellano, el "astaño, lo mismo que el corchn.

2. Fam. Juglandáceas. Flores misexuales monóicas; las masculinas en anentos simples; perianto 5-6-lobado; estambres 3 á 36 en dos ó más sćries; las femeninas con cúpula de varios dientes; perianto t-dentado. Ov. atherente, parcialmente 2-4-locular. Fruto una muez indehiscente, con una semilla sin endospermo. Arboles corpulentos, con hojas compuestas, pinnadas, sin estípulas. Regiones templadas del hemisferio boreal.

Juglans: J. cinerea L. (nogal), $J$ ? bacrate L. (nogal). ('arya: r. olicreformis Nutt.

3. Fam. Salicáceas. Flores mnisexules dióicas; las masculinas desnudas, con dos ó más ests.; las femeninas con un ov. 1-2-locular; estilos 2. Cáps. 2-valva; sems. mui pequeñas, enrueltas completamente en largos pelos sedosos; endospermo nulo.-- Arboles ó arbustos de hojas altermas, simples, enteras ó loladas, con estípnlas. Zonas templadas i frías.

Salix: S. Humboldtiana (sáuce).

4. Fan. Miricáceas. Flores unisexuales, frecnentemente dióicas, desnudas; las masculinas sin brácteas 6 con dos lateralts; estambres 2 a 8 ; las femeninas con dos brácteas laterales. Ov. 1-locular con un sólo óvulo. Fr. capsular dehiscente, í drupáceo indehiscente; sem. sin endospermo; embrión recto. - Arbustos de hojas alternas, simples. ame- 
nudo fragantes, con o sin estípulas. Hemisferio boreal, India, Africa meridional i Antillas.

Myrica: M. cerifera L. (árbol de la cera), $M$ microcarpa Benth. (arrayán), etc.

5. Fam. Piperáceas. Flores hermafroditas i desmudas, ó minsexuales i ron perianto; ests. 2ó más: anteras extrosas. ()v. libre, 1-locular, monospermo. Fr. en baya; endospermo carnoso; embrión pequeño, inverso. - Hierbas á aroustos aromáticos, con tallos nudosos i hojas opuestas ó rerticiladas, simples i enteras. con peeiolos envainadores en la hase, i sin estípulas. Kona cálida.

Piper (Potomorphe, Peperomia. Eukere, Artanthe): P. peltatum L. (broquelejo), P. Amalago L. (guayuyo), P. astunem L. (anisillo), $P$. numbellatum L, $P$. mummolarifolimm $\mathrm{Sw}$, etc.

(ORDEN II. Crticimeses. Flores diclines; perianto sencillo. Orario unilocular con un sólo órulo; inflorescencia nunca formando amento. Plantas generalmente herbácess.

1. Fan. Urticáceas. Flores unisexuales, monóicas ó dióicas: perianto de las masculinas ralicino. "egular, 3-5-lohado; estambres opuestos á las laciuias i en número ignalal de ellas: perianto de las femeninas calicino, 2-4 lobado. irregular, á reces tubuloso, a mulo. Or. libre. Aquenio desmodo a incluse en el perianto. Sem. epecta: endospermo capmoso: embrióm inverso. - Hierbas í arbustos, rara vo\% lactecentes: hojas opmestas an frecuencia, simples, ron pelos mrticantes, i con estipnlas. Inflores(rmcia en espigas. pamejas ó cabezas axilares. Trópiens.

Core (pringamosa) Citier, t'iled, Proris Bohmeria, ete. 


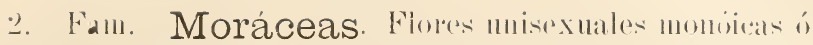

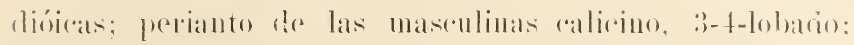
estambers : o-t, opestos á las lacinias: perianto de las femeninas 3-5-foharlo. con las divisiones an dos séries, la axterior mayor. () v. 1-6 e-focular cou 111 sólo óvulo. Fr.

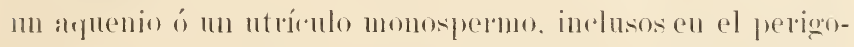

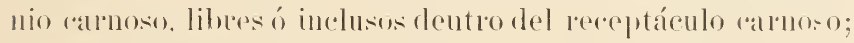
sem. gaurhuda: rndospermo armoso: embrión derecho ó ganchudo.-A Aboles ó arbustor lechosos, de hojas simples. alternas. outeras ó lobadas, con estípulas persistentes ó deríluas. Inflorescencia on cahezas densas. Trópieos.

Itorus: M. reltidifolia H. B. et Kth. (mora), Machuru: M. tinctoric Nut (mora, fustete), $F$. Ameriréme Aubl. (higo cimarrón), $F$. laurifolia Lam. (laurel) $F$. montulete L., $F$. incliru L. (jagüei), F. carica (higo) cult., etc.

8. Fan. Artocarpá eas. Fls. mincexuales monoias á dióicas. perianto de las maserilinas calicino. 2)-3-bobado i casi siempre tubuloso, á véces nulo: estambres en uímero igual al de los lólunlos i opuestos á cellos: perianto de las femenimas tubuloso : i-fido ó eutero. () vibe. l-loculatr. Fr. compuesto. rodeado por un iurólucro ó por el perianto "aruoso, lleno de muchos aquenios ó utrínlos. Sem. sin rudosperuno: rotiledones grandesi espesos: embriòn inverso. Arboles ó arbustos con el latex lechoso: hojis alternas. simples, emteras ó lobadas con estípulas libers. decíluas. Flores sobre un receptáculo camoso ó rell espigas. Trópiness.

Aitornimes: A. incise L. (pan de fruta; arbo-pan del Cibao), Tro 1his: T. Americana L. (ramón), recroplice: 'E. peltate L. (yatcrumo hembra), Piratinere (Brosimum): P. Alicestrum H. Bn. (palo de leche ó de vaca), P. spuriri H. Bn. (id.). 
1. Fam. Celtideas. Flores hermafioditas, o misexuales monóicas por aborto; perianto calicino 5 -fido ó 4 dentado; estivación empizarrada; estambres 5. opmestos. Or. libre. 1-locular. con un sólo ćvulo. J)rupa monosperma: sem. pendiente; embospermo camoso: embrión recto- - Irbeles ó almstos espinescentes: hojas alternas simples. enterds 6 aserradas, :i-nervias i con estípulas deciduls. Flores solitarias of en imas apanojarlas ó en racimo. Trópicos.

C'eltis: r': arenterente Sw., r': accidenterlis L.

ORIDEN. III. Centrospém meas. Flores an al perianto grande, sencillo ó doble. Or. uniorulado; plecente centrel; estumbirs [1-10] en una ódos séries. Fruto én cripss. ó aquenio.-Plantes comenumente herbueceses.

1. Fan. Poligonáceas. Floré her"nalionditas"

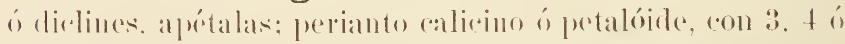

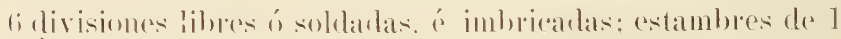

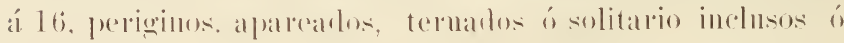

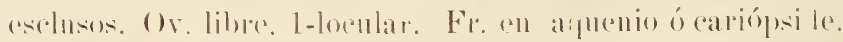

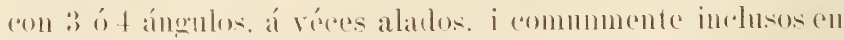

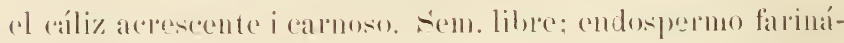

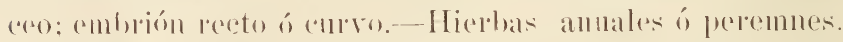

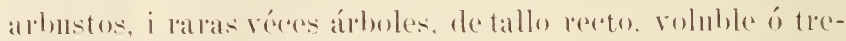
pador: hojas altermas. meminanosas is cortáceas, simples.

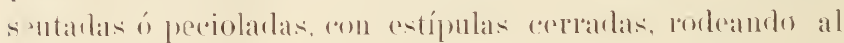
tallo en cada nula de sils alticulaciones (orerea). Flores soli-

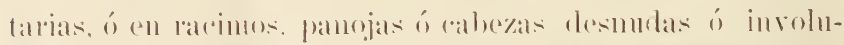
"rantas. Zantas templadlas i cálidas.

Iolygumm: I'. are H. B. et Kth., I. lidmpipm L. Romex: R.

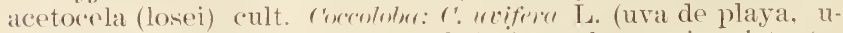
Vat caleta), 1 . pulduscris L. (hojancha), da madera mui resistente, 
(: ache Gr. (uvero, malagueta), ('. diresifwlin Jacq., etc., Antigonon (guirnarda americana, coralina) cult. en jardines.

2. Fam. Quenopodiáceas. Flores hermationlitas ó diclines por aborto. apétalas: perianto alicino. *on 2)-:3-tj. sépalos más ó mémos soldados é imbricados: estambres j. ó ménos por aborto: filamentos exertos. Or. simple. pr lo

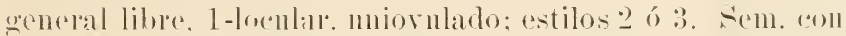
tegumento simple ó doble: endospermo firlináceos, embrión anular, ó espiral, i eletónces sin emblospermo.- Hierbas ó finitices: tallos redontos ó angenlosos. artienlarbs a continnos; hojas alternas, ramas véces opluestas, simples i con estípulas. Fls. peequeñitas, rerdosas, solitarias ó en gelumérulos axilares. en espiqas. panojas ó cimas, con brácteas. Ko11a. trimplarlas.

('hemoremen: Ch. antelminticum (apasote) i Ch. ambrocioides (apasote común) cults. (\%. mmirle L. (celedonia) expontáneo, salsolu, Salirorniu.

3. Fall. Baseláceas. Flores hermalioditas, alpétalas: periantos petalóide, doble, rarnoso ó membranoso: 2 - épalos exteriores opuestos í iguales, i 5 interiores iquales 6) desiguales. imbricados: estambres i, periginos, opmestos á los sépalos. () v. libre, 1-forular aon 111 sólo óvnlo. I-

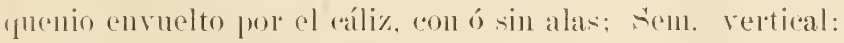
enrlosperuno farináceo: embrión annlar ó repiral. - Hierlas ó frétices, de tallos rolubles ó trepardores: hojas simples i alternas. "alluosas i sin estípulas. Flopes perpueñas, a-

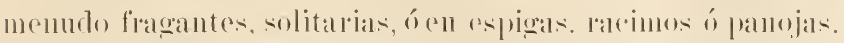
(“oul buáćteas. Trópicos.

Animbere scumdens Juss. (suelda-consuelda). Basellat: B. cordifolia, cult. 
4. Fam. Amarantáceas. Flores hermafirolitas

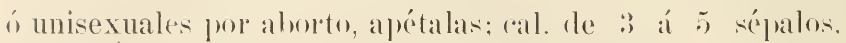
rara rez 1, libres, amenudo colorealdos. persistentes ó imlurieados; 5 estanbres fértiles, opuestos á los sépalos. Or.

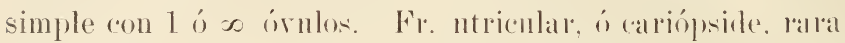
rez eu baya. envoltelos por el cáliz inalterabl. Sems. 1 i

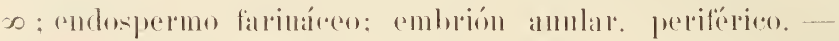

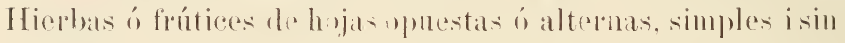

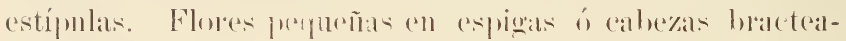
dis. Trópiens.

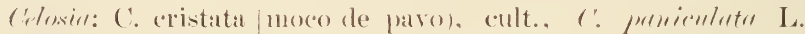
(moco de paro), Amaranthus: A. paniculatus, cult., Eim,rolux: E:

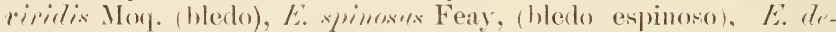

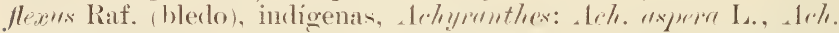
whesifolin Lam., commes. Gomphrena: G. globosa (siempre-

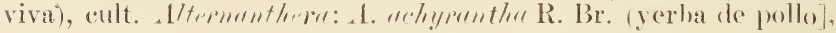
Iprsine, Telanthen: T. polygonoides [terehinto]. cult.

万. Fam. Fitola áceas. Flome hermalionlitas.

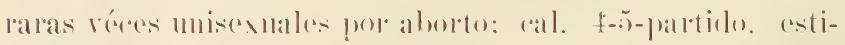

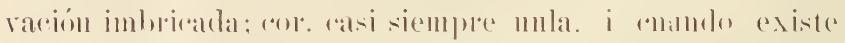

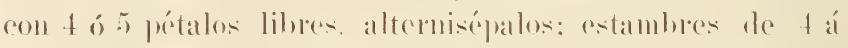
30, hipoginos. () r. simple. ó compmesto de varios calpeles

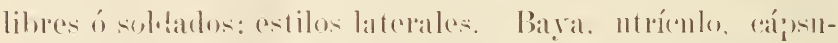

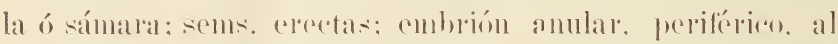

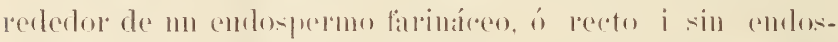

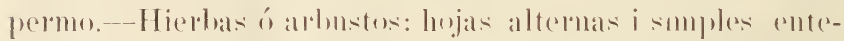

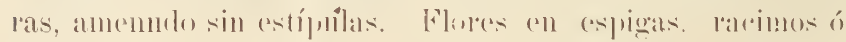
corinbes. \%ona intertwpiral anterinana.

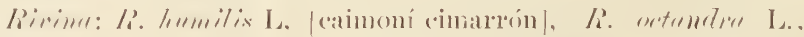

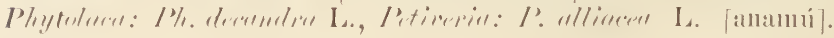


i. Fam. Nictagináceas. Floreshermafroditas, apétalas: cal. petalóide. tubuloso. campanulardo í infundibuliforme. coloreado. Fistambers definidos. de 5 a 30 , hipoginos: inclusos ó exertos. ()r. libre, 1-locular: estilo terminal. Aquenio rirenudarlo por la base del áliz enclurecido:

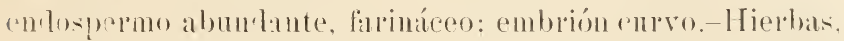
flútires, arbustos 6 áboles ron tallos articularlos: hojas (1)puestas. Flores romearlas por mo invólnero raliciforme, 1 :3-filo, solitarias ó en espigas, racimos. umbelas ó capítulos. Trópicos americanos.

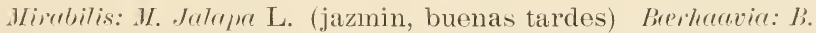
hirsute L., B. preniculate L., B. erecte L. (todas con el nombre vulgar de tostón), Pisonia, Bougainvillea spectabilis (trinitaria) cult.

7. Fam. Cariofiláceas. Flores hermafroditas, cal. con t-5 sépalos libres á soldarlos en tubo: cor. con t-5 pétalos libres, enteros ó partirlos. orelinariamente unguirulados á réces nulos. Estambles libres, diplostemones, á véres anisostemones. ()v. libre. (on 2)-3)-5-reldas; estilos 2-5). Fr. nna ráps. 1-locular ó imperfectamente 2-5-locular. locnlícirla. sems. so : endospermo amiláceo; embrión encorvado.--Hierbas á subfrítices con tallos articularlos: hojas estrechas, opuestas, enteras, simples, estipuladas o nó. Flores. regulares en cimas biparas axilares ó terminales, ó en cimas racimosas. \%onas templadas.

Sil en cas--c'al. gamoxépalo.

Dianthus: D. caryophyllus (clavel), D. chinensis (clavel de la china), D. barbatus (clavel de terciopelo), D. plumarius (clavelito), todos cultivados en los jardines. (*)

(*) Estas, i las demás especies cultivadas en los jardines i huertas, citadas en este libro, se rerán $\leftarrow \mathrm{n}$ mi obra incidita śr,$t$ cim lisitense. 
Policarpeas.- Cal. polivépalo; retilos soldados.

Drymaria: D cordete Willd., Molluge.

8. Fam. Portulacáceas. Flores hermafiorlitas: cal. con 2 sépalos coherentes en la hase. raras véces 3. to 5; cor. con 5-4-3 pétalos libres ó soldados, raras vécess mulos. Estambres en número variable por desdoblamiento, opositipétalos cuando anisostemones; anteras t-loculares. i) libre. 1-locular; órulos 1-o; estilo simple con :3 hazos estigemáticos. Fr. ma cápsula loculícida ó septícida á réces 1 p pixidio i otras una sámara. Sems. pocas ó $x$ : cnelospermo amiláceo; embrión anular ó periférico.-Hierbas suculentas ó carmosas, con hojas opuestas ó altermas, simples. enteras, con fiecuencia carnosas; estípnlas ciliares ó mulas. Flores regulares, amarillas ó rosadas, solitarias ó en rimas racimosas. apanojarlas ó en eapítulos. \%onas templadas i rálidas.

Portuluce: $P$. olemede L. (verdolaga), P. pilose L. (verdolasuilla), P. grandiflora (portulaca, amor dormido), cult., Tulimum: T. triangulare L. [verdolaga de España], Triantheme, sesurinm: s. portrilacastrum Tourn. [verdolaga de costa, platanillo], r\%uytomial.

ORDEN IV. Policarpicas. Flores con perianto doble ó sencillo, en este caso uni a biseriado. Estambres insertos sobre al re-

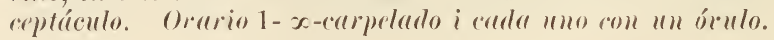

1. Fam. Lauráceas. Flores hermafrorlitas ó diclises por aborto, apétalas: cal. con t-ti sépalos solularlos en

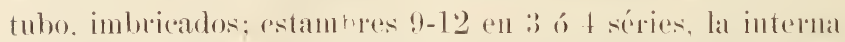
reducida á glándulas ó á simples estaminodios: anteras o-tloculares. Ov. libre ó algo adherente. 1-locular. Baya desmula o drupa radeada por el cáliz armoso i cmpuliforme. 
serm. sin coldospermo: cmbrión recto: cotiledones ralmosos. - Irbustos á áboles generaimente alomáticos: hojas asi siempre prosistentes, altermas. simples, enteras, membrano-

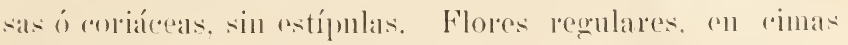
dispmestas en macimos: mubelas ó capútulos. Trópiros.

Persen: P. arutissima Grert. til. [aguacate], P. indicu Spr. [aguacatillo], Nectamelire: N. r'igue A. Rich. [cigua prieta], N. Boniento A. Rich. [cigua amarilla], $N$. sengminen Rottb. [laurel], Oieodeplene, ete.

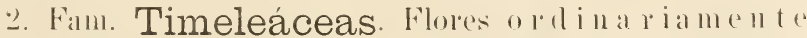
hermafionlitas: periantosencillo, coloreado, tulublar-4-5-par-

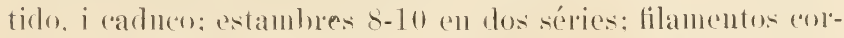
tísimos, insertos en la garanta del perianto. Or. libre, 1locular. miorulado: (stilo corto: estigma sencillo. Fr. drufa. ó $11 n$ acpenio dehiscente: semilla ordinariamente sin endospermo. i cuando lo tiene es rodimentario: embriom recto.-- Arbustos i mui ratras réces áboles con hojas alternas. simples i sin estípulas. Fls. axilares ó terminales solitarias ó fasciconlarlas. en espogas ó racimos. Zomas cálidas i templadas.

Lugettu: L. lintererie, Juss. (daguilla] árbol corpulento con haces liberianos textiles, Duplumplsis, [arbusto con flores unisexuales]: D. cribure Gr., D. Suretzai Meins., etc.

$\therefore$ Fan. Menispermáceas. Flores mnisexulules dióicas. raras réces hermatioditas, ó diclines: 6 sépalos i 6 pétales en dos á más séries. imbrieados. Fstambres isostrmones, opositiputalos ó polistemones. ()rs. distintos. 1-locenlares: lórolos miovulados. Fre en drupas monospermas: endospermo escaso ó anlo: mubrion reniforme. - Hierbas. arbustos volubles ó trepadoles. "aras véres áboles. an ho- 
jas altermas, simples, lobatas, palmatinervias ó enteras, sin estípnlas. Fls pequenas, regulares, en repligas ó racimos i raras réeces solitarias. Trópicos.

Corculus, Cissampeles: r'. mierocarpa DC.

4. Fan. Anonáceas. Flores he r ma fl onl i tas.

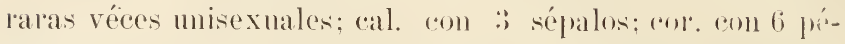
talos ell dos séries, valvar; estambles so hipogimos, plrededor de un disco grande; anteras subsesiles, extrorsats. () tr. so-3, libres a algo coherentes, 1-loculares. Fr. un sincarpio; sems. á véces aislarlas, endospermo carnoso. r’mminalo; (2mbrión recto. - Arboles ó abbustos rom hojas alternas, simples, enteras, i sin estípulas. Flores freenentemente fiagantes. regulares, solitarias ó agrupadas en cimas pancófloras. Trópicos.

Anome: A. muricrete L. (guanábana), A. glębre L. (mamón), A. reticulute L. (vulg. chirimoya), A. squermoser L. (anón), A. muensses Jacq. (candongo), A. pelusti is L. (guanábana cimarrona), A. obtusiflora Tuss. (guanábana de perro), A. manirote Kth. (guanabanita de perro), A. montana (guanábana cimarrona), cult. XyIopia, Guatteria: G. Ianerifolie Dn. (yaya), G. virgeten Dn. (id.), l'variu, Habzeliu.

5. Fam. Miristicáceas. Flores muisexuales diói(as, apétalas; cal. gamosépalo :3-tlentarlo: ests. :3-16; monadelfos; anteras t-loculares. ()x. simple, 1-locular; estilo

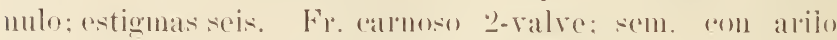
carnoso, rọizo-anaranjarlo; endospermo r runtinado: embrión recto i homótropo. - I rboles a arbustos aromáticos, rom hojas altermas, simples, enteras, más ó mémos corráceass sim estípulas. Flores pequeñas regulates, solitarias ó en rarimos ó mmbelas axilares ó terminales. Trópieos. 
Muristicu: M. futun Sw. (nuez moscada de la tierra).

6. Fam. Ranunculáceass. Flores hemafroditas. 1:1-

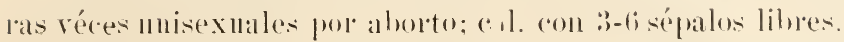

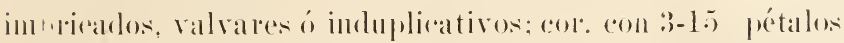

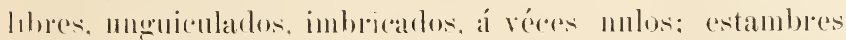

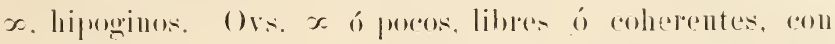

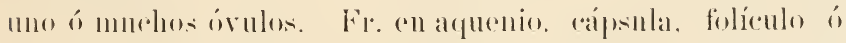

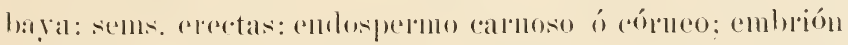
perqueño, ortótropo.-Hierbas ó arbustos salmentosos; hojas altermas í opuentas. simples. de limbo partido gencralmen-

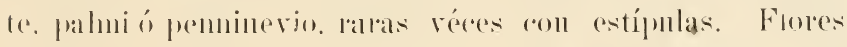

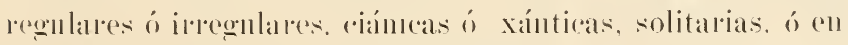
rarimos o panojas. Komals templarlas.

('lemutis (nuestras especies viven en la regiones alpinas), Rinumcrulus (id.).

7. Fan. Begoniáceas. (") Flores miscxuales, monóicas: las mascolinas tienen un perianto pelalóide. con t

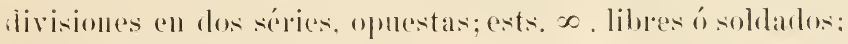
las femeninas ron perianto ignalmente petalóide, con 2 di-

(*) La afinidad botánica de esta famalia no ha sido, hasta ahora, determinada de un modo cierto, i los autores han estado en desacuerdo sobre este punto. En su Genera plantarum, Endlicher colocó esta familia entre las Cucurbitáceas i las Cactáceas: Lindley [I'egetable himlon], entre las Ficoideas i las Cruciferas, i algun otro autor cree q. su puesto es entre las Quenopodiáceas i las Poligonáceas. Ninguna de las familias citadas ofrece una verdadera analogía con las Begoniáceas, ni por la extructura morfologica de su flor, pero ni tampoco por el hábito de ellas.

Respetando el criterio de los profesores citados, i sin sentar cátedra de doctrina, creemos nosotros, que el puesto de las Begoniáceas en el Sistema natural, es entre las Ranunculáceas i las Dileniáceas, ofreciendo con la primera verdaderas afinida des, especualmente con las especies del ginero r'tematis. 
visiones opuestas, á véce- t-9, de estivación imhricada ó valvar. Or. allierente al perianto, 2-3-5-hoeular, con las reeldas aladas, conteniendo muchos óvnlos en placentas axilares; estilos 3, cortos, soldados por la base, 2-fidos; estigma grueso. Fr. una cíps. locnlícila, membranosa, con tantas alas dorsales como celdas; sems. pequeñas sin endospermo; embrión cilíndrico.-Hierhas vivaces á peremnes, suculentas, con hojas radicales ó caulinas, alternas, dísticas por lo comńn, con estípulas libres i raduaas. Fls. en cimas dicotomas, axilares, 6 en pamojas i corimbos terminales. 'Trópicos.

Begonia: B. nitidu Ait. (begonia), bancos de las corrientes, principalmente en las del Cibao, $B$ acutifolin Jacq. (begonia), igual localidad; B. peltata, B. tuberosa, B. discolor, B. incarnata (begonias), cult. en los jardines. ${ }^{* *}$ )

8. Fam. Ninfeáceas. Flores hermaforlitas; cal. cont-t-6 sépalos persistentes i coloreados interiormente; pétalos en número indeterminado, en séries alternas con los sépalos; ests. $\infty$ sobre mn disco, i dispnestos en séries altermas i siempre en vias de transición á pótalos. Or. compuesto: 8-24 carpelos soldarlos por los horles; estigma radiado. Fr. en drupa ó haya; sems. solitarias ó co. ron ó sin arilo: ondospermo farináreos ó nulo: embrión encerrado (ell III saro membranoso: cotiledones carasos.--Plantas acoúticas, ron rizomas, peremmes: hojas glandes, alternas, simples, largamente pecioladas, enteras, peltadas ó cordadas, flotantes. Flores solitarias, notables por su tamaño, í véces mui grande. Konas templadas.

(**) V. la Nota de la pág. 5:3. 
Nympluru: N. ampla II: (yerba ó flor de hicotea), en los arro yos i ciénagas.

ORDEN V. C'ruciferes. Orario de 2 ó muchos carpelos;

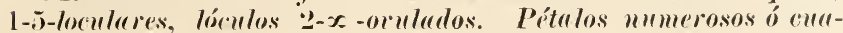
t.ro.

1. Fam. Cruciferas Flores hermafroditas: eal. eon t sépalos: cor. con t prétalos libres. mongicularos ignales ó desiguales, cruciformes: estambres 6 , retradínamos. Or. 2carpelato, soldado por los hordes, 2-locular por un falso tabique placentífero. Fr. capsular (silicua ó silícula) dehiscente a indehiscente. Sems. sin endospermo; embrión encorvado. oleajinoso: cotiledones rariablemente encorvados sobre la raicilla que mira hácia el hilo.- Hierbas con hojas alternas, simpless enteras 6 partidas i sin estípulas. Flores regulares ó irregnlares en racinos casi siempre, raras véces en panojas. Zonas templatas.

Lepidium: L. Tirginicum L. (mastuerzo), ('akile: C. requalis DC., ('. Americana Nutt, Nasturtium (berros), Brassica: Br. oleracea (col), B. eler. capitata (repollo). B. oler. asparagoides (brocolí), B. Napus (nabo), Raphanus: R. sativus (rábano), Sinapis: S. alba [mostaza blanca] cult., Alyssum: A. maritimum [aliso dulce] cult. en los jardines del Cibao.

¿2 Fum. Caparidáceas. Fls. hermafionlitas; cal. coul + sépalos libres ó solilados; cor. eour a pétalos ungeuicu latos a sesilos. insertos sobre un diseo hipogino; estambres (j. Immca tetradínamos, $c$ i siempre múltiplos de 4, hipo-

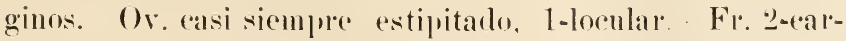
pelaclo, silícena ó silícula dehiseentes, ó eom más carpelos i entrinces mua haya ó mo drupa indehisecentes: sems. eom ó sin endosperno: embrion enrvo; cotiledones incumbentes. - Hierbas. arhostos ó árholes eom hojas altermas. simples ó 


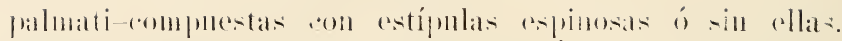

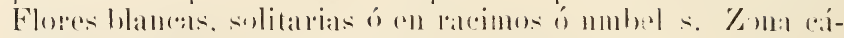
lisla.

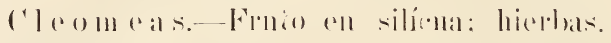

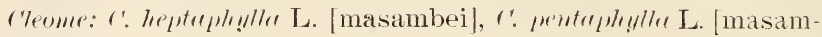
bei], etc.

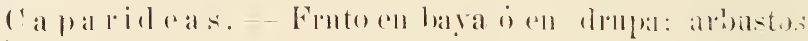
(i) árboles.

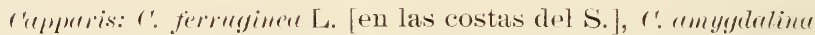

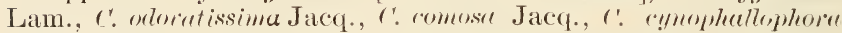
H. B. et Kth., etc. [todas en los bosques], Irorismin: M. Americrma L., crutern, etc.

3. Fan. Papaveráceas. Flures hemafrolitas:

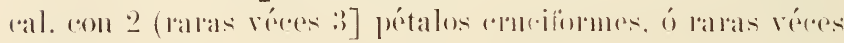

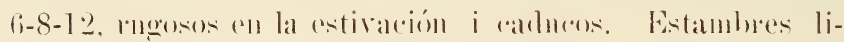

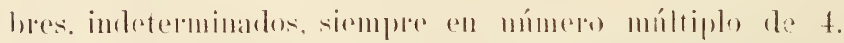

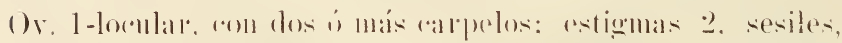

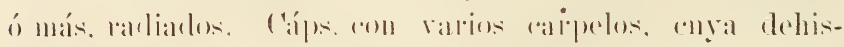

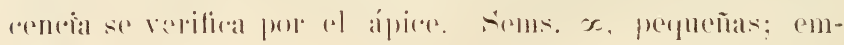

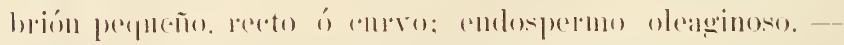

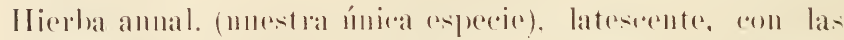

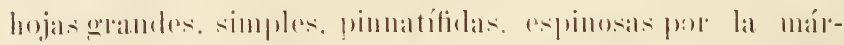

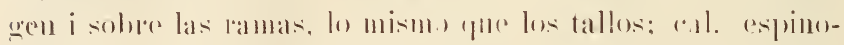

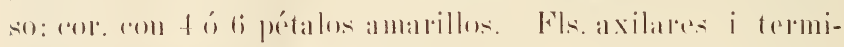
males, perlum unlarlas.

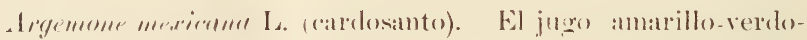
so contiene mortinit.

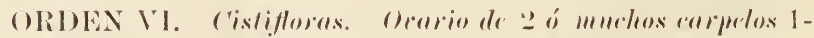
loculares; criliz entrizarmado; corola con i pretales. 


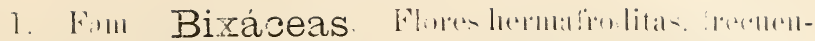

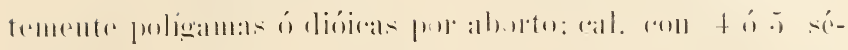

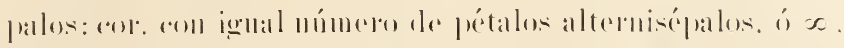

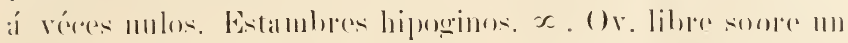

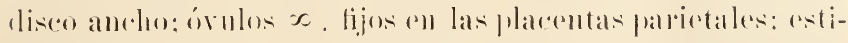

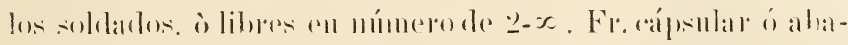

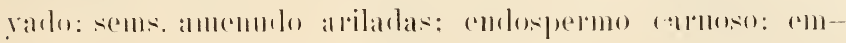

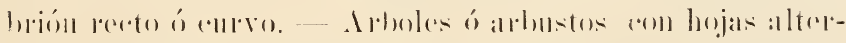

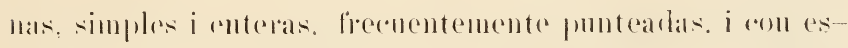

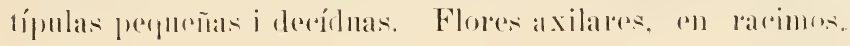
c) cul pamojas terminales. Trópiens.

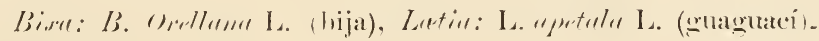
ete. Prowline.

‥ Fall. Samidáceas. Flore lormatroditas

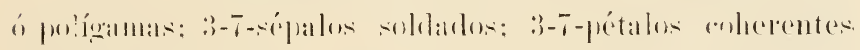

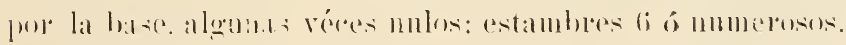

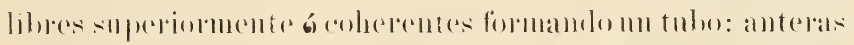

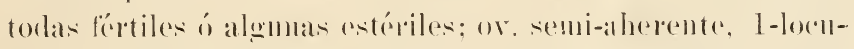

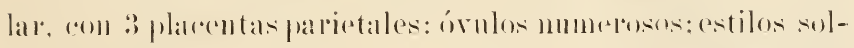

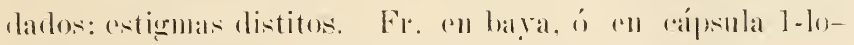

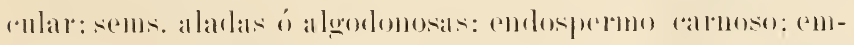
brión recto. - 1 lbustos 6 árboles con lonjas simples, alter-

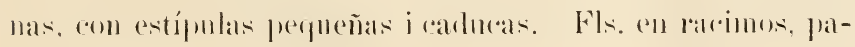

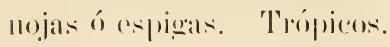

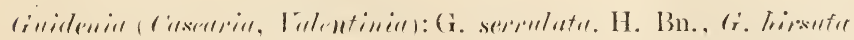

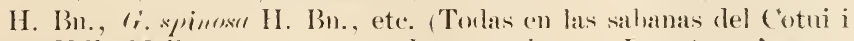

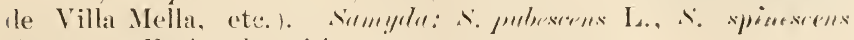
sir., ete, (En iquales sitiosi,

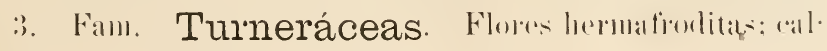


5-fido; core con je pétalos soldarlos en la base é inserta con lus estambres soldarlos entre sí. en la qaroanta del ráliz. ()x. 1-locular. libre, con 3 placentas perietales; estilos :3. distintos. Fr. capsular, 3-celdado (•on mmerosas semillas alrilardas: emdospermo rarmoso: embrión recto. - Hierhas a arbustos con logjas alternas, á véces con glándulas hasales simples i sin estípulas. Fls. solitarias, amarillas. provistas de brácteas. 'Trópicos.

Tinrmeru: T. "lmifolin L. (marikópez) T. I'mmilea L., T. diffuse W., (torlas con las flores diamorfas: macrostileas i microstileas).

4. Fan. Papayáceas. Flores 1111 isex 11 al les dióicas: las mascoulinas con cal. gamosépalo pequeñito. 5dentado; cor. gamopétala. 5-loha. cmporlarla i valvar: cstambres diplostemones. inserto en la garganta de la eorola. los alternos rasi nulos: or. rulimentarios á véeces so desarrollas:

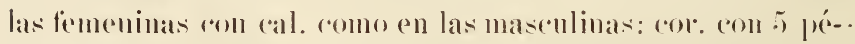

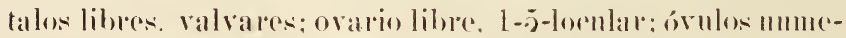

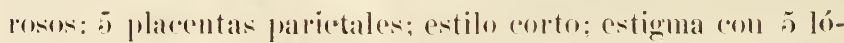
bulos rarliarlos. Baya com numerosas semillas ariladas: emblospermo carmoso; embrión ortótropo. - I - Iboles latesrentes de tallo simple a poco ramoso. con hojas largamente pecololarlas. palmarlon-dijitadas i sin estípnlas. Fls. masrnlimas en racimos apanojados: las femeninas sesiles i axilares. Trópitas.

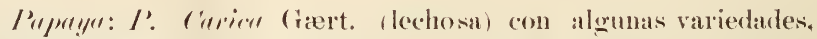
naturalizada.

5. Fan. Pasifloráceas. Flores lermafioulitas: perianto 5-10-partirlo. petalóde. tuhnloso ó urenolado. en 
una ó dos séries, i roya garganta Heva oplinariamente 1-2:3 séries de apémoliees filiformes, planos, pintajarrearlos (co)roma) i designales en caula série; estambres isostemones, insertos en la base del perianto ó en la cima de un ginoforo; filamentos libres ó monadelfos; anteras gramles, versátiles. Ov. libre, estipitalo. 1-focular con 3-6 placentas parietales i mmmerosos óvulos; i estilos. cada mo ron un estigma rlaviforme. Fr. en haya indehiscente, latas véces en cápsula, con 3-6 valvas loculíciclas; semillas con allilo pulposo; endospermo carnoso; embrión recto.-Arbustos por lo regular trepadores, con hojas alternas, simples ó compuestas. con ó sin estípulas. Fls. solitarias por lo común, con ó sin brácteas. Trópicos.

Pussiftura (corona radiada ó nula): P. maliformis L. (calabacito), $P$. fretida L. (caguasa), P. suberosa L. (morita), P. pallida L. (morita), etc. espontáneas; P. quadrangularis (granadillo), P. laurifolia (parcha) cult., Murucuja (corona tubulosa, truncada): $\boldsymbol{M}$. ocelata Pers., II. (Tacsonia) bilobatr, etc.

6. Fam. Tamarixáceas. Arbustos marítimos de las regiones templadas i cálidas del hemisferio boreal, de la India i del Africa austral, con hojas pequeñas i flores regu. lares 4-5-meras. en espigas ò racimos.

Tamarix: T. articulata, profusamente cultivada en los jardires i cementerios, con el nombre vulgar de ciprés.

7. Fam. Violáceas. Flores hermafroditas, 5-meras; cal. con jó sépalos libres ó algo coherentes en lia base ¿ imbricados; cor. con jótalus libres ó algo coherentes, de estivación imbrincado-convulutiva, iguales ó desiguales, el superior prolongarlo en la base en mu espolón; ests. insostemones ron anteras introrsas i comnirentes sobre el pistilo. 


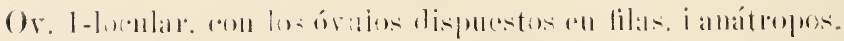

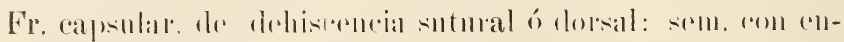

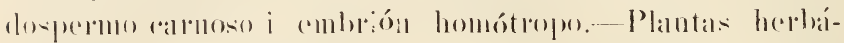

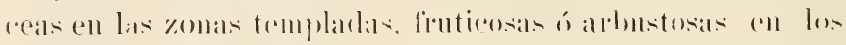
trópicos, rom hojas simples, altermas. i estipularlas. Fls. á

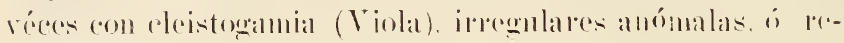

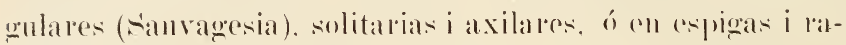

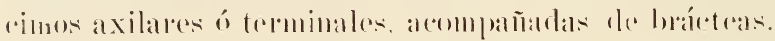

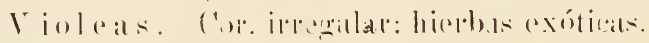

Viola: V. adorata (violeta), V. tricolor (pensamiconto), anbas (en) los jurdines.

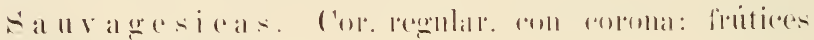

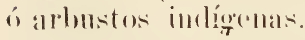

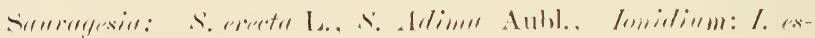

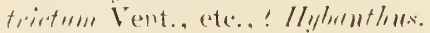

$\therefore$ Fill. Ternstremiáceas. Flore hermatfoli-

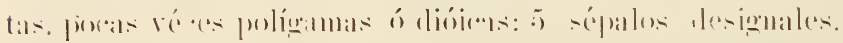

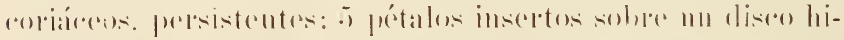

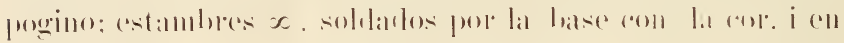

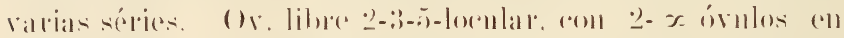

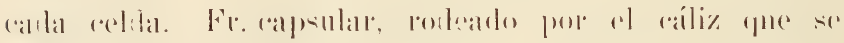

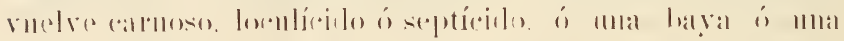

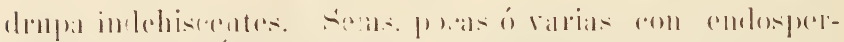

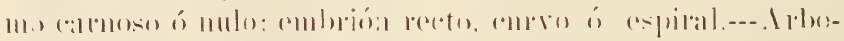

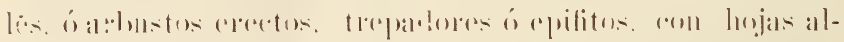

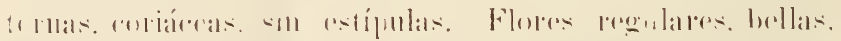

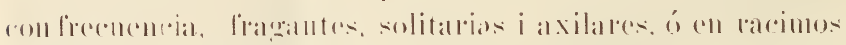

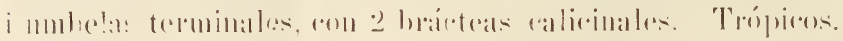


Teinstiremia: T. punctata $\mathrm{Sw}$. (botoncillo), en las praderas del Cibao, Maregravire: H. unbelatr L. (bejuco de palma).

9. Fam. Clusiáceas. Flores polígamas ó dióicas, raras réces hermafroditas: sépalos 2, decíduos, ó t-6. persistentes. membranosos; pétalos 4-10, en dos ó tres séries; estambres $\infty$ á réces en dos séries alrededor de un disco, raras réces definidos i entonces t; anteras 2-t-loculares. (Or. uni óplurilocular; óvulos $\infty$, biseriados en cada celda, ó dos pendientes. Sems. ariladas con frecuenci: Caps. loculícida. ó drupa ó baya indehiscentes; endospermo nulo, embrión recto: cotiledones á véres nulos.- Arboles 6 arbustos, algunas véces epititos cuando jóvenes. con eanales secretores de un jugo gomo-resinoso; hojas opmestas ò verticilaras, sim¡les, enteras, coriáceas, sin estípulas. Flores xánticas, solitarias 6 en racimos axilares ó en panojas terminales. Trópicos.

Clusia: C. rosen L. (copei), a albu L. (copei chiquito, copeyito), Crelophyllum: r: Culuba L. (palo Maria, mara del Cibao), Mammea: M. Americana L. (mamei), Cenella: C. alba Murr. (canela de la tierra).

10. Fam. Hipericáceas. Flores hermafroditas: cal. con 4-5 sépalos desiguales; cor. con 4-5 pétalos, de estivación convolutiva: ests. $\infty$ dispuestos en haces, á véces

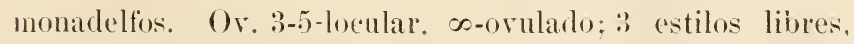
raras recess soldados. Fr. en cáps.. en baya ó en drupa; sem. sin endospermo: embrión recto ó curvo.-Hierbas ó arbustos, raras véces árboles, con hojas opuestas, simples i sin estípulas. Fls. regulares, en racimos de cimas con 6 sin brácteas. \%ozas temp)larlas i cálida.

blodes [ Meritiol, etc. 
11. Fam. Dileniáceas. Flores hermafrorlitas, rara vez poligamas dióicas; 5 sépalos persistentes; 5 pétalos decíduos: estambres so. biseriados i libres ó uniseriarlos i poliarlelfos, todos fértiles ó con estaminodios; anteras t-lorulares. Ors. 2-5, lilres ó soldados. Fr. folicular ó abayado acompañado por el cáliz. Śems. ordinariamente ariladas; endospermo carnoso con un embrión pequeño i recto ell su base. - Arboles, ́́ arbustos erectos ó trepadores; hojas áternas, simples, enteras, amenudo cordiceas i sin estípulas. Flores solitarias ó en racimos simples ó compuestos. Trópicos.

Tetracera, Curatella: $1:$ Americrma L. (peralejo) en la línea NO., etc.

12. Fant. Ocnáceas. Flores hermafioditas; jépalos persistentes; ;) (rara vez 10) pétalos decíduos. Estam-

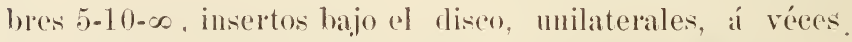
con estaminodios en rarias séries. ()r. con 5 carpelos é igual número de celdas. Fr. en ápsula septícida, ó en drupa. Sems. sin endspermo ó con nno rudimentario; embrión recto.- Arboles a arbustos con lojas simples, alternas, coriáceas i sin estípulas. Flores en racimos simples ó cimosos, ó solitarias. Trópiens.

Gomphiu, Castella, etc.

ORDEN. VII. Colummiferas. Orario de"z ó más carpelos phriloculares; estambress s., monadelfos of poliadelfos. Perianto ratror; cor. conrolutr.

1. Fam. Malváceas. Flores hermaforlitas: 5) sípalos muidos en la base, amenudo rodearlos por 1 in inró- 
Incro: j pétalos hipoginos. estambres so. monodelfos; ante-

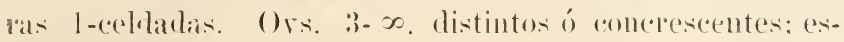
tilos varios. ('aps. pluriloenlar, ó or ajas monospermas á indehiscentes. Sems. an ó sin endospermo: emhrión carvo.--Hierhas. arbustos ó áboles ron hojas simples alt rnas. enteras. lobadas ó palmado-diqitarlas. con estípulas pefueñas. Flores asilares i solitarias por lo común. i con menos frecenencia en racimos simples ó compnestos ó en r.imas. \%olla cáliılı.

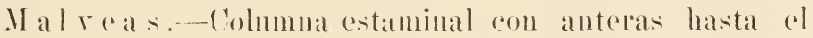
ápice; cajas:

Maleastrum: Wr. spicatum Gr. (malva) etc., Anode: A. hastutu Car. (violeta), sida: numerosas especies, entre ellas S. cordifolin L. (malva rosa), S'. viscosa L. (escobita) etc., Abutilon, Althæa: A. Rosea (vara de San José), etc.

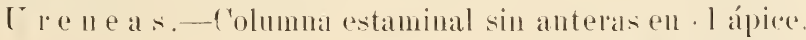
que es dentado ó tromcarlo: cajas ron dientes asi siemprer.

Malachire, Crema (cadillos de perro), Provonir (cadillos de tres piés), Malcuriscus: M. arborens Cav.: etc.

H i hisce as.-folumna estaminal sin anteras en el ápi. re. que es rentado; rápsulas:

Hibiscus: H. clypectuse L. (majagüilla), H. feenims, Wild, H. mutabilis (maravilla), H. militaris, H. Syriacus (sangre de Cristo), H. Rosa-Sinensis (cayena), H. [Peritinm: tilinceum L. (majagua), Abelmoschus: A. sculentus (molondrón), A. Moscheutos (algalia), Thespesiu, Gossyprum: G. Bubudense L (algodón): etc.

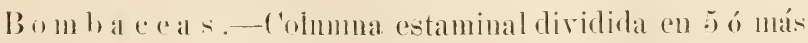
fillanges: álboles colpullentos:

Btmeldrer: B. Ceibu L. (ceiba) Eriodendion, E. anfractuosum DC. (ceibo), Ortermme: O). Latgrmus $\mathrm{Sw}$. (lana, palo de lana), Pechire: 
P. insignis $\mathrm{Sw}$. (cacao cimarrón), Carolina: C. Princeps (carolina), cult.

2. Fam. Esterculiáceas. Flores hermafroditas; 4-5-sépalos midos en la base: $4-5$ pétalos que suelen faltar.

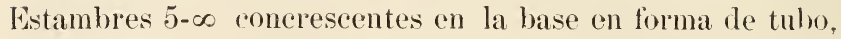
los fértiles alternando con estaminodios; anteras z-celdadas. Or. compuesto de $2-5$ carpelos distintos ó soldados. Fr. er cápsula ó en foliculos dehiscentes, rara vez en baya. sems. sin lana, á menudo anidadas en una materia pulposa; endospermo oleoso ó carnoso, rara vez nulo; embrión recto con los cotilerlones foliáceos ó carnosos, plegarlos.- M rboles, arbustos ó frútices ron hojas alternas, simples, enteras ó palmado-lobarks. con estípulas decíduas. Flores caulinas, solitarias i axilares, ó en panojas terminales, ó en espigas ó glomérulos. Trópicos.

Fisterculieas. - Flores casi siempe unisexuales; corola nula:

Sterculia: S. caribea R. Br., s'. crinita Cav. (palos de col), etc. Cola: C. acuminata (cola) cult. ahora en el Cibao.

Bitnerieas. - Flores hermafroditas eon corola; filamentos fértiles i estériles, jos primeros alternipétalos, i los segundos opositipétalos:

Bittneria, Theobroma: 7h. ('acuen (eacao), Gruazuma (Bubrema): G. ulmifolia Lam. (guázuma ó guácima), Ayenia: A. tomentosa I., ete.

Herma nicas. - Flores hermafroditas ron corola; tilamentos 5, todos fértiles:

Melochie: M. piremidate L. (malva), Wattherie: W. americe"a L. (malere), 
Lasiopet a lea s.--Flores hermafroditas; corola pequeña, escamiforme ó nula, filamentos 5-10, alternativamente fértiles i estériles:

Ilelicteres, Anacumu: A. Regime [*] R. Mose. (primavera), común en los alrededores de la ciudad de Santo Domingo.

:) Fam. Tiliáceas. Flores hermafroditas; 4-5 sépalos libres; 4-j pétalos alternos con los primeros, libres é imbricados. Estambres $\infty$, libres. (Ov. eompuesto de $2-10$ (arpelos soldados; éṕsula pluri, is uniceldada por aborto; sems. $\infty$, en cada celda ó una solamente; cndospermo carnoso; embriòn recto.-A - Arboles ó arbustos, raras véces hierbas, con las hojas alternas, simples, con estípulas decidnas. Fls. axilares. Trópicos.

Triumfette: T. Lappula L. i T. lecterophleylle Lam. (cadillos de burro), Corchorus: ( $Y$ siliquosus L. (malva té) C. hirsutus L., ('. hirtus L., etc. Muntingia: M. ('alabura L. (memiso)

ORDEN VIII. Grminales.-Oeario plurilocular; corola con cinco pétulos; estambres en número de 5,10 o 15 , coherentes, $i$ generalmente biseriados.

1. Fam. Geraniáceas. Flores hermafroditas; cal. con 5 sépralos, el posterior á véces prolongado en espolón; cor. con 5 pétalos mguiculados, alternisépalos i convolutos. Ests. diplostemones '2-seriados, los alternos amenudo estériles, ó 15 divididos en 5 falanges; filamentos coherentes por la lase, con glándulas basales los interiores. Or. 5locular; estils. 5. Cáps. loculícida ó septífraga ó un aruenio,

[*] Nov. gen. et. spec. en Bot. i.tl. de sto. Dyo., loc. cit. V. además mi herbario. 


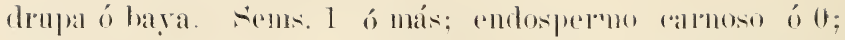

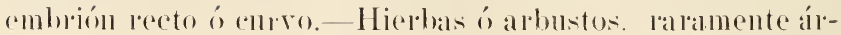
holes con hojas alternas ú opmestas, simples ó compuestas i eou estipulas. Fls. regulares ó ireggulares, solitarias ó axilares. ó en cimas mmbelarlas. Zomas templatas i cálidas:

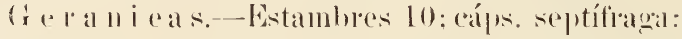

(reranim (geranio) cult., Perlagonimm: P. zonale creramio escarlata), eult.

Trupeoleas.-- Kstambres (i-10: arplentus:

Tropoeolum: T. majus (vulg̣. jacinto).

Ba l

Impatiens: I. Balsamina (espuela de caballero).

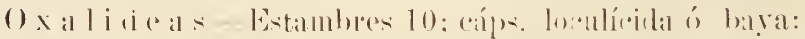

().rolix: (). cormironlutu I. (vinagrillo, entrebolina del (ihao), ().

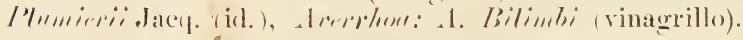

2. Finm. Rutáceas. Fls. heromafionditas ó polígamas

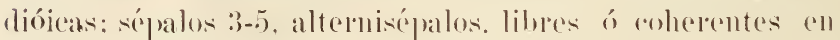

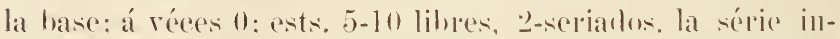

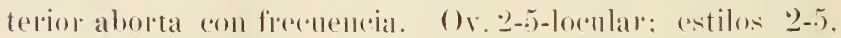

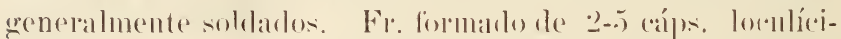
la ó $111 \mathrm{a}$ :

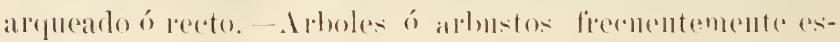

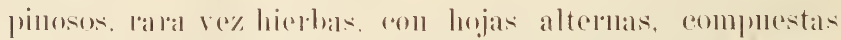
mui ratamente simples. sin estipulas i ron gelámdulas trans-

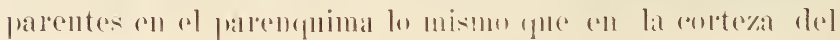


tallo. Fls regulares en racinos, cimas ó mmbelas. terminales 6 axilares. Trópi sos.

Ruteas.-Flores hermafroditas:

Ruta: R. angustifolia (rula) cult.

$\mathrm{X}$ a $11 \mathrm{tox}$ i l a a s.- Flores polígamas:

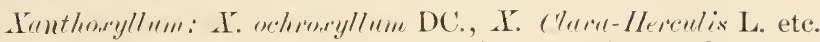
(Nuestras especies llevan el nombre vulgar de primo mecho).

3. Fam. Auranciáceas. Flores hermstioditas; al. gamosépalo 3-5-dentarlo; cor. con 3-5 pétalos libres ó algo soldados en la base i empizarrados; ests. 5-10 o más; filamentos planos, libres ó soldados en tubo hasta más arriha de la mitarl. ()r. s-locular; estilo sencillo. Fr. so-locular (esperidio) ó unilocular (drupa). sems. sin endosper1110, con 1110 ó más embriones rectos; cotileclones grinesos. - Albóes ó arbustos commmente espinescentes. con hojas simples ó rompuestas. altermas. sin estípulas, con glándulas transparentes. Fls. regulares, fragantes, axilares ó terminales. solitarias ó en rarimos ó corimbos. Trópicos

('itrus: C. Biguredia Duham. [naranjo agrio] (. limemem Riss [limón], C. Aurantium [naranjo de china], C. medica [cidra], C. decumana [toronja], C. Limeta [lima], Glycosm is [gonita], Murraya exotica [azahar de jardín] cult.

4. Fan. Zigoriláceas, Flores hermafroditas; j) sépalos libres ó soldados en la hase; 5 pétalos libres i cullpizarrados; estambes diplostemones, biseriados; anteras H-loculares. (). 5-10-locenlar; estilos soldados ó libres. Fr. una cápsula loculícida is sejticida, polisperma; sem. (*on el éndospermo carnoso, ó nulos embrión recto ó encorvado. 
-Hierbas rastreras, arbustos ó árboles con hojas compuesto-pinnarlas, alternas, con estípulas. Fls. regulares, solitarias i axilares, ó en cimas biparas terminales. \%onas templadas i cálidas.

Tribuleas - cemosin endospermo: hierbas:

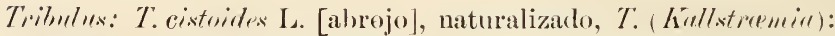
marcimus L. [abrojo], indígena.

Zi go fil eas.-Fém. con conospermo: arbustos ó álboles:

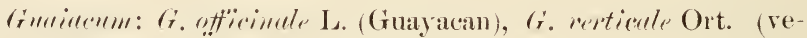

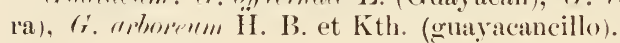

5. Fan. Meliáceas. Flores hermafroditas: 3-5 sépalos empizamarlos: 3-5 pétalos liberes ó soldarlos en la base. entre si i ron el tuoo estaminal, i valvares: estambres diplostemones, raramente más ó ménos; filamentos collepentes en tubo dentarlo ó lariniarlo. rara vez libres. Ov. libre. 3-5-locular con 1-2-t-ti órulos en cada celda. Fr. en caps., en drupa ó en layaj sems. á réeres ariladas, eon endospermo carmoso, ó nulo; embrión variable. - Arboles ó arbustos con hojas altermas: compuesto-pimadas g simples, sin estípulas. Fls. regulares en panojas axilares ó terminales. Kornia cáliclal.

Heliu: M. sempervirens L. [lila], M. azedarach [lila, árbol enano, etc.] en los jardines, Trichilir: Tr. spomdirides Jacq. i Tr.

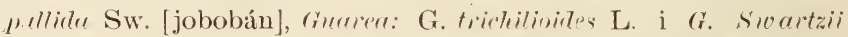
DC. [cabomba, sabina?), Moschorylum, sicietenia: swo. Mlahogan!y L. [caobo], cestrele: ('odenerte. L. [cedro], o: angustifolia DC. [cedro macho, cabima]. 
i. Fan. Simarubáceas. Hores hermafroditas, muisexuales ó liclines por aborto: t-5 sépalos woherentes por la base; t-is pritalos libres, de estivación torcida; estamhres libres cutre sí, en 1 ó 2 verticilos que se desdoblan hasta 10. ¿ insertos sobre una escama lignlar; anteras 2-6-4loculares; disco nectarífero anular ó cupuliforme. Or. compuesto: 1-5) arpelos libresó coherentes. Fr. formado de varias drupas ó cáps. bivalvas, monospermas; sems. sin endospermo; embrión recto.-Arboles ór arbustos eon hojas al. termas, simples ó compuestas. sin estípulas. Fls. en racimos, panojas 6 cimas axilares 6 terminales. Zona tropical.

Simarube: S. amere Aubl., s. glaned DC. (palo blanco), suriena, Pirramniu: P. pentandra Sw. (aguedita), etc.

7. Fam. Terebintáceas. Flores hermafroditas ó políganas, dióicas ó monóicas: 3-5̃ sépalos libres ó coherentes: en la base. empizarrados ó valvares, á veces nulos: ests. isostemoues ó diplostemones, en dos séries alternas; filamentos libres $o$ soldados en tubo, á veces unidos en la base con el perianto; anteras introrsas con 4 sacos, de dehisrencia longitudinal. Or. formado de varios carpelos libres $i f$ soldados, con los óvulos anátropos; estilos libres. Fr. drupáceo ó capsular. cuycos pedícelos se ensanchan á véces en forma de pera (Inacardium). Sem. sin endospermo, conteniendo un embrión recto ó curvo.-Arboles 6 arbustos con hojas alternas, simples ó compuesto-pinnadas. sin estípulas; tallo con eanales oleo-resinosos. Fls. regulares 6 irregnlares, en racimos ó panojas. Trópicos.

Bursereas.-Or. $\infty$-locular.

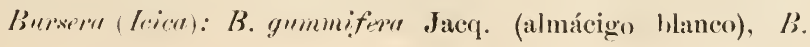


acremincete Wild. (almác. colorado), B. glablererimen II. Bn., ete.

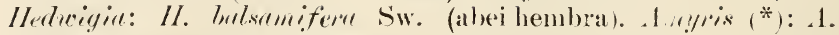
syleatica Jacq., 1. maritimen I. (costas hi vieganas), 1. dientrypa Spr. (Las especies citadas llevan el nonbre vulgar de conbi, generalmente, i producen ma oleo-resina semojante á la de la Bursera Tacamahaca de la (ruayana).

A llacaldicas. - ()r. l-locular.

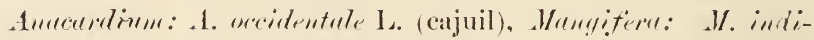
ra L. (mango), de cuyas variedades se cuentan hasta quince en mestro país, la mayor parte, espontáneas en las márgenes de las

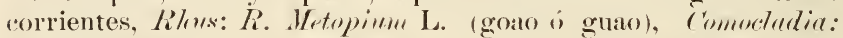

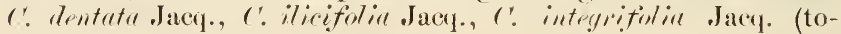
das con el nombre de gruan): etr.

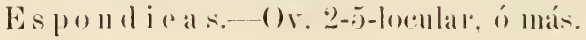

Spondias: s. luten L. [jobo de pueroo, jobohán del (Cibao), s purpurea L. (ciruela morada), S. dulcis Fort. [jobo francés, ciruelo amarillo def ('ilnoto].

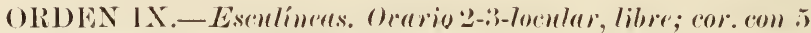
pétalos o ménos; estamlires diplostemoness it, 7 a s, libres.

1. Fam. Sapindáceass. Flores hemalroditas, á réces muisexuales por aborto: t-j) sépalos libres ó algo (o)herente por la base; t-i) pétalos imbriandos, provistos intefiormente de mal escama, á reces mulos: estambres j-10

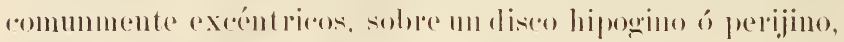

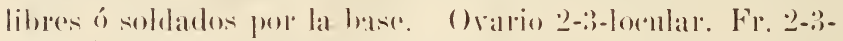
locular, abayado. rapsular ó samaroideo. Semp por lo co-

(*) En H. Baillon (Mistuire de's pluntes. IV, 430), este género está referido á las Rutáceas, formando, con otros géneros, la tribu de las Amirideas.

Nosotros seguimos el criterio de Bentham i Hooker (Gen., I. 3:7), quienes colocan el género en cuestión en las Bulseráceas, hoi tribu do las Terebintrócos 
mún arilarla: culo-permo escaso ó nulo: embrión comunmente emro de espiral. - Apboles, ó aphustos trepadores. con hojas alteroas, compnesto-pinnadas ó simples, sin estipulas. Fls. amenudo irregulares, en racimos ó panojas. Zona cálicla.

Panllinia: I'. pinnutu L. [hejuco de tres tilos], P'. C'urum L. [hej. de tres tilos], P. polyphylla Schum., ete., Serjania: S. tritemintre [bejuen colorado], s. promiculate H. B. et Kth., s. an-

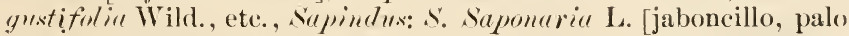
amargo), Blighie, schmidelie: s. Cominia Sw. (palo de eaja],

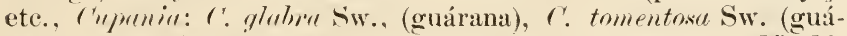
rana), etc., Melicacer: M. paniculate Juss. (limoncillo), M. bijuga L. (limoncillo), ('ardioxpermum, Trevillea, Dodonece, Thonimire, Ratomia (Ephielis), Timpiniu, ete.

2. Finl Malpigiáceas. Flores hermafroditas; “al. j-partido, persistente: cor. con jo pétalos libres, unguirulados, desiguales, á véces nula. Kstambres diplostemones. raramente anisostemones. lihres $\dot{o}$ algo coherentes por la basc; anteras todas fértiles ó alqunas estériles. Or. 3locular, con tres carpelos soldados; 3 estilos libres ó soldados. Fre. 3-locular, ó 1-locular por aborto, drupáceo ó samaroideo con los huesesitos monospermos. Sem. solitaria sin endospermo, alojando mn embrión encorvado, rara vez recto. Arbustos con firenencia rolubles, 6 arbolitos con hojas opuestas, simples, glabras ó con pelos urentes, i sin estípulas. Flores solitarias, ó en umbelas, corimbos, racimos ó panojas terminales ó axilares. Trópicos americanos.

Malpighin: M. urens L. (cerezo), M. punicifolia L. (cereza), $\boldsymbol{M}$. ('nide Spr., M. setosa Spr. (cerezas), etc., Byrsonima: B. crassifolia H. B. et Kth. (peralejo), B. spicata Rich. (peralejo), etc., Bunchosire: B. glemdulose Rich. (cabra), Galphimia: G. glauca (consulita) en los jardines, sinchea. (Arbustos todos erectos). Banisterin, 
Stigmaphyllon, Heteropterys, Triopterys, Telmplerys, Mirma. [Las especies dominicanas de estos siete géneros, todos vilubles, llevan el nombre vulgar de angelitos).

3. Fam. Eritroxiláceas. Flones hermaliroditas; aal. 5-partido; cor. 5-pétala, empizarrada. mrovista de escamas interiormente. Estambres diplostemones. wherentes por la base. Or. 3-locular, por aborto de dos reldas: 3 estilos libres. Fr. ma drupa monospertial sem. con elldospermo córneo alojando un embrión central, recto.-. Irbustos 0 arbolitos con hojas alternas. simples, lampiñas. con estípulas agndas. Flores solitarias io agregardas. Zona cálida.

Erythroxylon: E. hypericifolium Lam. (pajaxilla, fruto de pa. loma), común en la parte $\mathrm{N}$. de los alrededores de la ciudad de Santo Domingo, E. lacunense Jacq., E. subcordetum DC., E. rufurn Cav., etc.

4. Fam. Poligaláceas. Flures hermalforlitas: (al. con 5 sépalos, dos internos (alas) i tres extermos, menores: cor. con 3-5 pétalos, de los cuales 22 alortan i se redncen á 3, el auterior mayor (quilla), amemude provisto de apéndices. Estambres monadelfos ó libres. cn número de 8 por aborto de do-. Ov. 2-locular: estilo encorvado: estigma bilobulado. Fr. ma cápsula loculírida. mor aquenio alado, una trisámara, una drupa ó mua baya. Sem. con un penacho de pelos ó un arilo; endospermo carmoso ó mulo: embrión recto.- IIierbas ó arbustos trepadores por medio de ramas ordinarias arrolladas en zareillo: hojas simples. alternas, sin estipulas. Fls. irregulares, en espigas, racimus ó calezas, rala rez solitarias. Zonas templadas i cálidia.

Polygula, Budieru, Kromerin: K. ixind L. (ratania) Seroridure: s. virguta Sw. (yerba de maravedí). 
ORDEN $\mathrm{X}$. Frangulimeas. Oeario z-ri-locular, libre ó ullerente; corola con 5 pétulos; estumbres isostemones, libres.

1. Fam. Celastráceas. Flores hemaliroditas ó polígramas; cal. con 4-5 sépralos més ó ménos soldados; cor. con 4-5 pétalos imbricarios, insertos sobre un disco; estambres 3-5. insertos debajo, encima ó dentro del burde del disco. Or. 2-3-5-locular, con celdas momospermas ó polispermas: Fr. una cápsula loculícida. un aquenio ó ma sámara, una drupa ó una baya. Sem. commmente arilada, á réces alada; endospermo carnoso á nulo; embrión recto.- A rbustos ó árboles, erectos ó trepadores, con hojas simples, alternas й opuestas, con estípulas caducas. Fls. regulares. en espigas ó racimos terminales. ó más conmmmente en vimas axilares. Zona cálida.

Celastrus, Myginda, Hippocrutea: H. mutn Lam. (jaiquimei), H. comusa Sw. [almendro], etc.

2. Fam. Ilicáceas. Flores hermalioulitas a polígamas, dióicas; 4-5 sépalos pequeños i coherentes; 4-5 pétalos libres ó coherentes por la base entresi i con los estambres (3-5) alternipétalos; anteras 4-loculares; disco mulo. Or. pluriloenlar con 1-20 óvulos en cada celda, Fr. en drupa; sem. con endospermo carnoso i cubbrión recto.A rboles ó arbustos con hojas alternas, simples, coriáceas i sin estípulas. Fls, pequeñas, regulares, en monblas axilares, en cimas. raras véces solitarias. \%ona cólida.

Ilex: 1. occidentalis Macf., ete.

3. Fam. Aquifoliáceas. Fls. (cu nuestras ispecies) hermafroditas; cal con las piezas soldarlas. trumcando ó den. tado i acrecente; cor. con t-6 pétalos lihres í cohorentes 
entubo ó campana. provistos de apéndices filiformes. bistambres ì torlos fértiles, ó sólo a fértiles. i los demás reduci-

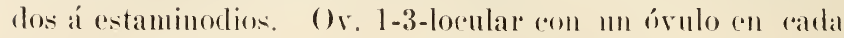
colda. Fr. en dirlpal sem. con endospermo rarmoso i embrión basilar. Irboles, a arbustos volubles ó treparbores. (on lonjas alternas, simples i sin estípulas. Fls. solitarias i axilares. ó con comas. rarimos ó capítnlos. \%ona cálida.

Ximenien: $X$ Amerianme. L., X. elliptien Forst., ete.

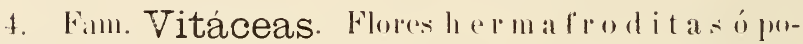

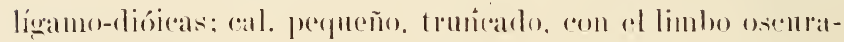

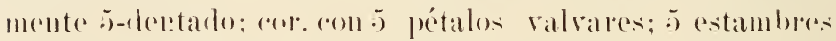

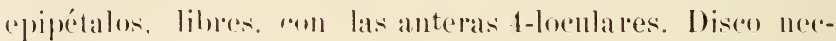

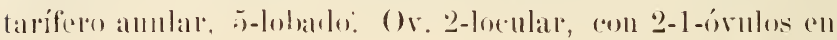

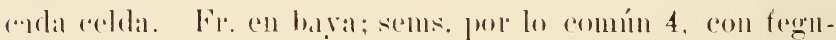

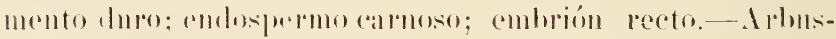

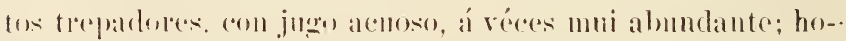
jas altermas. simples ó rompulestas, enteras ó lobarlas i generalinente ron rotípulas. Fls. pequeñas, regnlares, en

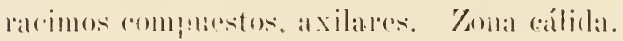

r'issus: r' sicyrides L. bejuco de parra, bej. de agua, bej. car-

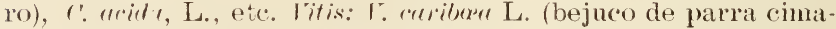
rrona, uva cimarrona?), V. Librusca (uva) cult., i $V$. vimfera (uva) minos cult.

5. Fam. Ramnáceas. Flores hermalrorlitas ó po-

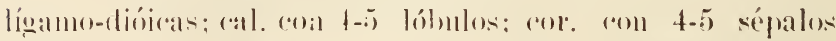
soldarlos con el rálize i enya parte libere es escamiforme i

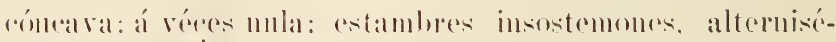

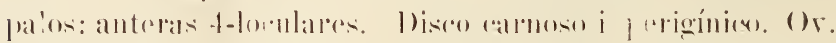

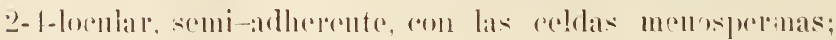




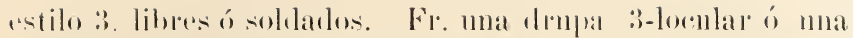

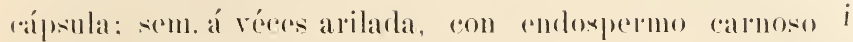
ambrión recto.- Irinstos ò árboles, espinosos ó incrmes, á réces treparlores por zareillos, con hojas alternas. simples i con estípmlas que suelen tracsformarse en espinas. Fls. ell racimos ó en cimas apanojadas. Zomas templarlas i cálirla.

Zizyplues: \%. tomentose Poir. (zopáipo), \%. Sueme (*) R. Mosc. (saona), localizada en la Común de Baní: etc., khammus, Colubriue: r'. reclinatu Brogn. (mabí), r'. ferruginosı Brogn., etc., Gou"nia: G. tomentose Jacq. (bejuco de Indio), $G$, Domingensis L. (id.), (i. renat" Lam., etc. (Los zizyphus contienen una materia colorante amarilla: la Colubrina reclinata i la Gouania tomentosa producen una fermentación alcohólica en los líquidos azucarados).

(1RDES XI. ('rotonimeas.-Onario 3-locular, libre; estambres 1- x, amemudo soldudos. Flores unisexuchess con periento serucillo of doble, ó mulo.

1. Fam. Euforbiáceas. Flores d i clines; aal. qamosépalo con 3-6 lóbulos, ó nulo; cor. con igual número

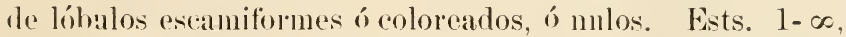
libres ó solutados. ()v. 3-locular, sesil, o estipitado (Euphorhia): estilos distintos a coherentes, ramiticarlos. Fr. con :3 carpolıs formando :3 cajitas, con $1-2$ semillas en rada celda: 6) ma drupa con $11 n$ hmeso, con 5 celdas monospermas; endos permo carluoso: embrión recto; cotilertones planos i foliácens.-Hicrbas, arbmstos ó árboles con freenencia laterentes; hojas simples. alternas ó verticiladas, con estípulas. Fls. á réces con invólncro conpuliforme, en rimas. umbelas ó rloméprlos axilares. \%ona cálida.

[*] Spec. nov. en Bot. iff. rle s'to. Dyo., ya cit. V. además mi herbario. 


\section{EUFORBIACFAS INIOVULADAS:}

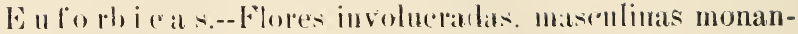
dras en cimas alresterler de ma flor femenina rentral:

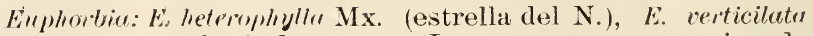
DC. (palo de lecheó de yuca). (Las numerosas especies de Euphorbia de nuestra flora, excepto las citadas arriba, son hierbas bajas, conocidas con el nombre vulgar de yerbus lecheras), Pedilunthus: P. tithymaloides Poit., i $P$. padifolius Poit. (ipecacuana de lit tierra), Poinsettia pulcherrima (tlor de pascua) cult.

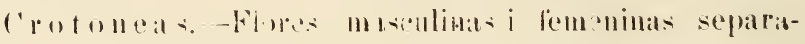
das:

Ricimns: li. commmnis L. (higuera, higuereta), Acchlyplin, .Jutimplu: J. gossipufollin L. (tuatúa), J. multiflda [piñon de España],

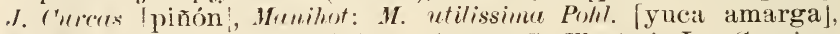
11. Anteris H. Ba. (yuca dulce), Croton: C. Elenteria L., ('. on iganifolinum Lam., r. lmumile L., ( $\because$ Domingensis Vahl, i otras muchas especies útiles, Hippomane: H. Mancinella L. (Inanzanillo), Hura:

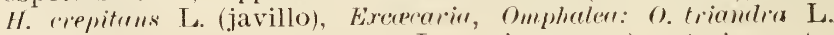
(avelland), Thorgin: Tr. volubilis L. (pringamosia), sirpinm, etc.

\section{EuForbiackas biOvUladAs:}

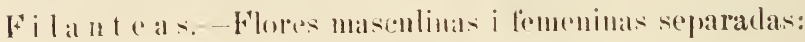

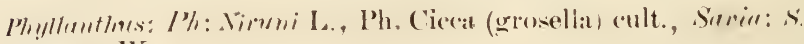
Nasilifters $\mathrm{W}$.

(ORUES XII. Cimbeliforus. Or. adherente; flores i-t-me-

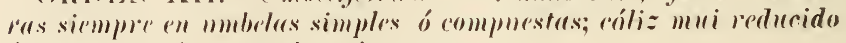
i) rudimenturio; estamblores isostemon's.

1. Fan. Umbeliferas Flores hemalroulitas: (al.

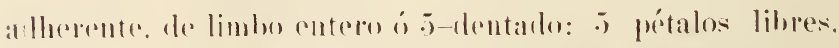

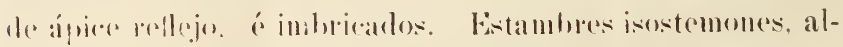

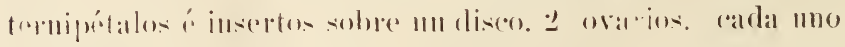

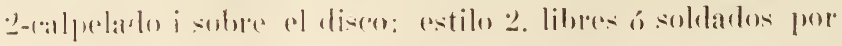


la base. Fr. formado de dos atquenios separables (mericarpos) i suspendidos en la extremidad del carpóforo: aquenios con jo o y costillas longitudinales, i entre éstas, glándnlas olcíferas; endospermo carnoso ó córneo; embrión recto. Hierbas anuales, bisanmales o peremes, con hojas alternas compuesto-pinnadas, provista de mat vaina en el preciolo. Flores en mmbelas simples ó compnestas. Zoma templada.

Firynginm: E. fietidum 1. ( cilantro, culantrico), Hydleria: W. Portoriccensis DC. (perejil cimarrón), espontáneos. Se cultivan en las huertas: Coriandrum (culantro), Petroselinum (perejil), Daucus (zanahoria): en los jardines: Ammi (perla), Anethum (vulg. hinojo).

2. Fanr. Araliáceas. l'omo las C'mbelíferas, pero: ovario 2-15-locnlar. celdas con 1 ivulo; estilos 2-5. Fr. carnoso ó seco 3-15-locular; celdas monospermas. Ariboles. arhustos i hierbas. \%ona rílida.

I'unar: I'speciosum W. (yagrumo macbo), Lrolin, Hedera, (ireopanar, etc.

\section{ORDEN XIII. Cáctens. Curacteres de la única}

Faur. Cactáceas. Flores hermafroditas: verticilos dispnestos en espiral rontínua i en número indeterminado: sépalos libres ó soldarlos en tubo por encima del ovario: pétalosigua:mente libres 0 soldacios en tubo por encima del 0 vario. Estambres numerosos, libres entre sí ó coherentes con los pétalos; estos dos verticilos pasan uno en otro por sim. ples transiciones; anteras 4-loenlares. Or. artherente, 1-locular, con numerosos óvulos anátropos; estilo sencillo; estigma con tantos brazos como carpelos. Fr. en baya con unmerosas semillas. negras; curlospermo amoso ó mulo; cm- 


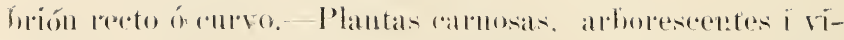
vaces, ron hojac reducilas á rescamas a á espinas: tallos articularlos ó contínuos i en éste caso colmmuarios ó triangonlares. Flores regulares, frecontemente grandrs, solitarias

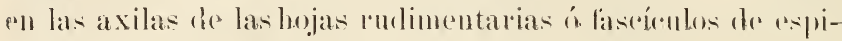
nas. Trópicos anterianos.

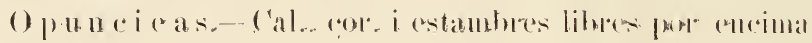
del ovario:

(Penencer: 1/. Tume Mill. (tuma hrava) común en las costas, ménos abundante en el interior, Prov. de sintiago, (1. spimoxissima Mill. (alpalgata) (). trifcuntlon Haw. (tuna te perro), O. Ficus

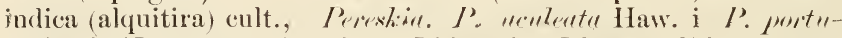

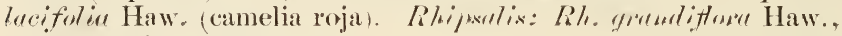
Rile. assoytla Grert., ete.

Ey entube jer enoima del ovarios:

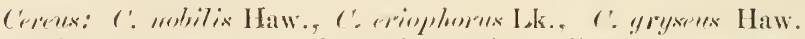
(Estas i otras especies de tallos columnarios se llaman valg. cayn-

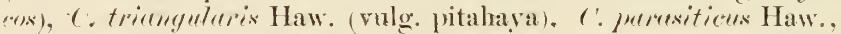

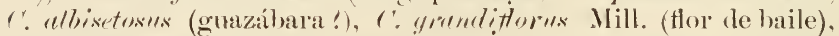
ete., 1/elocuctux: 1/. commmm is Lk, (melón espinoso), 1/um-

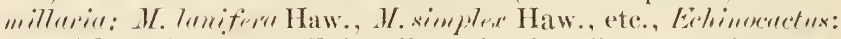
E. yibrws. Haw, ete. Epiphyllum (flor de haile), en los jardines: ete.

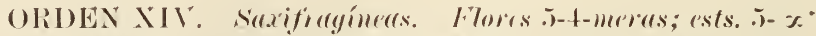
Ovarios libres ó culluremtes, Z-loculures, ron órulos x; rstilos libres.

1. Fan. Crasuláceas. Fores lumaforlitas; á-

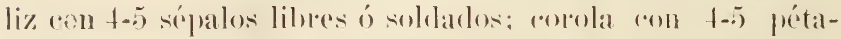
los libers ó soldarlos: estambles diphostemomes. Orarios 4-5), opositipétalos. escamosose all la base: estions libles. Fre. capsular, en mimelo ignal al dre los ovarios. ron so semi- 
Mlas; endospermo carmen: embrión recto.-- Plantas crasas aon las hojas simples ó pinirarlas. alternas i sin estípulas. Flores simétricas, sesiles. rommmente en cimas. \%onas templadas.

Bryolly yllum: Br. colycinum Salisb. (yerba bruja) procedente de la India, i naturalizada, Kalanchoe: K. æegiptiaca (lluvia de estrellas) cult. en jardines.

2. Fam. Saxifragáceas Flores hermafioditas: ‘al. con 4-i) sépalos libres á soldados en la base: cor. con 4--i pétalos insertos dentro de los lóbulos del cáliz; estamhres t-i), alternipretalos, ó numerosos. Orarios más ó méJus adherentes, (*on 2 arpelos commmente coherentes en la baser. distintos i dirergentes por los ápices. Fr. en eáp-llla 1-2-locular, polisperma; semillas pequeñas; endospermo carnoso. embrión recto.--Hierbas, arbustos ó árboles con las hojas opuestas ó alteruas. simples, mui raras véces compuestas. con ó sin estípulas. Flores regulares. en espigas. racimos, capítnlos ó cimas. \%onas templadas i frias.

Weinmanniu: W. glabra L. fil. (Probablemente la única especie de esta familia representada en nuestra flora; crece en las sierras).

ORDEN XV. Mirtifloras. Flores 4-i)-meras, de estiración comunmente valdar; estrimbres isostemones, ó diplostemones on dos séries, ó polistemones en earias séries. Ovario simple, adherente, rara rez libre; hojas comunmente opuestas.

1. Fan. Titráceas. Flores hermafroditas: cal. gadmosépalo, tubuloso, 4-6-rlentado; cor. con t-6 pétalos insertos en el cáliz. alternos á imbricados; estambres insertos en el cáliz, altermos, en mina i varias séries. Or. libre 2-6locular: estiln terminal, simple. Fr. capsulatr, acompañado 
def ráliz: cholospermo mulo; "mblión recto.- Hierbas, alhmstos ó árboles rom hojas opmestas. simples i sin estipulas.

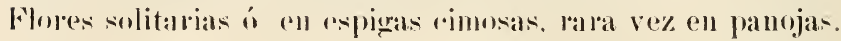
Trópious.

l'upher: 1'. rismosissimn Jacq., Melanium, Ammannia, Lagerstremia: L. indica: (almira) cult., Lawsonia. L. inermis (rulg. resedá) cult.

2. Hail. Onagrariáceas. (Enoteráceas). Flores hormafioditas: cal. t-3-2-partido. valvar: or.eon 4-3-2 pétalos insertos solne mo disco situalo en la garganta del cáli\%, al tornos, toridos: estambres isostemones 6 diplostemones, insertos roul los pétalos: prólen trigono. Or. adherente t-2-locn-

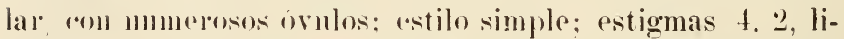
neares. ('áps., aquenio ó baya: semillas mmerosas: endospermo nulo: (rmbloion recto. - Hierbas palúdicas, ó arbustos (ou loyjas simples, altermas ú opmestas, sim estipulas. Fls. reculares, solitarias ó on rarimos ó espigas. Zonas cálida $i$ firias.

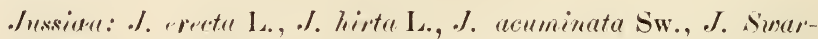
I zirm DC ., etc. (Estas i otras especies, viven en los sitios húmedos i hordes de las cañadas, i se llaman vulgarmente yerbas de himoten], Fuchexia: F. meremosa Lam., en la Sierra de las Matas (Mosc. ]. Sierra de Jarabacoa, márgenes del Arroyo Cenobí [W. Gahhl, F. anceinea. [fusia] en lox jardines.

:3. Fam. Combretáceas. Flores hermafroditas i polígamas: cal. t-i-fido, valvar: (cor. (•on t-5 pétalos alternos á mulos; estambres diplostemones ó isostemones. Ov. artherente. 1-locolal an e-5 cirnlos. Fr. monospermo, en dru-

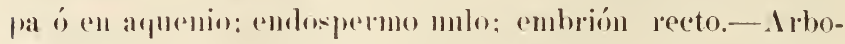

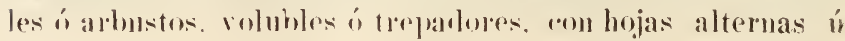


opmestas simples o trifoliarlas. siu estipmlas. Fls. regulares. en espigas. racimos, panojas i capítulos. Trópicos.

Terminalia: T. cutappe L. (almendro) naturalizado en las cos. tas, T. capitute H. Bn., (mangle prieto), T. Buceras H. Bn. (mangle prieto). ('hirchironia: ('h. intermedia Rich. (chicharTón), Conocarpus, c'ombretum.

4. Fam. Rizoforáceas. Flores hermafroditas, raras réces polígamas; cal. 4-5-lobo, valvar; cor. 4-5-loha, á véces uula; estambres 8-15 ó numerosos por desdoblamiento. en dos ó más séries altermas; anteras con 4 ó más sacos. ()v. adherente 2-6-locular, con 1-2-4 ó más óvulos en cada celda: estilos soldados. Iquenio ó baya, rara vez cápsula; sem. con ó sin ala; endospermo nulo generalmente; embrión recto ó curvo.-Arboles ó arbustos, con los tallos suspendilos sobre las aguas por largas raices adventicias, con hojas ppuestas. simples, i estípulas interpeciolares caducas. Fls. regulares, ell espigas ó racimos simples ó compuestos. Trópicos.

Rizophora: R. Mangle L. (mangle colorado), sitios pantanosos á orillas de los rios.

5. Fam. Melastomáceas. Flores hermafroditas; cal con 5-6-4 divisiones imbrincadas ó torcidas; cor. con 5ti-t pétalos libres ó algo coherentes por la base, insertos en la garquanta del cáliz, alternos i torcidos en la estivación; estambres diplostemones ó anisostemones; anteras todas fértiles $i$ algunas estériles, i pendientes en la estivación. Ov. ínfero (en nuestras especies) con numerosas celdas; estilo sencillo. Fr. en baya (nuestras espec.); sems. nmmerosas, pecyueñitas i sin endospermo: embrión recto.-Arbustos glabros is hirsutos, con hojas simples, opmestas, 3-9-nervias ó 3- 
9-plinervias i sin estipulas. Fls. regulares. solitarias 6 en racimos. cimas. ofr. 'Trópicoss.

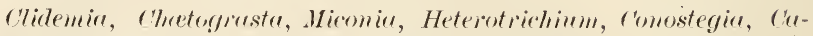

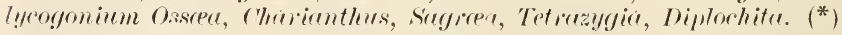

6. Fan. Mirtáceas. Flores lıemafrorlitas: cal. 4i-fido ó partilo, persistente ó ealueo. valvar: :3-4-5 pétalos insertos en la gardeanta del cáliz, imbrincados ó convolutos.

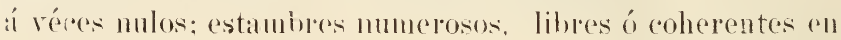
hrees. O) arlberente ó semi-arlherente. mi óplurilocular: astilo terminal por lo comín. sencillo: esticma entero. F. en baya ó drupar. rapsulat en especies exótians: embrion

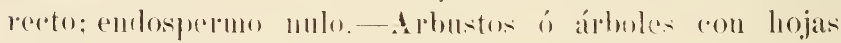
"puestas, simples i sin estipulas. La corteza del tallo i el faren puima de las hojas contienen gláurlulas serotoras de aceites esenriales. Flores regulares, desmudiss ó iurolurelal das, axilares. sulitarias. en eimas. panojas. ete. Trópicos.

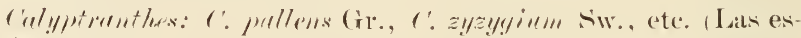
pecies de este, i del siguiente género, se llaman rulg. "romyin),

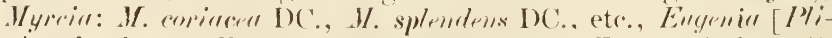

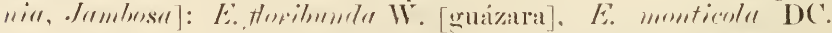
[escobón]. E. . Jombers I. [pomarrosa. pomo] naturalizada en toda lat República, E. malaccensis [eajuilito suliman]. coult., I';

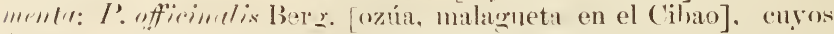
frutos verdes i secos comstituyen la pimienta [malagueta] de Jal-

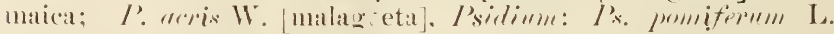

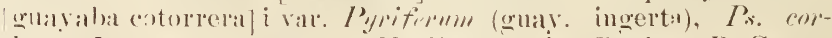

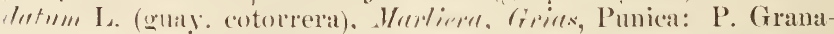

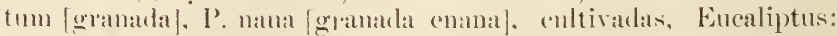

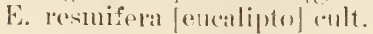

(*) Las especies indígeuas de esta bella familia son tan numerosas, i los nombres vulgares confunden tanto dichas especies, q. (') innil abotarlas aquí, señalando únicamente nuestros gémeros. El nombre valgar de jou-jiun en el más común parai un ran número de rsprecies de distintos gáneros. 
7. Faln. Loáceas. Flol os lemafroditas: aal.

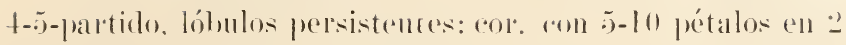
séries é insertos solne el ráliz. Ests. so insertos ron los pétalos, libres ó solelarlos en varias séries. Ov. 1-locular con varias plarentas partetales ó ron ma solal central: 1-3 estilos. Fr. appular polispermo. Sem. con endospermo arnoso i embrión recto.-- Hierbas erertas ó volubles. á réces con pros nuticantes; hojas alternas ú opuestas, simples ó compuesto-pinnarlas i sin estípulas. Fls. regulares, grandes, solitarias i terminales. en cimas, ell espigas ó capítulos involuerartos. Trópiros americanos.

Mentzelir.

\section{ORDEN XVI. Rosifforas. Caracteres de la inica}

Fanı. Rosáceas. Fls hermafrorlitas: cal. j-4-partilo, inblicaldo ó vialrar en la estivación; rol. con utıos tantos pétalos libres que abortan á véces; estanbres insertos sobre el receptáculo, ordinariamente indefinidos i dispuestos en varias séries: filamentos libres; anteras introrsas 4loculares; éstos tres rerticilos se sueldan inferiormente, formando de ordinaro una copla is an tubo urceolado. en cuyo borde se destacan los sépralos, pétalos i estambres. Or. perigino ó epigino ron los carpelos libres a soldados, con 2 ó más órulos anátropos: estilos libres ó coherentes. Fr. en folículos, ayuenios ó drupas libres, i en número igual al de los arpelos libres. ó en cápsula cuando los carpelos están soldados. Fems. por lo común sin endospermo; embrión recto.-- Hierbas ó arbustos ó árboles inermes ó agijoHosos, ron lojas alternas. simples ó pimbadas, eon estípulas arlnatas ó libres i axilares. Fls. regulares, solitarias ó en 
enpigas, racimos, appitmlos ó cima. Konas templadas i cálida.

C'risobala nceas.-Con carpelo: óvulos ascendentes: Hrilpa:

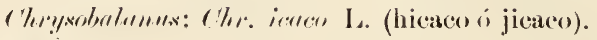

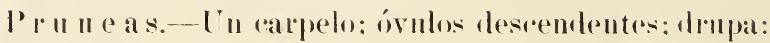

L'rumus: P. accidentalis Sw. (membrillo, almendro en el (ibao) I'. sphtrepocurpus Sw. (membrillo: almendrito en el Cibao).

F'ray ar i e as.-. Muchos carpelos: un óvulo; drupa (en nuestras esperoics):

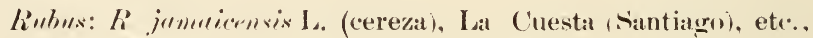
R. "lpim, Macf. (cereza), Sierra de Jarabacoa.

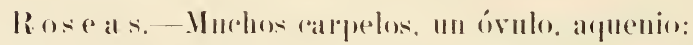

Rosa, rarias especies i variedades húbridas en los jardines. $\quad$ *) ¿Qué especie de $R$ oxil es la que se encuentral silvestre en la Sierra de San José de las Matas!

(IRI)EN XVII. Leguminosas. Flores irregulares ó regulares 5-meras; estambres monadelfos ó poliadelfos; Orario libre formado de un sólo carpelo (3̈ en la Moringáceass); órulos pocos ó mumerosos. Fivuto gemeralmente e'n leginmbre.

1. Fam. Moringáceas. Flores irregulares: estambres monadelfos en tubo hendido; Ov. formado por :" earpelos soldartos. 1-locular: óvulos all dos séries; frute capsular; semillas a rees alatas. separarlas por tabiques

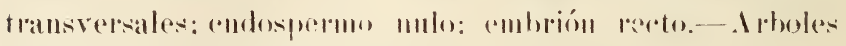
asiátions ranl hojjas pimmalas:

(*) V. la Niste do la lág. oxis. 
Moringa: I. pterigosperma (moringa is libertad) cult.

¿. Fam. Leguminosas. Flores ordinariamente

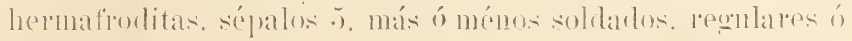

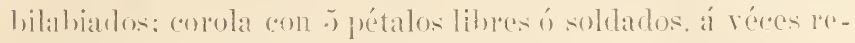

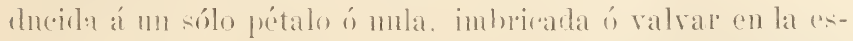

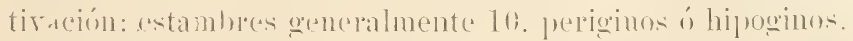
cliarlelfos monadelfos ó lihres: antrias introrsas. ()x. forma(l) por un sólo (arpelo. 1-locular. sentado ó estipitarlo: órnlos poros á numerosos. anátropos ó campilótropos: estilo i

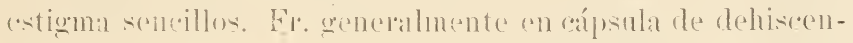

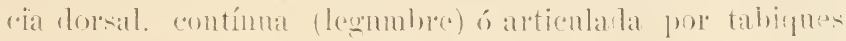
transversales (lomento): á vérese en annenio alarlos i mni

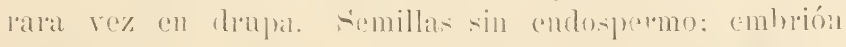

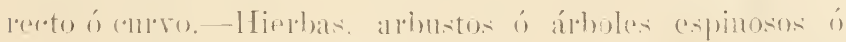

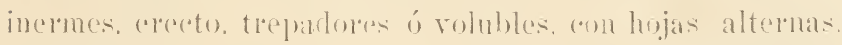

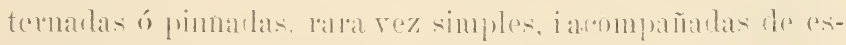

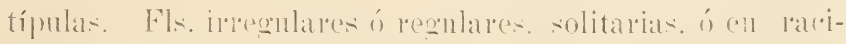

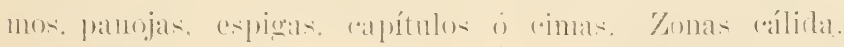
templadas i firias.

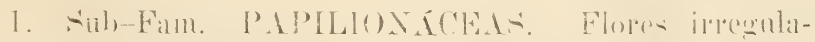
les: estambres diadelfos $(9+1)$ ó monadrlfos (10). ralas róres libres: estivarón vexilar: combrión carvo.

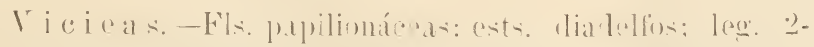
valva.-Hierhas (o) hojas zalroillowas:

13rix: 1. premturims L. (peronila, peonía) provedents del hemisferio oriental, i arrastrada por la corriente del Gulf-strean í nuestro país, donde se hat naturalizado, tante en las corstas como en el interior, Ter(turns, ete., ('icer. ('. arietinum (garbanzo), Faha: F. rulgario (haha). 
Fastoblats. Fls. papilionaceas: estambres i fir como en las Vicieas. Hierbas erectas ó volubles. rabas véces ar. bustos o árboles, con hojas pimmarlas ó 1 -.3--5-7-foliarlas:

Cientrosema: ('. rirginianum Benth. (azulejo). Clitoria: C: termeatu L. (conchita), Mucuna: M. urens Adans (pica-pica, gratei en el Cibao), $\%$. altisima Adans (guaimate, ojo de buei) 11. pruriens Adans (pica-pica, gratei en el (Cibao), Erythrina: E. Corallodendron L. (brueal), Dolichos, Canuedelin, Vigna, Rhynchosia, Poiten, Plaserolus: Ph. semierectus L., Pl. Portmiconsis Bert., i otras especies indigenas, $\mathrm{Ph}$. vulgaris i $\mathrm{Ph}$. multiflorus (hahichuelas, frijoles en el (ibao) se cult. en grande escala, $\mathrm{Ca}$ janus: C. indicus (guandul), Voandzeia: V. subterranea [mani congo], Galactia. Orolus: etc.

Galege as.- Estambres dialelfos: legunbre 2-valva ó indehiscente i membranosa. 1. Espermas.--Hierbas erectas. árboles ó mbustos con hojas pinnarlas ó 1-3-foliadas:

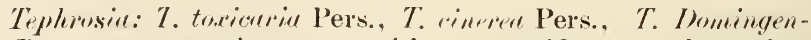
*is Pers., etc., son plantas narcóticas conocidas con el nombre. vulgar de guanitorei, Ludigofere: I. cytisoudes Thumb., I. Iomingensis Spr., I. "ruil L., ete. I todas con el nombre vulgar de $u \tilde{n} i l]$. Robinea, Dalest.

Hedisa reas- Legmmbre articulaula (lomento); estambres diadelfos ó momadelfos.- Hierbas erectas ó trepadoras:

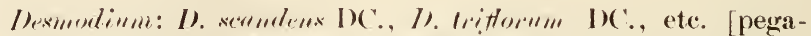
pega, amor seco]. IIedywirmm, Zormin, stilosenthes. Aechymome-

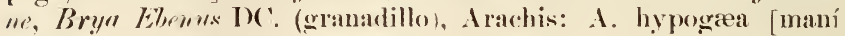
largo].

D a lbergieas-- Estamber momalelfos á diadelfos; fr. indehiscente, seco ó carnoso ell parte.-Arboles ó arbustos con hojas pinnarlas. raras véres 1-8-foliarlas: 
Mixridier: I'. engthrime L. [en las mairgenes de los rios], Andi-

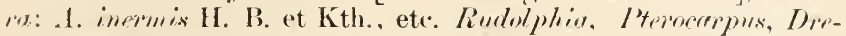

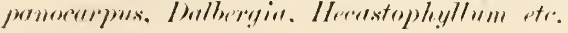

fien istea. Fstambes momadeltis otedinariamente.-

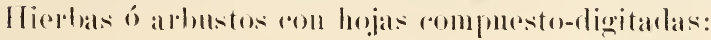
ete.

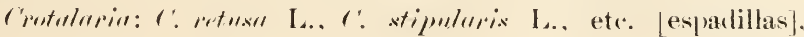

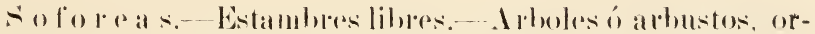
dinariamente () hojas pimmadas:

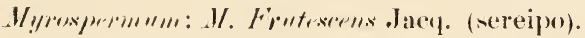

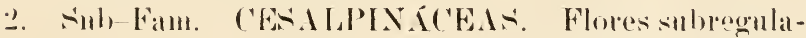
res: astambles libres ó más ó mémos solulados: estivaroiom imbriarda: (ambrión leertu.

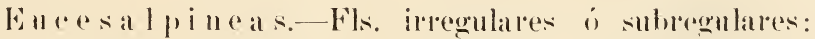
ral. polisépalo: estambres 10 o 5 , libres. Irholes rom hojas lipinmalas omlimariamente:

Cosulpinia: ('. bijugu Sw., C. brusilensis L., C'. cristu L., C', echinata Lam., todas con el nombre vulgar de palos del Brasil, dan materia colorante, Parkinsonia: P. aculeata L. (espinillo?). Homathoxylon: H. "ampechianum L. (campeche), Lividivia: L. coriaria Sch. (guatapaná, dividivi), Guilandina, Prioria, Poinciana: P. pulcherrima (clavellina) i P. regia (flamboyant) cults.

I m hesticas. ( al. imbricado: cor. irregular a mula : pistilo excontricon.- Irholes con hojas. pari ó imparipinadas:

Tamarimlus: T'. orridentalis Gartn. (tamarindo), Hymenosa: $H$. contbuil L (algarrobo), H. floribundu. H B. et Kth., (nazareno). dan copal, Bromener (palo de cruz). 


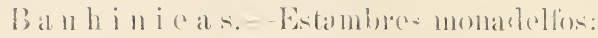

Benthinie, sedmelle.

r as i eas.-Flores irregnlares ó rasi remulares: estam-

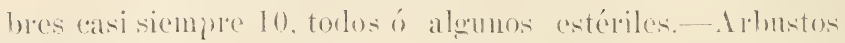
a hierbas com hojas pari ó imparipinmadas:

('assia: C'. Fistule L. (caña-fístula), ('́ bresiliene Lam. (cañafístula cimarrona, chácara), (?. recidentulis L. (brusca macho),

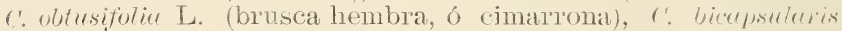

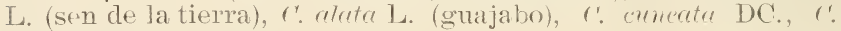
sericer Sw., etc., etc.

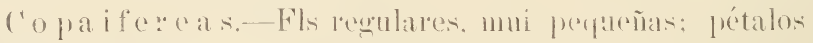
nulos ó raramente 1-j. imbriarlos: estambres diplostemo-

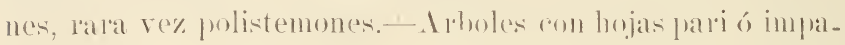
lipinadas:

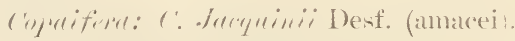

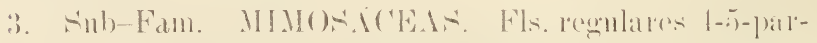

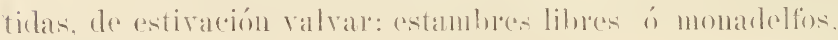
isostomones o polistemorese é insertos con los pretalos; embrión recto. - Aplobles, albustos a hierbas an hojas hipinmadas i las fls. en racimos a capítnlos.

An en a n toreas.-Estambers libes. diphostemones. atompañados de grlándulas.

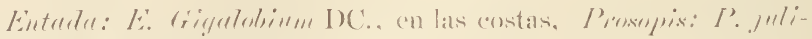
Hore DC: (carambomba): ote.

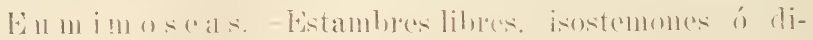
plostemones, lesplor istos de glándulas:

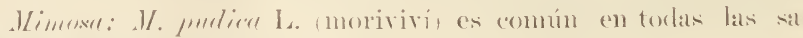
batats, 1\%, rien L. ete. 
I ra ce icas.--Estambles indelinidos, monadelfosó poliadollus: (a) arelos numerosos:

Lenciu: 1. formsin un. Wild., (aroma), 1. lirmutrstome bert.

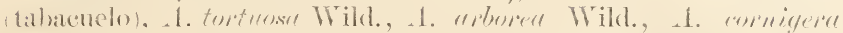

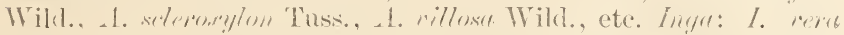
IVild. (guama), I. In, inen Wild. (jina), I. circinalis Wild., ete.,

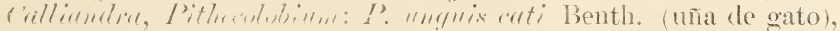
Einteroluhiom, ete.

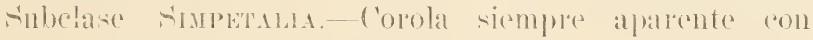
los pétalos más ó ménos soldacios antre sí.

ORDEN 1. Primulineas. FHors j- (ó t-)meras; estambres isostemones por aborto; carpelos isostrmones; ortrio anilocular.

1. Fam. Plumbagináceas. Flores hermalloditas 5-meras: "al. gamosépalo, tubular. 5-dentado: cor. hiperateriforme con los prétalos soldados en liv hase, á véenes libres: estambires jo, insertuse all la base de los pétalos i

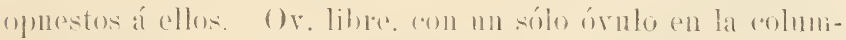

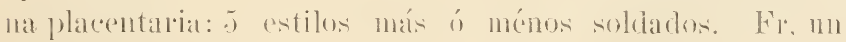
aprenio ó mal rípsula : semilla anítropa: endospermo aniláreo 60 nulo: combrión recto.- Hierbas 6 matas. erectas ó volubles. con hojas altermas, simples i sin estípulas. Fls.

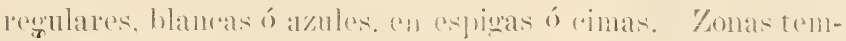
plarlas.

Phombargo: P. sendens L. (mata pollo), únic'a especie en nuestra flora: P. Capensis (Isabel II) cult.

2. Fam. Mirsináceas. Flores hermatroulitas ;-

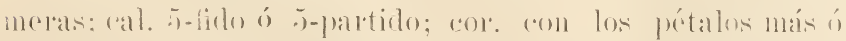

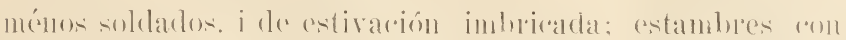

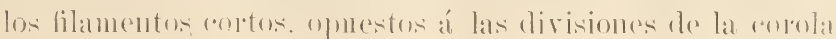


$e$ insertos en ella; anteras ordinariamente asaeteadas, introrsas. Ovario libre ó infero de placentación central ó basilar; óvnlos poeos ó muchos: estilo i estigma sencillos. Fr. una drupa monospelma ó una baya eon rarias semillas; endospermo carmoso ó córneo; embrión cilíndrio i curro.Irbnstos ó árboles, de tallos simples ó ramificaulos, ron lojas alternas, simples i sin estípnlas. Flores regnlares, pequeñas ó grandes, en lacimos 6 eimas apanojadas, axilares 6) terminales.

Ardisiu: A. acuminata W. (fruto de toro), A. coriben Miq. (caimoní), Myrsine: 11 . floribunda R. Br. [pajarilla ó lengua de vaca], Theophrestu: Th. Jussienii Lindl. [guayaba cimarrona], Jorquinia; J. womer Vahl., J. armillaris. Jacq., ete.

ORDEN II. Bicómeas. Florest-(ó 3-8-)meras; estambres. isostemones ó numerosos; carpelos isostemones; orario plurilocular

1. Fan. Sapotáceass. Flores hermafinditas: cal

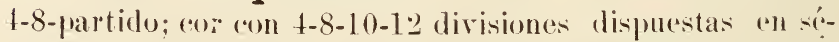
ries cuyas interioresse reducen á escamas; cstambres isostemones i opuestos á los lóhulos de la colola. óindefinidos i ell varias séries. i amemulo mezclados con estaminodios: anteras extrorsas. ()r. libre, phurilocular, aon un órnlo en cada celda: estilo sencillo: estigma j-lido 6 5-lobo. Fr. baya phrisperma, a véces mnisperma por aborto; endospermo rarnoso ó nulo: embrión recto.- Irboles ò arbustos lactes contes, ron hojas alternas, simples i ordinarimente sin estípulas. Fls. romulares. solitarias o en grmpos mmbelados i) corimbos. 'Trópicos.

(hrysophyllum: Ghr. Gainito L. [caimito], rhe olviforme L. [caimito de perro] Chr. microcurpum $\mathrm{Sw}$. [caimito cocuyo] Chr. myriforme W. [caimito de perro] etc., Lurnur: L. mammosa Juss. [sapote] cult., Suprota: S. Achres Mill. [níspero], s. slongruto Gært. 
[totuma ó tocuma] etc., Bumeliu: B. nigrn sw. [cainito cocuyo del Cibao] B. salicifolia Sw., R. fatidissima W.; etc., Sideroxylon: S. pallidum Spr., S. Auzuba Plum. [auzuba, osuba], S. Mcestichodendron Lam., ete., Dipholis: D. salicifolia. A. DC., Mimmsops: 11. globosc Gærtn. [ácana], etc., Ponteria.

․ Fam. Ebenáceas. Flores mnisexualen, dióicas; ‘al. gamosépalo :3-i-lido; cor. hipogina, cadura. 3-7-loba, lóbulos imbricarlos: estambres ordinariamente diplostemones, inserto en el tubo de la corola ó sobre el receptáculo; filamentos libres, ósoldados por la base de rlos en dos, i "ada par opuesto á los lóbulos de la colola. ()r. libre tria plurilorular con 1 á 2 ávulos: stilos libes ó rolerentes por la base: estigmas pequenos. Fr. ma haya eon pocas semillas por aborto: endospereno carnoso; embrión recto ó rurvo-Arboles ó albustos, de madera negra. con hojas altornas simple i sin estípulas. Fls. rogulares, axilares ó terminales. en rimas mubeladas. Trópiros.

Diosplyios: I), whocotu Jacq. Unica especie indígena de esta familia; su madera es dura i bastante negra: es el Ebano de Occidente.

:3. Fam. Estiráceas. Flores hermafroditas en ra-

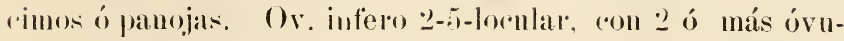
los; estilo simple. Fr. haya of Mrupa. Cetera Ebenarea. 'oura cálida.

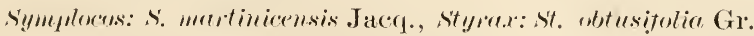

ORDEN III. T'ubulifforas. Flores T-meras, regulares; estambres isostemones; Or. libre, 1-2-locular.-Arbustos of irboles ron hojas altermas.

1. Fam. Solanáceas. Flures hrmalforlitas; ral.

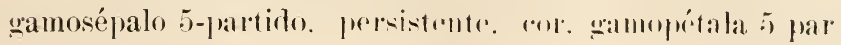


ticla. de estivación ralrar ó plegada, i anemudo entodarla; jo cstambres coherentes con ol tubo de la colola, alternos con sus lóbulos; anteras e-celdadas. () r. 2-lorenlar con numerosos óvulos; placentas tahicales: estilo sencillo con estigma "abezudo. Fr. nua cápsula septicida ó septifraga, in nua haya enrmelta en el cal. que se liace acrescente; endospermo carnoso; embrión recto, curvo ó arrollarlo.- Hierbas ó arbustos, erectos ó volubles, á véces treparbores por medio de las hojas. que son simples i sin estípulas. Flores solitarias, ó en cimas axilares ó extra-axilares. ó más frecuentemente terminales. Zona cáilira.

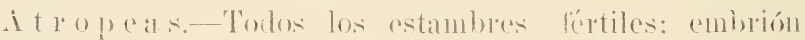
arrollarto; baya:

Solanum: S. memmosum L. [calabacita], s. triste Jacq. [tabacon, friega plato] S. jusminoides s. serndens L. [jazmín de Italia], s. oleraceum Dun. [yerba mora], s. verbuscifolium L. [tabacuelo,] i otras muchas especies indígenas, $\mathbf{S}$. melongena [berenge na] i S. tuberosum [papa] cult., Lycopersicum: L. sculentum, L. 1)yriforme, L. cerasiforme i L. Humboldti [tomates] cult. i expont., Plysalis: Ph. mubeserns L., P. angulata L., etc. [tope-topes], ('ap)sicum: ('. microcripum DC., [ají montesino], C. annum C. frutescens, C. dulce, etc. [ajies] cult. Acuistus: A. abonescens Sch. [mata gallina], es la especie llamada belladona de las Antillas.

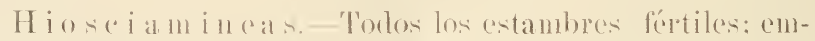
horón arrollado: rápsula.

Deture: D). Thatul., I. (chamisco, cornicopio en el Cibao), I). Stramonimm (chamisco, estramomion (dult, I). alloorea var. suaveolens (campana do P'aris) eult.

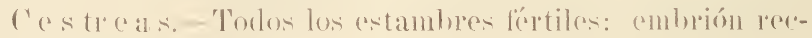
to: (“ápsilla ó haya:

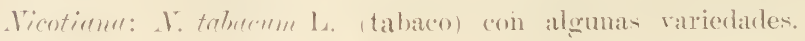


Cestrum: C. vexpertinum L. (rufiana, jazmín de noche), C. dimmum L. (rufiana), C. fotidisimum Jacq., ete.

S a l piglosideas.-No todos los estambres fértiles: embrión recto; cápsula:

Petunia: P. violacea (petunia) cult.

2. Fam. Borragináceas. Flores hermafroditas; cal. 4-5-firlo ó 4-5-partido; cor. infundibuliforme, campannlada, rotácea o hipocrateriforme, con 4-5 dirisiones imbricadas en la estiración: garganta desnuda ó restida; 5 estambres insertos en el tubo i alternipétalos, con anteras libres 6 coherentes por la base. Or. 2-4-locular con dos órulos en carla celda; estilo sencillo, ginobásico ó terminal; estigma entero 6 ramificado. Fr. formado por 4 aquenios separables, ó una drupa con 4 núcleos distintos ó coherentes.-Hierbas, arbuston ó árboles con hojas generalunente ásperas i herizadas de pelos, simples i sin estípulas. Fls. regulares ó raras réces irregulares, en cimas hiparas ó uniparas helicoideas. Zonas cálida i templadas.

Cor di e as.-Estilo terminal de ramas bífidas:

Cordia: C. speciosa Wild. (capá prieto) C. Gerascanthoides H. B. et Kth. (muñeco), C. integrifolia R. et Sch. (Juan prieto), $C$. Radula Spr. (rompe-ropa), C. mirabiloides R. et Sch., C. collococca L., C. Boissieri (anacahuita) cult., ete. Elretia: E. Bourreria, L. (roble amarillo). Bourreria, Tournefortia: T. laurifolia Vent. (nigua), T. liersutisxima L. (nigua peluda), T. fuetidissima L. (nigua hedionda).

Heli otropeas.--Estilo terminal simple:

Helivetropium: II. indicum L. (moco de pavo), H. curassavicum L. (yerba de alacrán), II. mumile Lam. (alacrancillo), H. peru vianum (heliotropio) cult. 
3. Fam. Hidrofiláceas. Flores hermafroditas; cal. 5-partido, persistente, amenudo con apéndices en las divisiones; cor. 5-lobada, anenudo con 10 escamas en el fondo del tubo, que suelen bifurcarse; 5 estambres inserto en la corola; anteras 4-celdadas. Ov. con carpelos abiertos i entónces 1-locular con placentas parietales, $\dot{o}$ con carpelos cerrados i en este caso 2-locular con placenta axilar; ¿vvulos numerosos; estilos 2 distintos, ó soldados en 1 sólo, profundamente partido. Fr. una cápsu'a; endospermo carnoso; embrión recto.-Hierbas, amenudo peludas, con hojas simples i sin estípulas. Fls. regulares en cimas helicoideas, con ó sin brácteas. Zonas templadas.

\section{Iydrolea.}

4. Fam. Convolvuláceas. Flores hermafroditas, pentámeras; cal. con los sépalos generalmente libres i persistentes, imbricados; cor. campanulada, infundibuliforme ó asalvillada 5-fida ó 5-loba, convoluta en la estivación; 5 estambres ordinariamente desiguales, insertos en el fondo del tubo corolino. Ov. 2-3-1-(rara vez 1-)locular, con 1-2 óvulos en cada celda. Fr. una cápsula con 2-4 (ó ménos por aborto) semilla, glabras ó vellosas; endospermo carnoso; embrión curvo.- Hierbas ó arbustos, excepcionalmente árboles, lactescentes, volubles, á véces afilos i sin clorofila, i entónces parásitos; hojas alternas, simples, sin estípulas i con frecuencia cordado-lobadas. Fls. regulares, solitarias i axilares ó en cimas umbeladas ó capítulos, rodearas de brácteas ì sin ellas. Zonas cálida i templarlas.

Ipomea: (Butatas, Pharbitis, Cruamoclit): I Batatas (batata) naturalizada, I. Pez capre Sw. (batatilla), en las costas; I. Bona nox 
L. (estrella vespertina), $I$. dissecta W. (pasta de almendra), $I$. Quamoclit L. (cambustera) natur., I. coccinea, cult. en los jardines; las siguientes especies se confunden con el nombre vulgar de campanitas: I. cathartica Poir., I. violácea L., I. racemosa Poir., I. Domingensis Spr., I. tuberosa L., I. macorrhiza R. et Sch., I umbelata Mey., I.altissima Bert. (arbusto erecto), etc. Convolvulus (pocas especies): C. modiflorus Desc., C. jamaicensis Jacq., Cuscuta (plantas parásitas sin clorofila; hojas rudimentarias; sin cotiledones): C. Americana L. (fideo), Evolvulus.

ORDEN IV. Contórteas. Flores 4-5-meras, regulares; estambres 2-5̃; ov. libre, 2-locular, con numerosos óvulos.-Hierbas. ó arbustos, á véces árboles, con las hojas opuestas ó verteciladas ordinariamente.

1. Fam. Oleáceas. Flores hermafroditas en panojas, espigas, cimas, i solitarias; cal. i cor. 5-8-partida; 2-4 estambres insertos en el tubo de la corola. Fr. una haya ó una cápsula; semillas pequeñas con ó sin endospermo.Arbustos volubles, ó árboles con hojas simples ó compuestas sin estipulas. Zonas templadas.

Linociera: L. compada R. Br., Jazminum: J. sambac [jazmín de papel] i J. azoricum [jazmín de heno] se cult. en los jardines.

2. Fam. Gencianáceas. Flores hermafroditas: cal. 4-5-fido ó 4-5-prartido, valvar ó retoreido en la estivación; col 4-5-loba, infundibuliforme ó asalvillada, con la garganta desnuda ó provista de apéndiers frangeados; limho valvar induplicativo, convoluto ó imbricado en la estivación; estambres 5 . alternos con los lóbulos corolinos, é insertos en el tubo. Or. con 2 carpelos soldados, ordinariamente 1-locular, con numerosos órulos en placentas parietales; estilo simple; estigma 2-fido, 2-lamelado, á réces entero. Fr. una cápsula septicida con numerosas semillas; endospermo carnoso; embrión recto.- Hierbas glabras. 
arrargas, con hojas enteras, ordinarianente simples, opuestas, á véces alternas i sin estípulas. Fls. regulares, solitarias ó dispuestas en racimos, panojas ó cimas. Zonas templarlas i cálirła.

Limnunthemum: L. Lacunosum Griseb., Eisstomec, Slevogtia: s. occidentulis Griseb., Lisiuntlues: L. exaltatus Sw., L. scandens: [?], Eacecum: E. verticillatum W.; etc.

3. Fam. Apocináceas. Flores hermafroditas; cal. 4-5-partido ó 4-5-fido, persistente: cor asalvillada, infundihuliforme ó campanulada, rotácea en la estivación i caduca: 5 estambres alternos, insertos en el tubo de la cor,; anteras asaeteadas ó acuminadas: pólen granuloso. Ov. 2 distintos b́ soldados, 1-2-locular, más raras véces 3-4 ovarios;óvulos numerosos; estilo simple; estigma ordinariamente 2-fido. Fr. 1 ó 2 folículos, mona cápsula, una baya ó una drupa; sem. alada ó con un penacho de pelos sedosos, ó glabra; endospermo carnoso ó nulo; embrión recto.-Arboles, ó arbustos i hierbas, volubles ó trepadores, lactescentes; hojas upuestas ó verticiladas. simples i sin estípulas. Flores regulares, solitarias ó en racimos i cimas mni ó bíparas. Trópicos.

P I u m e ri e as.-()varios libres, semillas sin pelos sedosos:

Rauvolfu: R. nitida L. (palo de leche), K. canescens L. (palo de leche), Cameraria: C: latifolia L. (palo de leche), Plumeria: P. obtusc L. (alelí), P. alba (atabaiba blanca) i P. rubra (atab. rosada) se cult., Taberncemontana: T. citrifolia I., T. alba Mill., IVinca: $V$. rosec L. [todo-el-año] naturalizada en los bancos de los rios, V. minor [lila, piló, trinitalia] en los jardines., Cerbera: C. Thevetic L. [retama].

E „y uit eas.-Ovarios libres, semillas con pelos sedosos: 
Echites: E. repens Jacq. [abraza-palo], Ech. biftorce Jacq. (bejuco mangle), Ech. suberecta Jacq. [curamagüei], Ech. floribunda Sw. [ahogavaca] Ech. umbelate Jacq., Ech. Domingensis Sw., Ech. corymbosa Jacq., etc., Apocymum, Nerium: N. Oleander [martinica, rosa del pirú (Perú ?) en el Cibao] es planta de adorno en los jardines.

4. Fann. Asclepiadáceas Estambres soldados por sus filamentos á un tubo c. rodea al ovario, i provistos de una corona de 5 apéndices variables en forma: pólen aglutinado en masas (polinidios), reunidas por pares. Cetera A pocinacea.- - Hierbas ó arbustos erectos ò con frecuencia volubles, mui rara vez árboles, con hojas opuestas ¿ verticiladas, simples i sin estípuias. Fls. regulares, ordinariamente en umbelas axilares ó terminales. Zonas cálida i templadas.

Asclepiats: A. niver L. (algodón de seda, mal casada), A. curassevica L. (algodón de seda, mal casada), Lachenostonua (Ibutia) tigrinum H. B. et Kth. (guanabanita), Surcostemena, Metastelma, Secamone, Gonolobus, Ceropegia, Marsdevia, etc., Stephanotis: St. floribunda (estefanotis) i Hoya: H. carnosa (botón de nácar) cultivadas.

ORDEN V. Personadas. Flores 5-meras, irregulares; corola más ó ménos bilabiada; estambres 4 (rara véces 2), didínamos por el 5. rudimentario ó 1 olo. - Ordineriamente hierbas con las hojus opuestas.

1. Fam. Escrofulariáceas. Flores hermafiodi= tas; cal 4-5-partido. regular ó irregular; cor. 5-lobada, bilabiarla; labio superior 2-lobularlo, el inferior 3-lobulado: estambres 4. didínamos el posterior nulo ó ruclimentario, á véces 2 solamente, i los otros dos anteriores nulos á rudimentarios, insertos en el tubo de la corola. Ov. libre, 2celdado, con óvulos numerosos; estilo simple terminal: es 
tigma bilobulado. Fr. una cápsula de dehiscencia variable, una baya ó un aquenio; semillas numerosas con ó sin endospermo carnoso; embrión recto.-Hierbas ó frútices, más raras véces arbustos ó árboles, con hojas opuestas ó verticiladas, simples i sin estípulas. Fls. solitarias i axilares í en cimas. Zonas templadas. Entre los trópicos son raras las especies.

Capraria: C. biftora L. (fregosa, té criollo), Herpestes: II. Domingensis Spr., II. cuneifolia Fursh., Buchnera, Gerardia, Angelonia: A. salicarifolia H. B. et. Kth. (violeta), Stemodia: St. durantifolia Sw., St. maritima L., ete. Brunfelsia: B. Americanu L. (aguacero) Scoperia: S. dulcis L. (orozús), ete.

2. Fam. Labiadas. Flores hermafroditas; cal. 5partido, tuluuloso i regular, ó irregular i bilabiado, con 510-20 eostillas salientes; cor 4-5 lobulada, subregular ó bilabiada; labiosuperior (galea) 2-lobulado, ó entero i cóncavo. el inferior más grande i 3-lobulado; estambre 4, didínamos. ordinariamente exsertos, á véces se reducen á 2 por aborti, de los dos superiores. Or. libre, profundamente 4-partido. cada división con una celda monosperma; estilo simple, ginobásico; estigma 2-fido. Fr. formado de 4 (ó ménos por aborto) aquenios separahles, inclusos en el cáliz persistente: á reces son 4 drupas; semillas con ó sin endosper'mo; embrión recto ó curro.-Hierbas, frútices ó arbustos con tallos ordinariamente 4-gonos: hojas opuestas ó verticiladas, simples i sin estípulas. Flores axilares, solitarias, fasciculadas ó en cimas, con ó sin brácteas. Las hojas i las flores secretan un aceite esencial. Zonas cálida i templadas.

Ocimum: 0 . thyisiflorum L. (albahaca-vaca), O. micranthum L. (alb-vaca), O. Basilicum (albahaca) cult., Teucrim, Satureia, Micromeria, Scutellaria, Huptis: H. capitata Jacq. (orégano común), 
H. verticilata Jacq. (mastranzo), H. scoparia Poit, H. lantanefoliu Poit., H. suuveolens Poit (orégano común), etc., Leucas: L. martinicensis $\mathrm{R}$. Br. (poleo) Leonitis: L. nepetcefolia $\mathrm{R}$. $\mathrm{Br}$ (molinillo, sebadilla en el Cibao), Salvia: S. serotinci L. [cizaña], S. occidentalis $\mathrm{Sw}$., S. coccinea, cult. Los siguientes géneros se cultivan: Rosmarinus: R. officinalis (romero), Menta: M. rubra (yerba buena), Coleus: C. Blumeii (tocador), Origanum: O. vulgare (orégano de España), O. Majorana (mejorana), etc.

3. Fam. Gesneráceas. Flores hermafroditas; cal. 5-partirlo, irregular i persistente; cor. 5-lobulada, 2-laliada. oblícua, con frecuencia gibosa en la base, á véces sub-regular; estambres 5, el posterior rudimentario ó nulo i los otros 4 didínamos, á véces 2 solamente, por aborto de los otros dos; anteras aproximadas. Ov. libre ó semi libre, 1-locular, sobre ó rodeado de un disco anular, completo ó incompleto; óvulos numerosos; estilo tiliforme; estigma cabezudo. Fr. una cápsula, una baya 0 4 aquenios; endospermo carnoso ó nulo con un embrión recto.-Hierbas ó arbustos erectos 6 trepadores, rarísimas véces árboles, con hojas opuestas i sin estípulas. Fls. axilares i solitarias, ó en espigas, racimos, panojas ò simas. Trópicos.

Gesnera: G. grandis Sw. (en los bancos del rio Hinoa) G. Craniolaria Sw., etc., Gloxinia, Columnea: C. scandens L., Besleria: B. sangrinea Pers., B. lutea L. etc.; Martynia: M. diandra Glox., Craniolaria: $C$. annua L. (escorzonera), Sesamum: S. orientale (ajonjolí) cult.

4. Fam. Bignoniáceass. F lores hermafroditas; cal. 5-fido ó 5-dentado, bipartido ó bilabiado; cor. 5-loba, bilabiarla, con el tubo ensanchardo en su parte media ó en la garganta, i carluca; estambres 5, el posterior estéril i los otros 4 didínamos, á véces 2 solannente, por aborto de los otros. Ov. libre, 2-1-locular, sentarlo sobre un disco carnoso i glanduloso, con uumerosos óvulos; estilo simple; es* 
tigma bilamelado ó 2-fido. Fr. una cápsula loculicida ó septifraga, ó una baya de epicarpio coriáceo. Semillas ordinariamente aladas, sin endospermo; embrión recto.-Arboles ó arbustos, rara vez hierbas, erectas. volubles ó trepadoras con họjas opnestas, binadas, ternadas, digitadas ó $1-2$ pinnarlas, rara vez simples, sin estípnlas. Fls. solitarias, caulinas á véces, ó en racimos ó cimas, Trópicos.

Bignonia: B. Unguis L. [abraza-palo], B. staminea Lam. [abriza-palo], B. oequinocticlis $\mathrm{L}$. [bejuco blanco] sirve para hacer las canastas, etc., Tecomu: T. pentaphylla Juss. [aceituno], T. stans. Juss. [sauco amarillo] etc., Catalpa: C. longisilicua Sims. [roble], Jacuranda: J. Sagrceana DC. [abei macho], Spathodea, Amphilophium, Crescencia: C. cujete L. [higüero], C. cucurbitina L. [higüero galión], $\because$ acuminata $\mathrm{H}$. B. et Kth. [higüerito]; etc.

5. Fam. Acantáceas. Flores hermafroditas; cal. 5-fido 6́ 5-partido, regular ó irregular i de estivación imbricarla; cor. 5-loba, subregular ó bilabiarla, inferiormente tubulosa ó intlada, convoluta i caduca; estambres 4-2. didínamoś diandros, por aborto ó esteriliclad. (Or. 2-locular con 2-4 ó numerosos óvulos; estilo terminal, simple; estigma 2-fido. Fr. una cápsula loculicida, 2-celdada, con 2-4-14 semillas, á véces sostenidas por prolongaciones de la placenta (retinácnlos), de forma de cúpula que se adhieren á la testa; endospermo carnoso ó nulo; embrión curvo.--Hierhas, subfrútices, matas ó arbustos nudoso-articulados, con las hojas opuestas ó rerticiladas, simples i sin estípnlas. Fls. axilares ó terminales, solitarias ó en racimos carnosos superiormente. ó en fascículos con 6 sin hrácteas. Zona cálida.

Ruellia (Dipteracanthus, Crypliacanthus): R. tuberosa L. (periquito), R. strepens L. (todo-el-año), R. scabrosa Sw., etc., Thum- 
bergin: T\%. alata Bojer (ojo de poeta), Justicin: J. pectorulis Jacq. (curia), Adhatoda: A. Vasica (justicia) cult. Hygrophila: $H$. hispida Nees, Ambrographis, Blechum, Barleria, Aphelamdra, Dianthera (coralito) en los jardines. Dicliptere, Erantlemen, Cylutamtherot.

i. Fam. Verbenáceas. Flores hermatioditas:

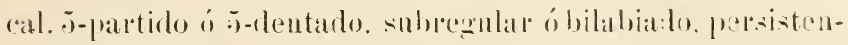

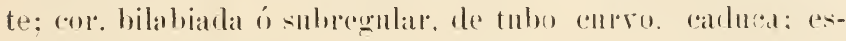

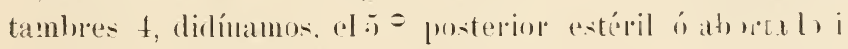
con ménos fiecuencia fértil: anteras t-loculares. Or. libre. ¿-t-locular. con 2 órnlos an ada celdas estilo terminal. simple: estigma simple ó bilobulado. Fr. mat dpupa. a 2 4 aquenios conarlo los anpelos están separarlo en el orario. raras réces una cápsula: semilas sin enfo-perm, commu-

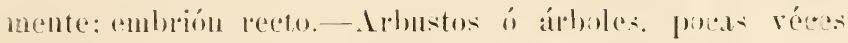
hiepbas. con lat hojits simples. opuestas i sin estipalas. Fls.

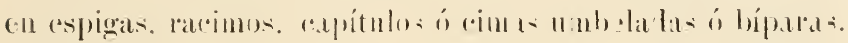
Trópicos.

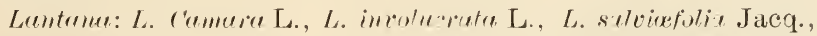
L. odorata L., etc. [Todas con el nombre vulgar de $D$ ma Anita í Inñu Sunita], stachytriphetu: st. jamaicensis Vahl. (verbena): espigas densas, st. strigosa Vahl. (verbena): espigas flojas, Priva: P. Inpulacer Pers. (amor seco, pega pega), Clerodendion (Tolkameriu): (\%. aruleatum Gr. [uña de gato, corazón de paloma], (\%. (Oriedu)spinosum (:), Cl. Thompsonæ i Cl. phlonoides, son rardmente cultivadas en los jardines, i confundidas con las verda.

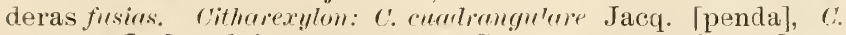
rimerenm L. [penda], '́. subservotum Sw., c. rillosum. Jacq. [panda], Avicemia: A. nitida Jacq. (mangle prieto), ('mutia: ('. purctutu Wild., crece en las sabanas, aquende la Hilera Centrai, Duranta: I). Ellisia L., Lippir, Petrea, ritex. Collicurpa, Aegiphila, Petitia, etc., Verbena: V. italica /peregil de la Reina, verbena] en los jardines.

7. Fam. Mioporáceas. (Trario ״̈-loculal; semilli con endospermo caltioso: hojas alterllas, or linaliamente con glándulas secretoras. l'etera Verbenarear. Komas frias. 
En muestra flora Bomtie doplemendes L.: Arbusto glabro. con las hojas subenteras, lanceolarlas, agurlas, de peciolo estrecho; pedúnculos axilares 1 -floros; flores amarillas, bilabiadas, pubescentes interiormente i con estrias de color púrpura; 3 estambre-; drupa oliviforme $i$ aceitosa.-- Hilera Central i sus estribaciones.

8. Fam. Plantagináceas. Flores hermutro litio 6 diclines, t-meras; cal. t-filo. irregular; (c)s. t-lobulatla.

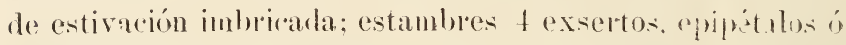

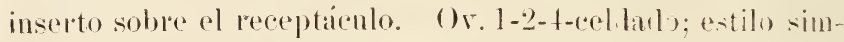
pile. Fr. un pixidio membranoso ó un arpenio: ento-perm, carnoso; embrión recto.-- Ifierbas ron lat hojas radicales,

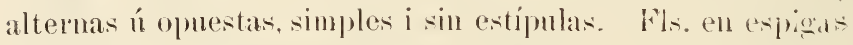
co capítulos. Zonas templadas i cálida.

IMntutyn: P\%. mujom L. (llantén), naturalizado.

ORDEN VI. Compunulíneres. Flores hermafioditus, reget lares ó irregulares; estumbres libres; "meteras libres ó cohorentes; or: 2-ó más-celdado. - Plantaso ordinuriamente lacteserutes, herbriacas ó lerioseses, munce trepadoras.

1. Fam. Lobeliáceas. Flores hermatrolitas; cal. 5-dentado ó entero; cor. irregularó subregular, r-luhialada. hendida hasta la base por un la lo: estambres 5, libes de la (o)rola i eoherentes por las anteras barbulas por el ápior. Ov. alherente ö-reldado; estilo simple; estigma bilobulado ó entero, rodeado de mu anillo (imblusio) de pelos eolectores. Fr. una cápsula L-valva, de dediserencia opereulat of lateral, ó indehiscente; semillas numerosas, con endospermo car-

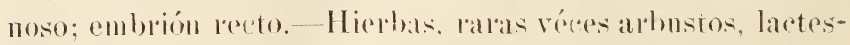
centes, con las logjas alternas $i$ sin estípulas. Fls. axilares i solitarias ó en racimos terminales, de la série ciánima. \%onas templadas i cálicla. 


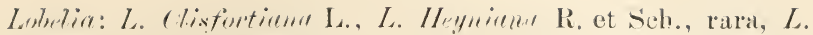

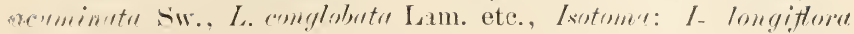
Presl. (quileei), T"pu: T. "swngms DC., Hilera Central, sierra de Jarabacoa, de 600 a $1,500 \mathrm{~m}$, rara i ménos altura; forma parto ell estil sierra, de la flora do los hos fues de pinos.

-. Fanl. Goodeniáceas. Plantas sin latex: cstivalción induplicativa: wario 1-2-lwoular. á réces t-lo:ular:

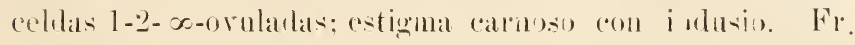
ma dimpa. un aquenio ó una cápsula; el endosperms puede faltar. Cetera Lobeliaceas. Anstralia.

En nuestra flora ol género someroln con la única expeie tro. IMmirmi; Wahl.

\section{ORDES VII. Cucurbitinas. Caracteresdelu}

Fam. Cucurbitáceas. Florés misexuales, monícas ó dióoras: las m toculinas con cal. j-bobnlado é inbrice-

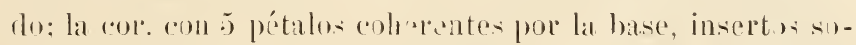
bre el cáliz i alterno en sus lóbulos; estambres 5. libres i coherentes en 3 séries. + formurlo dos pares, i el 50 libra. ()v. nulo, i ens su lugar un nectario glanduloso; las fe uninas con estambres rulimsutarios. () r. a therente, :i-caltadu. con :3 plarentas qu Hendu las avidades, i llevan numero-

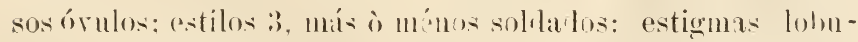
lados. Fr. ma baya de perioapio membranoso ó leñoso (pepónide); semillas mumerosas, á réees ariladas, sim endospermo; cotiledones planos: ambrión recto.- Hierbas, mui raras veres arbustos, ladstrems of trepadores pol zalleillos. con hojas simples alternas, por lo común lobarlas i sin estípulas. Fls regulares, axilares, solitarias ó en racimos ó panojis. Trópireos. 


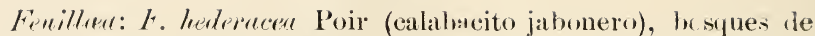
la Hilera Central, Letgenaria: L. velgarix Ser. (calabazo), naturalizada, Momordica: W. (Cherantia L. (cundeamor), naturalizada,

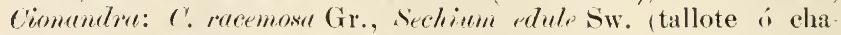
llote) Trichomenthe: Tr. amara L. [pepinito amargo, pepino de Sin. Gregorio], Cerutosanthess, Melothriu: M. peredula L., Sicyoss, ('ucurbita: C. Pepo [anllama], naturalizada, Citrullus: ('. vulgaris [patilla], Sicania: s. olorifera [pepino angolo], Luffa: L. cylindrica [servilleta de polre], Cucnmis: C. melo [melón], todas énltivadas.

ORDEN VIII. Caprifolineus. Flores hermafroditas, of unisexuales por aborto, 2-fi-meras; estambres isostemones, insertos sobre la corola; or. adherente, 1-2-celdado.-Plentes tervestress ó parcisitas, con las hojes opuestas.

1. Fam. Lorantáceas. Flores lermafioditas (Loranthus. etc.) ó unisexuales, dióicas (Phorodendron) por aborto: cal. de limbo corto, entero ó 3-5-8-rlentado; ror. wamopétala, t-8-lobularla, á véces polipétala, cortácea i de estivación valvar; cetambers isostemones, opuestos á los lóbulos ó pétalos al la corola; anteras sesiles ó solore filamentos libres superiormente. O). adlerente, 1-celdado (raras véces 3-celdado), uniorulado: estilo filiforme que sucle faltar: estigma entero. Fre ma baya misperma, viscosa. por lo común transparente; endospermo carnoso; embrión 1, a más, cilíndrico.- Arhustos verdes, parásitos sobre los arboles. eon hojas opuestas, ralas véeses alternas. gruesas, á réees rudinentarias, i sin estípulas. Fls. regulares, en espopas, lacimos, umbelas, rapitulos ó cimas. Tópicos.

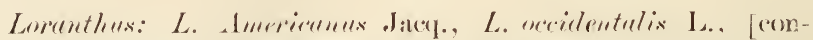
de, Juan aragán], [Morodemlom: IM: letifolinum lir. Feonde de

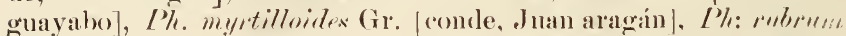

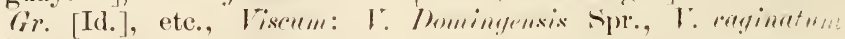
H. B. et Kth., etce. [eondes]. 
2. Fam. Rubiáceas. Flores hermafioulitas, raras vénes misexuales por aborto; cal. de limbo entero ó dentālo; ror. tubulosia, infundibuliforme, hipocrateriforme ó smbanpanulácea, t-fi-lobulada of dentarla, de astivación valval ó convoluta; estambless isostemones, alterous, in-

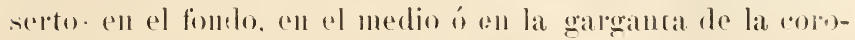
lit, inclusos ó exelusos: filamentos roptos ó regulares. ()i. adlerente, 1-20-plurilocular, ron ignal múnero de civulos. i

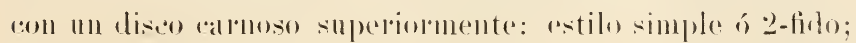
estigma 2-fide, 2-lantado, ó entron. Fr. nna dropa 2-

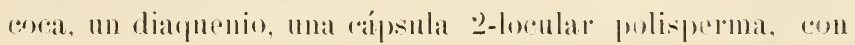
2 valvas e-tidas, ó ma baya; semilla con ó sin arilo, á véces alaria, conteniemilo nu endospermo romen ó rarnoso;

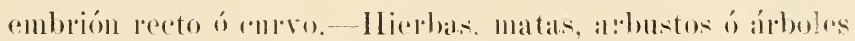

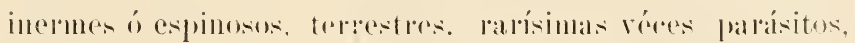
ron hojas simples puteras, opmestas i rom estipmlas interpeeiolares ó extraperoiolares. Fls. regulares. axilares ó terminales, solitarias, an fascionlos, espigas, ravimos, roldimbers, capítulos ó cimas, con brártras simples a involurrarlas. \%onas cálida i templadas.

('o f e a s.-C'eldas muiovuladas:

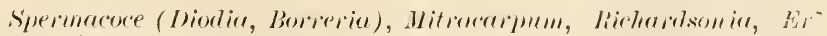
molec, Coffea: C. arabica (cafi) cult., Ps!rlustria, numerosas es pecies, entre ellas: Ps. mutums Sw. (cafe cimarrón, penda ex el

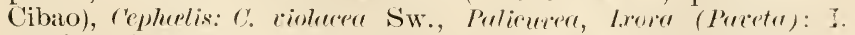
coccinea (corona de la Reina) cult., Furauren (Tefiamerimu), (x)e-

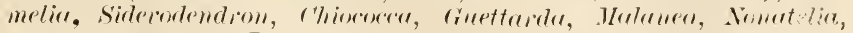

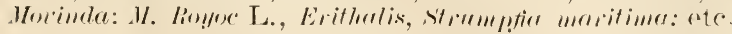

C'i 1100$) 110$ a s. C Colias multiovuladas:

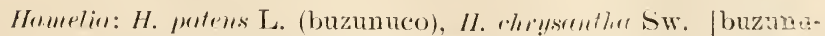

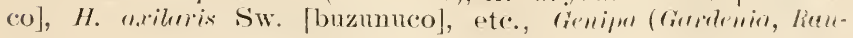


diu): $r$. Americenu L. (jagua), G. Horida (jazmín del Malabar)

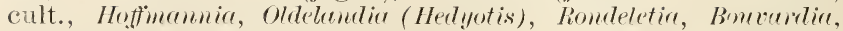
Hacrocmemum, Exostemma: E. crovibare W. (quina), E. longiftora R. et Sch. [quina, piñi-piñí], E. florilumda W. (quina, piñi-piñí), $E$. roriacer R. et Sch. [quina], E. Archembenttii (*) R. Mose. (lirio amarillo), de Sn. José de las Matas, E. parviftora Rich. (quina),

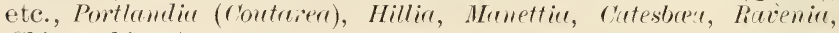
Chimerish is, etc.

3. Fam. Caprifoliáceas. Flores hemafiroditas: cal. t-s-dentado; ror. t-5-partida. regular ó irrownar. tubuL:11 6 rotácea, de estivación imbrieada; estambres isoste nones, insertos en el tubo de lat corola. Ov. atherente, 25-celdado; estilo simple; estigma capitalo. Fr. ma bayal, una drupa ó una cápsula: semillas con endospermo carnoso: embrión peequeño, recto 6 carvo.- - Arbustos volubles, 0 arbolitos, con hojis opuestas, simples of compuesto-pimnadas. sin estípulas. Fls. solitarias axilares ó en espigas ó cappítulos. Kontas templadas.

? Viburmum, Lonicera: L. Japonica (madreselva) cult., Sambucus: S. canadensis (sauco blanco) $\mathrm{c}$ גtt.

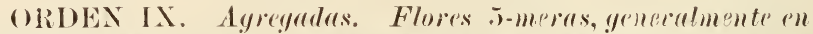
capítulos inrolucrados; orario unilecular i uniormlado; finto en aquenio coronado por el cáliz setoso. - Plantas herbuceus, fruticosas a arbustosus, mui reress réces arbórers.

1. Fann. Compuestas. (Sinintereas). Flores hermafroditas, unisexuales ó neutras por aborto; cal. entero, dentado, laciniardo, ciliado, plumoso (vilano) ó nulo; cor. regular, tubalosar. 5-dentada ó 5-fida. de estivación valvar. á menudo liggulada ó bilabiada: estambres a, alternos; filamentos libres; arteras seldadas en tulo que rodea al estilo;

(*) Spec. nov. en Brot. ift. de sto. Dgo, ya cit. 


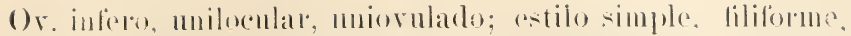

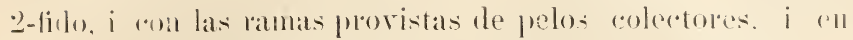

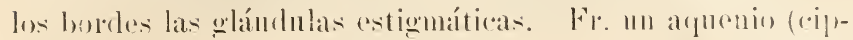

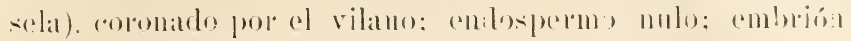

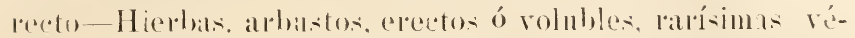
res abloles, cos logjas altermas í opmestas, simples ò rom-

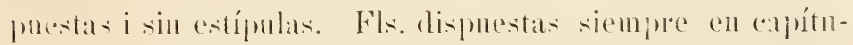
los solitarios ó diversamente agroplados axilares ó termina-

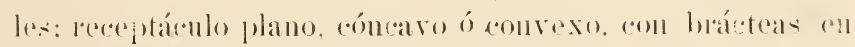

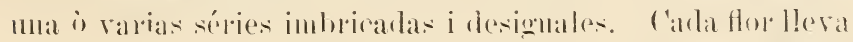
á véces ma bráctea (fala) memblamosa. Komas templadas i rálicla.

'T'ub h i i H

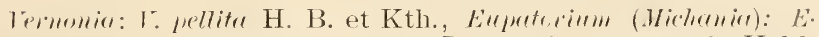

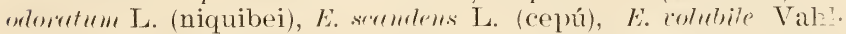

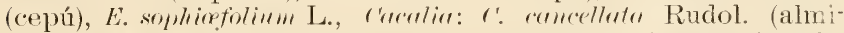
dón) C. incoma L. [almidón], C. coccinea (pincel de amor) cult.

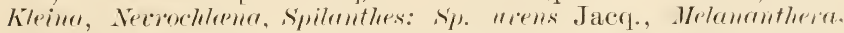

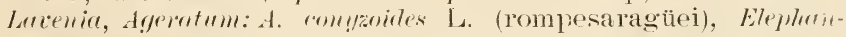
t.puse, etc.

Radi adas.-Flores tubulosas en el centor i liğnladis en la periferia:

Erigferom (comize): E. mfuretum (salvia), E. morolinemsis Jacq. (sa?via), etc., Aster (estrañas), eu los jardines, solideng: S. Inoming "nsis Spr., cinernicu, Tagetes: T. patula (clavel de muerto) i T. erecta [clavel de muerto] cult., Pertis, Amellus, lembesine (Herdelir), Zinnia: Z. elegans (celia, escopeta) cult., Birlens (foreopsis):

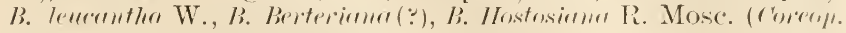

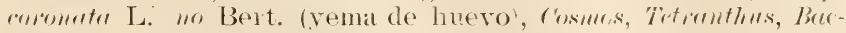

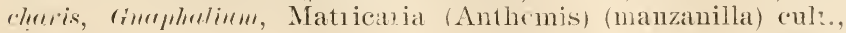
Santolina (Achillea): S. Millefolia (ciprés de Judea) cult., Mr yt -

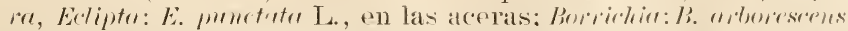
DC., B. finteserus DC., plantas marítimas commes; en la costa de Sto. Dore, Helianthus: H. annus [for ciel sol] rult., Mr'- 
Lampodium, I'arthenium: P. Histerophuress. I. [yerba amalga], Ghrysanthellum (Colleca): Ch: procumbens Rich. Pers. [yerba buen. cimarrona], comunísima en toda la República, Dahlia: D. variabilis [dália] cult., Helichrysum. H. bracteatum (inmortal) cuit., etc.

L, i gu li floras.-Flores todas liguladas:

Lactuca (somelnus): L olencen [achicoria], L. sativa i var. [lechuga] cult. etc.

La b i a t iflor as.-Flopes todas bilabiadas, ó con flores tubulosas en el centro. ó con liguladas en la periferia:

Leria, Ponstia, etc. 


\section{OMISIONES I ERRATAS}

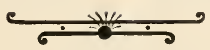

Pág. 54. Después de las Portulacáceas, agrégese :

9. Fam. Batidáceas. Flores dióicas; las masculinas con el cal. 2-lobulado; cor. 0; ests. 8, de los ruales 4 están reducidos á estaminodios i alternan con los fértiles; las femeninas desundas. Ov. libre, f-reldado, con las celdas uniovuiadas; estil. simple; estig. lobulado. Fr. una haya 4-locular; sem. sin endospermo; embrión recto.-Irbusto con las ramas opuestas i t-gonas, de hojas opuestas, simples, sentadas, enteras, lanceoladas, carmosas, i sin estípulas. Fls. en espigas amentáceas, axilares.

Batis maritima L., especie única, propia de las playas antillanas.

Pág. 107. Después de las Cucurbitáceas, agrégnese:

2. Fam. Aristoloquiáceas. Flores hermafioditas; cáliz colorado, tubuloso, casi siempre irregular i uni ó bilabiado; corola 0 ; anteras 6 , rara vez cinco, extrorsas, 2loculares, subsesiles sobre el estilo. Ovario 6-5-locular: cápsula 6-locular, 6-valva, polisperma; endospermo rarnoso; embrión pequeño.-Hierbas ó arbustos, con frecuencia volubles, con hojas alternas i las flores grandes, abigarradas i por lo común fétidas. Trọpicos.

Aristolochia: A. bilobutu L., A. peltata L., A. candata L., A. bilabiada L., A. punctata Lam., A. barbata Jaeq., A. presifleritfolia A. Rich., A. ringens Vahl. (flor de pato ó de paro), etc., todas en muestros montes bajos i bosques.

Pág. 7, lín. 30, donde dice: cecarse, léase: securse.

Pág. 18, lín. 5, donde dice: formando, léase: fırmando. 
Paig. 19, lin. 17, donde dice: esparangios, léase: esporangios. Pág. 27 , lín. 17 , donde dice: diplostemore, léase: diplostemone. Páa. 30, lín. ¿2, donde dice: esectos, léase: erectos.

Pág. 30, lín. 29, donde dice: Vemenáceas, léase: Verbenácen.. Pág. 31, lín. 19, donde dice: 1 locular, léase: 1-locular.

Paig. :31, lín. 24, donde dice: celdido, léase: celdado. Pág. 32, lín. 29, donde dice: a/bustos, léase: arbustos

Pág. 36, (Orden), donde dice: Lilfliifloros, léase: Liliiflomra. Pág. 41, lín. 16, donde dice: plátamo, léase: plátano.

Pág. 41, lín. 23, donde dice: gr nde, léase: grande.

Pág. 44, lín. 16, donde dice: Elores, léase: Flores. Pág. 46, lín. 26, donde dice: C rola, léase: Corola.

Pág. 49, (Fan. 3), dice: Artocarpá eas, léase: Artocarpaceas. Pág. 49, hn. 25, donde dice: emteras, léase: enteras.

Pág. 51, lín. 12, donde dice: gl ımuérulos, léase: glomérulos. Pág. 51, lín. 15, donde dice: antelminticum, léase: anthelminthicum)

Pág. 52, (Fam. 5), dice Fitolu ćcen, léase: Fitolaccicea.. Pág. 57, notu, lín. 5, donde dice: Kindon, léase: Kingdom. Pág. 61, lín. 1s, donde dice: aherente, léase: adherente. Pág. 61, lín. 22, donde dice: Albustos, léase: Arbustos. Pág. 62, lín. 3, donde dice: perietales, léase: parietales. Pág. 63, lín. antepenuiltima, donde dice: imbrincado, léase: im: bricado).

Pág. 68, lín. 23, donde dice: Bubrema, léase: Bubromu. Pág. 71, lín. 18, donde dice: (esperidio), léase: (hesperidio). Pág. 74 , mitı, lín. 31, donde dice: Bu/seráceas, léase: Burseráceas).

Pág. 80, lin. viltima, donde dice: 2 -ca/pelado, léase: 2 -carpelado. Pág. 85 , lin. 22, donde dice: imbrincadas, léase imbricadas. P’ág. 86, lín. 7, donde dice: imbriıcados, léase imbricados. Pág. 94, lin. 5, donde dire cilindrio, léase: cilíndrico. P’ág. 9s, lin. ciltimu, donde dice: l'zz, léase: Pex.

Pág. 99, (Orden), donde dice: rertrilades, léase verticilader. Pág. 102, lín. 11, dende dice: Bronfilsin, léuse: Brunxfelsin. Pág. 103, lin. 10, donde dice: 2 -la 7 iada. léase: 2 -labiada. Pág. 107, lin. primere, donde dice: Clisfortiana, léase: Cliforrtiana). 


\title{
INDICE ALFABETICO
}

DE IA I F I II IIAS IOESCRITAS

\author{
Trupo I.-Tinlofitas
}

Clase I.-ALGAN

$\begin{array}{ll}\text { Bacteriáceas, pág. } 5 & \text { Diatomáceas, } 8 \\ \text { Caráceas, } 7 & \text { Fucáceass, } 8 \\ \text { Cenobiadas, } 6 & \text { Gigartináceas, 9 } \\ \text { Conferváceas, } 7 & \text { Nemaliáceas, 9 } \\ \text { Conjugadas, 6 } & \text { Nostocáceas, 5 } \\ \text { Coralináceas, } 9 & \text { Sifoniáceas, } 7\end{array}$

Clase II.-HONGOS

Discomicetáceas, 1:

Gasteromíceas, 11

Gastromixáceas, 9

Himenomíceas, 11

Liquenes, 12

Mucoráceas, 10

\author{
Perisporiáceas, 1: \\ Peronosporáceas, 10 \\ Pirenomicetáceas, 1 른 \\ Saprolegniáceas, 10 \\ Uredíneas, 11 \\ Ustilagineas, 10
}

Tipo II-Muscineas

Clase I.-HEP ÍTTCAS

Anticerotáceas, 16

Marcanciáceas, 15

Ricctáceas, 15

Yungermanniáceas, 16

Clase II.-MISGOS

Andreáceas, 16

Briáceas, 17

Esfagnáceas, 16

Fascáceas, 17 
Troro III-Criptógamas vasculares

\section{clase I.-FILICÍNEAs}

Ciatáceas, 19

Esquiceáceas, 19

Gleiqueniáceas, 19

Eimenofiláceas, in

Maratiáceas, 19
Marsiliáceas, 20

Ofioglosáceas, 20

Osmundáceas, 19

Polipodiáccas, 19

Salviniáceas, 20

Clase II-_EQUISETÍNEAS

Equisetáceas, ㄴo

\section{Clase III-LICOPODÍNEAs}

Licopodiáceas, :1

Selagináceas, ㄴ1

Trpo IV._-Gimmospermas

Cicadúceas, 34

Coníferas, 34

Truo V.-Angiospermas

Galse I.-MONOCOTILEDGNEAS

Alismáceas, 40

Amarilibáceas, 36

Aráceas, 43

Eromeliáceas, 39

Ciperáceas, 46

Commelináceas, 40

Dioscoreáceas, 37

Gramináceas, 45

Iridáceas, 38

Lennáceas, 44
Liliáceas, 36

Maxantáceas, 4믄

Musíceas, 11

Nayadiceas, 45

Orquidáceas, 4 -

Palmas, 4:;

Pontederiáceas. 37

Tifácens 14

Zingibráceas, t2 


\section{Glase II.-DICOTILEDÓNEAs}

Acantáceas, 104

Amarantáceas, 52

Anonáceas, 56

Apocináceas, 100

Aquifoliáceas, 77

Araliáceas, 81

Aristoloquiáceas, 113

Artocarpáceas, 49

Asclepiadáceas, 101

Auranciácias, 71

Baseláceas, 51

Batidáceas, 113

Begoniáceas, 57

Bignoniáceas, 10:3

Bixáceas, 61

Borragináceas, 97

Cactáceas, 81

Caparidáceas, 59

Caprifoliáceas, 110

Cariofiláceas, 5 ?

Celastráceas, 77

Celtídeas, 50

Clusiáceas, 65

Combretáceas, 84

Compuestas, 110

Convolvuláceas, is

Cucurbitáceas, 107

Cupulíferas, 47

Crasuláceas, 8:-

Crucíferas, 59

Dileniáceas, 66

Ebenáceas, 95

Eritroxiláceas, 76

Escrofulariáceas, 101

Esterculiáceas, 68

Estiráceas, 95

Euforbiáceas, 79

Fitolacáceas, 52

Gencianáceas, 99

Geraniáceas, 69

Gesneráceas, 103

Goodeniácias, 107

Hidrofiláceas, gא
Hipericáceas, 65

Ilicáceas, 77

Juglandáceas, 47

Labiadas, 102

Lauráceas, 54

Leguminosas, 89

Litráceas, 83

Loáceas, 87

Lobeliáceas, 106

Lorantáceas, 108

Malpigiáceas, 75

Malváceas, 66

Melastomáceas, 85

Meliáceas, 72

Menispermáceas, 5.

Miricáceas, 47

Mioporáceas, 105

Miristicáceas, 56

Mirsináceas, 93

Mirtáceas, 86

Moráceas, 49

Moringáceas, 88

Nictagináceas, 53

Ninfeáceas, 58

Ocnáceas, 66

Olacáceas, 99

Onagrariáceas, 84

Papaveráceas, 60

Papayáceas, 62

Pasifloráceas, $6^{\circ}$

Piperáceas, 48

Plantagináceas, 106

Plumbagináceas, 98

Poligaláceas, 76

Poligonáceas, 50

Portulacáceas, 54

Quenopodiáceas, 51

Ramnáceas, 78

Ranunculáceas, 57

Rizoforáceas, 85

Rosáceas, 87

Rubiáceas, 109

Rutáceas, 70 
Salicáceas, $4 \bar{r}$

Samidáceas, 61

Sapindáceas, 74

Sapotáceas, 94

Saxifragáceas, $8: 3$

Simarubáceas, 73

Sinantéreas, 110

Solanáceas, 9.

Tamarixáceas, 63

Terebintáceas, $7: 3$
Terstremiáceas, 64

Tiliáceas, 69

Timeliáceas, 55

Turneráceas, 61

Umbelíferas, 80

Urticáceas, 48

Verbenáceas, 105

Violáceas, 63

Vitáceas, 78

Zigofiláceas, 71 





